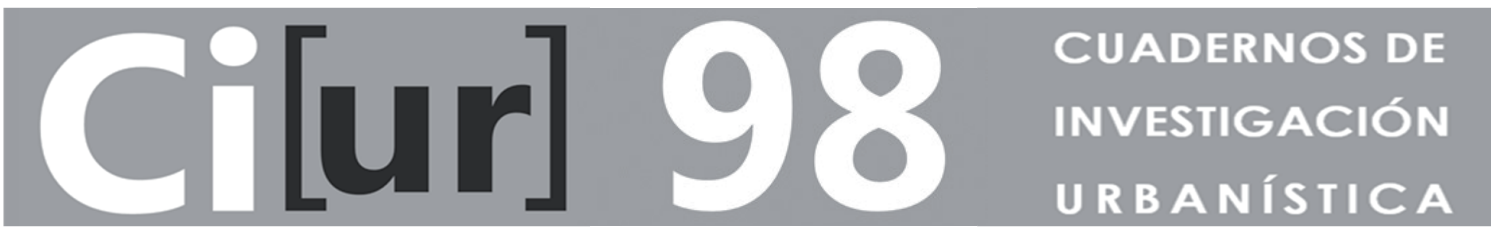

\title{
POLÍTICAS URBANAS DE LA UNIÓN EUROPEA DESDE LA PERSPECTIVA DE LA PLANIFICACIÓN COLABORATIVA
}

LAS INICIATIVAS COMUNITARIAS URBAN Y URBAN II EN ESPAÑA

\section{SONIA DE GREGORIO HURTADO \\ Doctora Arquitecta}

Este documento es un resumen de la tesis doctoral "Políticas Urbanas de la Unión Europea desde la perspectiva de la Planficación Colaborativa. Las Iniciativas Comunitarias URBAN (1994-1999) y URBAN II (2000-2006) en España", dirigida por la profesora Inés Sánchez de Madariaga y leída por su autora el día 26 de junio de 2012, en la Escuela Técnica Superior de Arquitectura de Madrid. 


\begin{tabular}{|c|c|}
\hline Director: & José Fariña Tojo \\
\hline \multicolumn{2}{|c|}{ Consejo de Redacción: } \\
\hline Director & Ester Higueras García \\
\hline Jefe de redacción & María Emilia Román López \\
\hline Vocales & $\begin{array}{l}\text { Julio Alguacil Gómez (Univ. Carlos III de Madrid), Pilar Chías Navarro (Univ. Alcalá } \\
\text { de Henares, Madrid), José Antonio Corraliza Rodríguez (Univ. Autónoma de } \\
\text { Madrid), Alberto Cuchí Burgos (Univ. Politécnica de Cataluña), José Fariña Tojo } \\
\text { (Univ. Politécnica de Madrid), Agustín Hernández Aja (Univ. Politécnica de Madrid), } \\
\text { Mariam Leboreiro Amaro (Univ. Politécnica de Madrid), Rafael Mata Olmo (Univ. } \\
\text { Autónoma de Madrid), Fernando Roch Peña (Univ. Politécnica de Madrid), Carlos } \\
\text { Manuel Valdés (Univ. Carlos III de Madrid) }\end{array}$ \\
\hline Consejo Asesor: & $\begin{array}{l}\text { Ma Teresa Arredondo (Directora de Relaciones con Latinoamérica, Univ. } \\
\text { Politécnica de Madrid), Luis Maldonado (Director de la Escuela Superior de } \\
\text { Arquitectura, Univ. Politécnica de Madrid), Antonio Elizalde, Julio García Lanza, } \\
\text { Josefina Gómez de Mendoza, José Manuel Naredo, Julián Salas, Fernando de Terán }\end{array}$ \\
\hline Comité Científico: & $\begin{array}{l}\text { Antonio Acierno (Univ. Federico II di Napoli, Nápoles, ITALIA), Miguel Ángel } \\
\text { Barreto (Univ. Nal. del Nordeste, Resistencia, ARGENTINA), Luz Alicia Cárdenas } \\
\text { Jirón (Univ. de Chile, Santiago de Chile, CHILE), José Luis Carrillo (Univ. } \\
\text { Veracruzana, Xalapa, MÉXICO), Marta Casares (Univ. Nal. de Tucumán, } \\
\text { ARGENTINA), María Castrillo (Univ. de Valladolid, ESPAÑA), Mercedes Ferrer } \\
\text { (Univ. del Zulia, Maracaibo, VENEZUELA), Fernando Gaja (Univ. Politécnica de } \\
\text { Valencia, ESPAÑA), Alberto Gurovich (Univ. de Chile, Santiago de Chile, CHILE), } \\
\text { Josué Llanque (Univ. Nal. S. Agustín Arequipa, PERÚ), Angelo Mazza (Univ. } \\
\text { Federico II di Napoli, Nápoles, ITALIA), Luis Moya (Univ. Politécnica de Madrid, } \\
\text { ESPAÑA), Joan Olmos (U. Politécnica de Valencia, ESPAÑA), Ignazia Pinzello (Univ. } \\
\text { degli Studi di Palermo, Palermo, ITALIA), Julio Pozueta (Univ. Politécnica de } \\
\text { Madrid, ESPAÑA), Alfonso Rivas (UAM Azcapotzalco, Ciudad de México, MÉXICO), } \\
\text { Silvia Rossi (Univ. Nal. de Tucumán, ARGENTINA), Adalberto da Silva (Univ. } \\
\text { Estadual Paulista, Sao Paulo, BRASIL), Carlos Soberanis (Univ. Francisco } \\
\text { Marroquín, Guatemala, GUATEMALA), Carlos A. Torres (Univ. Nal. de Colombia, } \\
\text { Bogotá, COLOMBIA), Graziella Trovato (Univ. Politécnica de Madrid, ESPAÑA) } \\
\text { Carlos F. Valverde (Univ. Iberoamericana de Puebla, MÉXICO), Paz Walker (Univ. } \\
\text { de la Serena, Santiago de Chile, CHILE), Fernando N. Winfield (Univ. Veracruzana, } \\
\text { Xalapa, MÉXICO) }\end{array}$ \\
\hline
\end{tabular}

Maquetación: Antonio Jesús Antequera Delgado: ciur.urbanismo.arquitectura@upm.es

Distribución: Mairea Libros: distribucion@mairea-libros.com

(C) COPYRIGHT 2015

SONIA DE GREGORIO HURTADO

I.S.S.N. (edición impresa): 1886-6654

I.S.S.N. (edición digital): 2174-5099

Año VIII, Núm. 98, enero-febrero 2015, 74 págs.

Edita: Instituto Juan de Herrera

Imprime: FASTER, San Francisco de Sales 1, Madrid 


\section{DESCRIPTORES:}

Regeneración urbana / Políticas urbanas / Planificación colaborativa / Iniciativa Comunitaria URBAN / Unión Europea

\section{KEY WORDS:}

Urban regeneration / Urban policies / Colaborative urban planning / URBAN Community Initiative / European Union

\section{RESUMEN:}

Este trabajo lleva a cabo un análisis de la aportación que las dos fases de la Iniciativa Comunitaria URBAN ${ }^{1}$ de la Unión Europea (UE) han hecho a la práctica de la regeneración urbana en España desde la perspectiva de la Planificación Colaborativa. La adopción de esta última como marco conceptual ha provisto la base teórica desde la que se ha analizado URBAN, a través de la realización de un estudio que ha profundizado en el contexto histórico y el debate teórico desde los que se pusieron las bases metodológicas de este instrumento para afrontar la degradación urbana.

El trabajo analiza la materialización de la dimensión colaborativa de los programas URBAN y URBAN II implementados en España. Los resultados alcanzados por los programas, considerados a la luz de la profundización en la práctica de la regeneración urbana del país, han permitido llegar a conclusiones sobre la aportación que la dimensión colaborativa de URBAN ha hecho al contexto español y señalar la línea de investigación que supone la continuación del camino emprendido por la Tesis Doctoral en la que se enmarca este trabajo.

\section{ABSTRACT:}

This work analyses the contribution that the two rounds of the URBAN Community Initiative of the European Union have made to the urban regeneration practice in Spain from the perspective of Collaborative Planning. The adoption of Collaborative Planning as conceptual framework has provided the theoretical base from which to analyze URBAN, through the development of a study that has delved into the historical context and the theoretical debate that laid the methodological foundations of this approach to fight urban degradation. The work analyses the implementation of the collaborative approach in the URBAN and URBAN II programs developed in Spain. The results achieved by the programs, considered in light of the development of the practice of urban regeneration in the Spanish scenario, have led to conclusions about the contribution that the collaborative dimension of URBAN has made to the Spanish context and have resulted in the identification of the line of research that represent the continuation of the path taken by this work and the Thesis in which it is contextualized. 


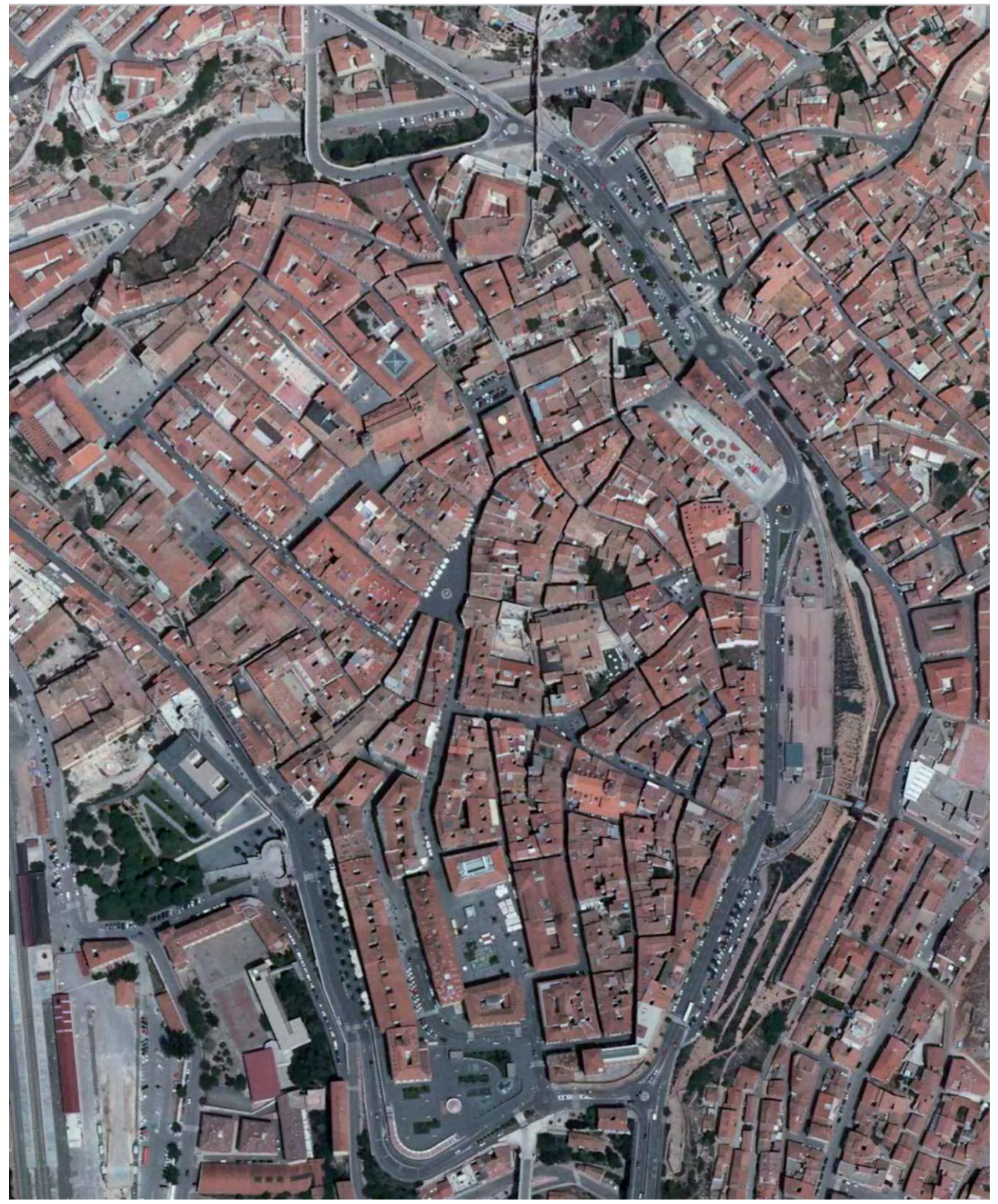

Figura 0. Teruel, la única ciudad en la que URBAN II operó en todo el ámbito urbano. Fuente: Archivo de la autora

\section{CONSULTA DE NÚMEROS ANTERIORES/ACCESS TO PREVIOUS WORKS:}

La presente publicación se puede consultar en color en formato pdf en la dirección:

This document is available in pdf format and full colour in the following web page:

http://www2.aq.upm.es/Departamentos/Urbanismo/institucional/publicaciones/ciur/ 


\section{ÍNDICE}

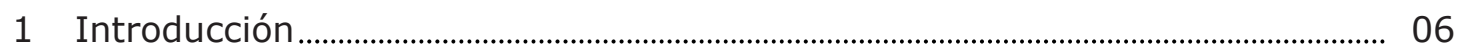

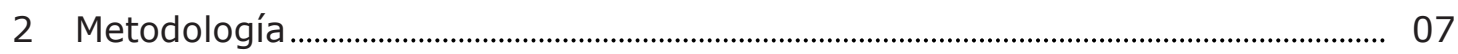

3 Marco conceptual: la planificación colaborativa.......................................................... 11

3.1 El Nuevo Institucionalismo y el enfoque comunicativo: la propuesta de Planificación Colaborativa de Patsy Healey

3.2 El enfoque colaborativo para la transformación de la gobernanza en la Iniciativa Comunitaria URBAN.

4 Formación y lanzamiento de la Iniciativa Comunitaria URBAN en el contexto de la Política Urbana de la Unión Europea.................................................................. 17

5 La práctica de la Regeneración Urbana en España....................................................... 23

6 La Iniciativa Comunitaria URBAN en España .............................................................. 30

7 La Iniciativa Comunitaria URBAN II en España ............................................................. 39

8 Conclusiones

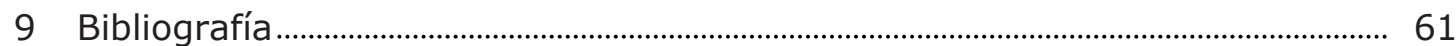

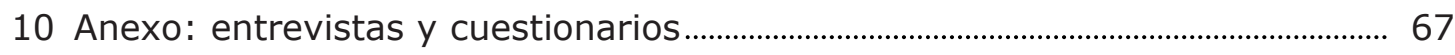




\section{INTRODUCCIÓN}

Este trabajo resume la Tesis Doctoral con Mención Europea de su autora, titulada Políticas Urbanas de la Unión Europea desde la Perspectiva de la Planificación Colaborativa. Las Iniciativas Comunitarias URBAN y URBAN II en España, dirigida por la Profesora Inés Sánchez de Madariaga y desarrollada en el Departamento de Urbanística y Ordenación del Territorio de la Escuela Técnica Superior de Arquitectura de la Universidad Politécnica de Madrid.

La elección del marco conceptual de la misma respondió al objetivo de realizar un estudio de URBAN que diera lugar a una aportación relevante en mayor medida. El análisis perseguía asumir un enfoque de estudio de esta Iniciativa Comunitaria que superase los aspectos donde la misma había llevado a cabo una aportación incontestable, pero no innovadora (transformación de la realidad física de los barrios, potenciación de actividad económica, etc.), para focalizar en la introducción de innovación en la práctica de la regeneración urbana en España a través de su propuesta metodológica.

Una primera fase de análisis puso de manifiesto que la dimensión colaborativa de URBAN, la que tiene que ver con la intención de la Iniciativa de transformar el modelo de gobernanza, constituía su dimensión metodológica menos introducida en España en 1994 y aquella que podría haber hecho una contribución de mayor relevancia a la transformación de la práctica de la regeneración urbana en el país.

El interés de profundizar en la dimensión colaborativa quedaba refrendado por dos de los objetivos que habían llevado a la Comisión Europea a lanzar esta Iniciativa Comunitaria en 1994: introducir innovación en el modo de concebir las políticas dirigidas a la rehabilitación de los barrios degradados y propiciar la transformación de las estructuras de gobernanza de los sistemas de planeamiento de los Estados miembros de la UE (Reiter, 2008). Esta transformación podía darse al introducir un sistema de gestión de los programas basado en un planteamiento colaborativo.

El establecimiento del foco de análisis en la dimensión colaborativa de los programas URBAN derivó en la elección de la Planificación Colaborativa como marco conceptual. La revisión de la Iniciativa Comunitaria y de las motivaciones que llevaron a la Comisión Europea a lanzarla llevó a considerar válido este marco conceptual en base a sus contenidos teóricos y a la relación cronológica y geográfica que se da entre su desarrollo por parte de los principales autores (particularmente la Profesora Patsy Healey) y la gestación de URBAN.

En base a todo esto la aportación de la Tesis Doctoral en la que se contextualiza este Cuaderno de Investigación se sitúa en varios ámbitos: i) producción de conocimiento sobre cómo se ha llevado a cabo una transferencia de políticas de regeneración urbana de raíz anglosajona al escenario español, a través de la política urbana de la Unión Europea; ii) producción de conocimiento sobre el desarrollo de URBAN y URBAN II en España, atendiendo a todos sus elementos metodológicos, iii) dentro del punto anterior, análisis de la dimensión colaborativa de los programas URBAN y URBAN II, con el fin de entender cuál ha sido la aportación de la misma a la práctica española de la regeneración urbana. El último ámbito de aportación coincide con el objetivo de este trabajo y no hubiera podido materializarse sin haber acometido los dos anteriores. 
Con el fin de adaptarse al formato de los Cuadernos de Investigación Urbanística y de presentar un resultado coherente en sí mismo, con independencia de la Tesis Doctoral que resume, el presente trabajo recoge las partes de la misma que focalizan en los resultados alcanzados por el desarrollo de la dimensión colaborativa de los programas URBAN y URBAN II desarrollados en España. Con este fin da cabida de manera resumida al marco conceptual y a la contextualización histórica, geográfica y disciplinar, considerados clave para hacer inteligibles los mencionados resultados, dejando fuera otros contenidos. Se ha establecido la siguiente estructura: el apartado 2 presenta la metodología de investigación; el apartado 3 establece y profundiza en el marco conceptual; en el apartado 4 se analiza el proceso de formación y lanzamiento de la Iniciativa Comunitaria URBAN, focalizando en la formalización de su dimensión colaborativa; el apartado 5 pone el foco en la práctica de la regeneración urbana en España durante el periodo que va desde los años 70 hasta el lanzamiento de URBAN, paso necesario para entender la contribución de esta Iniciativa Comunitaria al contexto nacional; los apartados 6 y 7 analizan respectivamente el desarrollo de las Iniciativas Comunitarias URBAN y URBAN II en el país, profundizando particularmente en la materialización de la dimensión colaborativa de los programas. Finalmente el apartado 8 recoge las conclusiones de la investigación y la línea de trabajo que supone su continuación. Para profundizar en todas o en alguna de estas partes el lector puede revisar la mencionada Tesis Doctoral.

\section{METOdOLOGÍA}

La metodología de este trabajo está explicada en profundidad en la Tesis Doctoral que resume. Acontinuación se expone de manera sintética:

La construcción de la metodología partió del establecimiento de la Planificación Colaborativa como marco conceptual. A partir de esta asunción se propuso una estructura de análisis basada en la definición de un conjunto de ámbitos de estudio entre los que, a través del trabajo empírico y analítico, se seleccionaron nexos que permitieron llegar de las contribuciones teóricas en torno a la Planificación Colaborativa a la identificación de URBAN como una política pública colaborativa de regeneración urbana.

A partir de ese estadio se procedió a analizar los programas URBAN y URBAN II desarrollados en España con el fin de entender cuál fue la contribución de su componente colaborativa a la práctica de la regeneración urbana en el país. La estructura metodológica se basó en el establecimiento de dos líneas de trabajo. La primera se desarrolló en base a los siguientes puntos:

- Revisión de las contribuciones teóricas en el ámbito de la Planificación Colaborativa. Para llevar a cabo esta parte del trabajo se realizó una revisión de las contribuciones teóricas de mayor relevancia. El objetivo fue entender sus elementos caracterizadores y objetivos.

- La Regeneración Urbana en Reino Unido. Durante el proceso de análisis previo al establecimiento de los ámbitos de estudio se detectó que URBAN constituyó una política urbana cuyas raíces se encuentran en gran medida en la experiencia británica. En base a esto se revisaron las políticas urbanas británicas lanzadas 
entre la década de los sesenta y el año 2000 (año de lanzamiento de URBAN II), con el fin de establecer la aportación que la experiencia en regeneración urbana desarrollada en ese país hizo a la definición de la política urbana de la UE y particularmente a URBAN, atendiendo particularmente a su dimensión colaborativa. Para la realización de esta parte del trabajo fue relevante la estancia investigadora de la autora en el European Institute for Urban Affairs de la Universidad John Moores de Liverpool.

El siguiente paso consistió en detectar qué aspectos y contenidos de la práctica británica de regeneración se transfirieron a la política urbana de la Unión Europea y, a través de ella, a la Iniciativa Comunitaria URBAN. En base a esto se realizaron tareas de revisión y análisis en dos ámbitos:

- La política urbana de la UE. El trabajo consistió en la revisión del proceso de nacimiento y desarrollo de la dimensión urbana de la política de la UE. El objetivo fue obtener un conocimiento de la misma (focalizando en su vertiente colaborativa) que permitiera identificar las necesidades y presupuestos sobre los que se basó el lanzamiento de URBAN.

- Caracterización de URBAN como una política colaborativa de regeneración urbana. Esta parte del estudio conllevó el análisis de la metodología de regeneración urbana plasmada en la Iniciativa Comunitaria URBAN. La meta última fue determinar cuáles eran los elementos clave que imprimían a URBAN un carácter colaborativo. El conocimiento obtenido a través de este paso permitió acometer la siguiente fase de la investigación desde el entendimiento de esta dimensión de la Iniciativa.

La fase siguiente consistió en el establecimiento de una metodología de trabajo que permitiera obtener conocimiento sobre cómo se plasmó el enfoque colaborativo de las Iniciativas Comunitarias URBAN y URBAN II en los programas que se desarrollaron en España.

- Desarrollo de URBAN y URBAN II en España. Su componente colaborativa. Las diferencias en cuanto a cercanía temporal e información disponible hicieron aconsejable abordar el análisis de cada una de las fases de URBAN de manera distinta. También se consideró como criterio en relación a este tema el número de programas que se desarrollaron dentro de cada fase de la Iniciativa: 29, en el caso de URBAN (1994-1999), y diez, en el caso de URBAN II (2000-2006). A pesar de la diferencia metodológica, y para permitir la comparación, en ambos casos se abordó el análisis en base a las siguientes dimensiones de la componente colaborativa de la Iniciativa: dimensión vertical (multinivel), dimensión horizontal y dimensión participativa:

\section{URBAN (1994-1999)}

El análisis de los 29 programas desarrollados entre 1994 y 1999 se abordó teniendo en cuenta las limitaciones que existían para conseguir información, debido a que estos se habían cerrado unos diez años atrás. La información con la que se contó fue principalmente documentación institucional y literatura científica 
sobre el tema. El análisis de la dimensión colaborativa de los programas se hizo a través de un acercamiento conjunto a los mismos, profundizando en cada uno de ellos siempre que fue posible.

\section{URBAN II (2000-2006)}

La relativa cercanía temporal de los programas URBAN II con el momento en el que se desarrolló el estudio permitió entrevistar a algunos de los actores que estuvieron implicados o siguieron los programas muy de cerca (ver Anexo). Por otra parte se enviaron cuestionarios a actores locales. Asimismo, se revisó abundante literatura institucional y literatura gris. La información con la que se contaba llevó a optar por desarrollar esta parte de la investigación en función de diez estudios de caso, que se llevaron a cabo en base a una estructura común, basada en la identificación de las siguientes categorías analíticas:

1. Elementos preexistentes relevantes. A través de la inclusión de esta categoría se pretendía entender si en los casos donde se había dado la preexistencia de procesos de participación se llevó a cabo una inclusión y desarrollo de dimensión participativa del programa URBAN más afín a las recomendaciones de la Comisión Europea.

2. Papel de la UE y los gobiernos nacional y regional en el programa. Esta categoría analítica estaba orientada a entender si se había dado cooperación y concertación multinivel en el marco de la Iniciativa.

3. Estructura adoptada por el ente gestor (colaboración horizontal). A través del estudio de la estructura de gestión adoptada por cada uno de los programas se perseguía analizar si esta había favorecido la cooperación entre diferentes áreas de gobierno a nivel de los Ayuntamientos o los entes implicados en la gestión de los programas.

4. Implicación de la ciudadanía y los actores locales en la estrategia de proyecto. Esta categoría analítica perseguía entender en qué medida en el marco de los programas se había dado lugar a un proceso sostenido y "real" de colaboración entre el sector público y los actores locales.

5. Acciones previstas en la estrategia original para propiciar la participación de la comunidad y los actores locales a lo largo de la vida del proyecto. A través de la revisión de este aspecto de los programas se perseguía entender en qué medida los entes ejecutores apostaron por la participación de la comunidad y los actores locales durante el desarrollo de los mismos.

6. Desarrollo del proceso de participación a lo largo de la vida del proyecto. El conocimiento de este aspecto permitía entender dónde se habían situado los principales problemas a la hora de desarrollar un proceso colaborativo entre las institucionesy los actores locales. 
7. Resultados del proceso colaborativo y adicionalidad del mismo. Análisis de la colaboración (multinivel, interdepartamental y participativa) de los programas e identificación del valor añadido (capacidad transformadora) derivado de la misma en el marco del desarrollo del programa.

Además del análisis sobre la base de las mencionadas categorías analíticas, dentro de cada estudio de caso se llevó a cabo un trabajo de contextualización, que incluyó un análisis de: el área de actuación del programa; la estrategia; el origen, contenido y equilibrio entre las dimensiones física, económica y social; la financiación; y la integración del proyecto de regeneración en otras acciones o estrategias a escala local y regional. Una vez terminados los estudios de caso, se procedió a la caracterización del enfoque colaborativo de los programas y a la comparación entre los mismos. Dicha comparación permitió identificar patrones comunes y derivar en un conjunto de conclusiones sobre el grado de introducción, desarrollo y resultados de la dimensión colaborativa de los URBAN II españoles.

A continuación se llevó a cabo la comparación entre los programas URBAN II y los URBAN, lo cual derivó en una serie de resultados, un conjunto de los cuales se elevaron a conclusiones. Una vez completada la línea de investigación descrita, se acometió la segunda línea de contextualización y análisis que consistió en la revisión de la evolución de la práctica de la regeneración urbana en España:

- La práctica de la rehabilitación urbana en España. Los objetivos de investigación de esta parte del trabajo fueron los siguientes: Establecer cuál era la situación de las ciudades en España antes de la introducción de la Iniciativa Comunitaria URBAN desde el punto de vista de la degradación, así como caracterizar la práctica de la regeneración urbana en ese momento. Esto permitió llegar a un doble resultado: por una parte entender cuál fue la aportación de URBAN a la situación existente en el periodo en el que se puso en marcha en el país $y$, por otra parte, comparar el panorama existente en 1994 con la realidad de nuestros días.

Una vez finalizada esta última línea de estudio se procedió a realizar un análisis comparativo entre la situación de la práctica de la regeneración urbana en España antes de la introducción de URBAN y el momento actual. La resultante de esta comparación se interpretó teniendo en cuenta los resultados del trabajo de análisis de los programas URBAN y URBAN II desarrollados en España. Esto permitió llegar a una serie de conclusiones.

El trabajo descrito conllevó la revisión de literatura científica, literatura gris, literatura institucional y legislación. También se llevaron a cabo entrevistas semiestructuradas y cuestionarios (ver Anexo). 


\section{MARCO CONCEPTUAL: LA PLANIFICACIÓN COLABORATIVA}

\subsection{El Nuevo Institucionalismo y el enfoque comunicativo: la propuesta de Planificación Colaborativa de Patsy Healey}

En este apartado se profundiza en la Planificación Colaborativa, el marco teórico adoptado por el estudio para analizar la aportación de las Iniciativas Comunitarias URBAN y URBAN II a la práctica de la regeneración urbana en España. La principal aportación teórica es la de la Profesora Patsy Healey. Su contribución se ha analizado a la luz de la influencia de autores que la han antecedido y/o influenciado ${ }^{2}$, con el fin de identificar cuáles son los aspectos y contenidos caracterizadores de una política de regeneración urbana colaborativa. Su identificación ha permitido, en fases sucesivas del estudio analizar la presencia de dichos elementos en la Iniciativa Comunitaria URBAN y, particularmente, en los programas que se desarrollaron en España durante los periodos presupuestarios de la UE 1994-1999 y 2000-2006.

La contribución de Healey y de autores como Friedmann, Forester o Innes ha llegado a constituir un ámbito de aportación intelectual. Aunque cada una de estas contribuciones está caracterizada por el contexto de trabajo e interés de su autor y su posición ideológica, todas ellas desarrollan alternativas a la planificación "tradicional" (entendida esta como la que se configura en el escenario de la segunda postguerra en Europa y Estados Unidos), en las que se da cabida en el proceso de toma de decisiones a todos los actores afectados por las mismas y se genera un proceso comunicativo e inclusivo que permite que el sector público, el privado, la ciudadanía, el tercer sector y otros actores colaboren, con el fin de actuar en torno a un determinado problema de política pública relacionado con la transformación del espacio en el que conviven o confluyen sus intereses.

En este trabajo se hace referencia a estas contribuciones como Planificación Colaborativa, haciendo mención al papel que en todas ellas desempeña el proceso de colaboración comunicativa entre distintos actores con intereses en un proceso de planificación en el ámbito público. La autoría del término Planificación Colaborativa resulta difícil de determinar, Tewdwr-Jones y Allmendinger señalan que parece haber evolucionado a partir de los debates previos al surgimiento de la normativa de planificación en el contexto inglés en los últimos años del s. XX, y particularmente a partir de la "reacción al laberinto neoliberal de reglamentos antiplanificación de la década de los ochenta3" (Tewdwr-Jones y Allmendinger, 2002a: 214). Fue en ese contexto, donde en 1997 la profesora Patsy Healey publicó su texto Collaborative planning: Shaping places in fragmented societies (Healey, [1997] 2006), en el que expuso en qué consistía la alternativa de planificación que proponía y que denominó Collaborative Planning (Planificación Colaborativa). Ella es la principal autora con la que se asocia este concepto aunque, como se ha dicho, han sido varios los teóricos y

\footnotetext{
${ }^{2} \mathrm{Se}$ han revisado las principales contribuciones al tema, los antecedentes aparecidos desde los años sesenta y particularmente las aportaciones que han tenido lugar en las últimas dos décadas del s. XX. El objetivo ha sido explorar las líneas de pensamiento y las propuestas teóricas que se situaron en la base del enfoque colaborativo que adoptaron algunas políticas de regeneración urbana en Estados Unidos y Europa, particularmente en Reino Unido, al final de la década de los ochenta y la década de los noventa, desde donde después ejercerían una influencia relevante en el contexto de la UE.

${ }^{3}$ Traducción propia a partir del texto original en inglés.
} 
planificadores que han desarrollado contribuciones cercanas a la suya, adoptando una visión matizada, que en sentido amplio tiene cabida dentro de lo que la literatura ha denominado planificación argumentativa, comunicativa o interpretativa.

Las distintas aportaciones que han alimentado, complementado o coincidido en algunos planteamientos con lo que en el ámbito de este trabajo se entiende por Planificación Colaborativa han sido denominadas generalmente haciendo uso de nomenclaturas relacionadas con las características principales o diferenciadoras que presentan las propuestas teóricas y/o metodológicas de planificación que desarrollan. Algunas de estas son: Advocacy Planning (Paul Davidoff), Progressive Planning (John Forester), Transactive Planning (John Friedmann), Communicative o Collaborative planning (Patsy Healey, Innes y Booher), Argumentative planning (John Forester). La multiplicidad de denominaciones y los matices existentes entre las propuestas a las que hacen referencia, ponen de manifiesto el carácter amplio y difuso de la Planificación Colaborativa, que radica principalmente en que relaciona un conjunto interconectado de problemas que son difíciles de conceptualizar y analizar. Esta misma dificultad se convierte en el principal obstáculo a la hora de dar una definición de la Planificación Colaborativa (Chisholm, 1998).

La Planificación Colaborativa propuesta por Healey pone el acento en como la participación de todos los actores relevantes en un determinado proceso de planificación puede dar lugar a una transformación de la gobernanza (el modo o los procesos a través de los cuales se gestionan los asuntos de interés común de las comunidades políticas) que derive en la construcción de la capacidad institucional ${ }^{4} \mathrm{de}$ los lugares (como se verá esta componente será uno de los objetivos señalados explícitamente por la Comisión Europea al caracterizar URBAN). La autora asigna a la planificación un papel en dar lugar a la transformación de la gobernanza hacia modelos colaborativos:

"El trabajo de planificación se puede implicar en esfuerzos de gobernanza deliberativa que bien intenten mantener o bien intenten transformar los discursos públicos sobre la calidad de los lugares. Allí donde el énfasis se pone en la transformación, la planificación puede convertirse en parte de un esfuerzo por construir nuevas conexiones relacionales entre redes que coexisten en una región urbana, nuevos sistemas de significado, nuevos referentes culturales. Juega por lo tanto un papel importante en la construcción de la capacidad institucional de un lugar"'5 (Healey, [1997]2006: 61).

Este párrafo de Healey pone el foco en la capacidad de la planificación de transformar la gobernanza de los lugares, dando lugar a procesos que desembocan en la construcción de la capacidad institucional de las comunidades. Es desde esta perspectiva desde la que se analizan las dos fases de la Iniciativa Comunitaria URBAN, desde la intención de entender si ha generado un proceso de planificación capaz de

\footnotetext{
${ }^{4}$ Se trata de un concepto desarrollado en la literatura sobre economía regional para hacer referencia a las cualidades sociales que parecen dar lugar a diferencias en el desarrollo económico regional. Se refiere, por tanto, a la calidad del conjunto de las redes relacionales de un lugar (Healey, [1997]2006: 61).

5 Traducción propia a partir de texto original en inglés.
} 
dar lugar a la construcción de esa capacidad en los lugares donde ha actuado en España.

Desde esta perspectiva, la Planificación Colaborativa propone aplicar la participación comunicativa a los procesos de planeamiento que tienen por objeto transformar el medio (urbano) en el que se desarrolla la vida de las personas con el fin de mejorarlo. El instrumento de planificación o de transformación se convierte en un medio para acercar a distintos actores y propiciar su conocimiento mutuo. A través de este proceso no sólo se llega a un mejor entendimiento de las demandas del otro, sino que se establecen las bases para poner en marcha políticas públicas colaborativas, al darse una transformación de las formas de hacer hasta entonces vigentes que pueden llegar a formalizarse en nuevas formas de gobierno.

A través de la utilización de esta alternativa de planificación se consigue incidir en factores determinantes en la superación de los conflictos que caracterizan la toma de decisiones en los ámbitos de política en los que se da una multiplicidad de actores con intereses encontrados o no coincidentes, a través del establecimiento de foros de diálogo que puedan derivar en la definición de un proyecto común por el que trabajar desde la colaboración. La superación de las diferencias y el desbloqueo de los procesos es uno de los puntos de fuerza de este tipo de planteamientos, que se relaciona con la mejora de la eficacia de los instrumentos de planificación y con la legitimidad de las políticas.

En el marco de este trabajo el concepto de Planificación Colaborativa se aplica a la regeneración urbana. A través de la puesta en marcha de procesos de regeneración participativos, que conllevan la devolución del poder a la comunidad y los actores locales y su corresponsabilidad en la toma de decisiones (empoderamiento), es capaz de generar capacidad institucional y de implicar a la comunidad con el desarrollo y mejora de su barrio, al dar lugar a la formación o reforzamiento de un sentimiento de identidad allí donde no existía o era débil. La activación de ese sentimiento permite dar lugar a capacidad local. Además, conlleva la evolución hacia modelos de gobernanza colaborativa que, más allá de restablecer el diálogo entre las instituciones locales y otros actores, da lugar a la transformación del gobierno local y de la gobernanza multinivel.

Por otra parte, la inclusión de la dimensión colaborativa en el urbanismo conlleva la consideración del conocimiento que reside en la comunidad (conocimiento no experto) y el conocimiento experto, y la utilización de ambos de cara a identificar de manera certera el problema, elaborar diagnósticos lo más completos posibles, y definir estrategias eficaces. El conocimiento derivado de la conjunción de ambos deriva en la identificación y movilización de recursos que hasta el momento estaban presentes pero no utilizados. El enfoque colaborativo conlleva, por tanto, la aplicación de una visión de planificación estratégica en el entendimiento inclusivo del problema y el diseño de las propuestas de actuación.

En su libro Collaborative Planning: Shaping Places in Fragmented Communities (Healey, [1997] 2006) Healey argumenta la conveniencia de dar lugar a un modo de gobernanza democrático pluralista y una Planificación Colaborativa, definida como un estilo de gobernanza, que lo haga posible. Su propuesta se fundamenta en el Nuevo Institucionalismo, que a finales de los años noventa se estaba desarrollando dentro de las Ciencias Sociales, y en el enfoque comunicativo de la teoría de la planificación 
(el desarrollado por las contribuciones de Forester y Friedmann que se fundamentaron, a su vez, en la Teoría de la Acción Comunicativa de Jürgen Habermas). En relación a esto Healey puntualiza en un artículo posterior (de 2003) que la contribución en la que fundamenta principalmente su pensamiento es la Teoría de la Estructuración del sociólogo británico Anthony Giddens ${ }^{6}$, la cual le proveyó la "ventana a la radicación social del poder que otros habían encontrado en Foucault o Bordieu"7 (Healey, 2003: 106).

El libro CollaborativePlanning: Shaping Places in Fragmented Communities recibió inmediatamente críticas que lo calificaron de idealista, de no tener en cuenta la realidad de los mecanismos de poder (por ejemplo (Flyvbjerg, 2002), Tewdwr-Jones y Allmendinger, Yiftachel y Huwley, Harris, Rydin ${ }^{8}$ ) e incluso de ignorar el conflicto. Sin embargo, al tiempo que surgían estas voces escépticas, en Estados Unidos y Europa empezaba a definirse un movimiento que proponía la puesta en práctica de procesos de planeamiento participativo y la toma de decisiones de modo colaborativo. Como la misma Healey señalaba en la segunda edición del libro, aparecida en 2006, a pesar de las críticas, a mediados de los noventa era innegable la aparición de un movimiento de potenciación del planeamiento participativo y de la toma de decisiones de modo participado en el ámbito de la gobernanza urbana, regional y ambiental en Europa y Estados Unidos (Healey, [1997] 2006).

El enfoque institucionalista de Healey pone el énfasis en las relaciones sociales a través de las que se realiza la acción colectiva y se regulan las actividades. Su atención cae tanto del lado de las organizaciones formales como del lado de las redes relacionales y los procesos de gestión colectiva. Al situar el planeamiento en esa perspectiva, Healey identifica en el mismo dos niveles de gobernanza: el que tiene que ver con los sistemas legislativos y los procedimientos que fijan las reglas en las que se basa la práctica (hard infrastructure) y el que tiene que ver con la formación y la puesta en marcha de la práctica de planeamiento (soft infrastructure).

Asumiendo que los individuos son capaces de transformar las estructuras en las que se desarrollan sus vidas, Healey aporta un enfoque que pone la atención en la práctica del planeamiento colaborativo con los individuos (soft infraestructure) y en los sistemas de planeamiento existentes, en los que la planificación urbana tiene lugar (hard infraestructure).

Es desde ahí desde donde profundiza su interés por la capacidad de las soft infrastructures para transformar las estructuras existentes (hard infrastructure) desde una visión incrementalista. El desafío clave para ella está en cómo se combina

\footnotetext{
${ }^{6}$ La Teoría de la Estructuración de Giddens explora si son los individuos o las fuerzas sociales los que dan forma a nuestra realidad social. Para él, aunque las personas no son totalmente libres para elegir sus propios actos y su conocimiento es limitado, son los agentes que reproducen las estructuras sociales y llevan al cambio social. En el pensamiento de Giddens la estructura y el agente constituyen una dualidad inseparable, por lo que ambos elementos no pueden ser concebidos o analizados de forma independiente. Las estructuras son creadas, mantenidas y cambiadas a través de la acción, mientras que la acción queda dotada de forma sólo a través del soporte que le provee la estructura, por lo que la causalidad se da en ambas partes, y ambas partes se dan forma la una a la otra a través de un bucle en movimiento constante.

7 Traducción propia de original en inglés.

8 Estos últimos citados por la propia Healey en el mencionado libro.
} 
el diseño de las nuevas infraestructuras duras con las luchas que se dan al transformar de manera deliberada las relaciones de poder.

Su interpretación de la realidad social a través de las ideas de Giddens le permiten dar una explicación de las razones que están en la base del bloqueo de los procesos de planeamiento en ámbitos en los que conviven una multiplicidad de actores y grupos sociales. Para ella esta explicación radica en su diversidad, en los sistemas culturales en los que se soportan sus identidades. En base a esto cada grupo tiene una noción de interés general, de lo que constituye un problema a abordar por una política y lo que no. Si la planificación es consciente de esta realidad puede proveer la arena que permita a estos grupos trabajar juntos en la definición de lo que tienen que cambiar o mejorar en el entorno en el que viven, en la definición común del problema. De esta manera se contribuye a construir la capacidad institucional de un lugar (Healey, [1997] 2006: 61).

Así, a través de procesos que desarrollen prácticas que deriven en la construcción de la capacidad institucional de los lugares, a través de nuevas formas de gobernanza colaborativa en las que estén representados todos los actores, el planeamiento tiene el potencial de contribuir al desarrollo de prácticas de democracia pluralista. Para ella una tarea clave del planeamiento es cuestionar de manera crítica la gobernanza de las comunidades políticas, para ayudarlas a desarrollar nuevos enfoques cuando los existentes fallan (Healey, 2003).

Los procesos colaborativos se caracterizan para Healey por la implicación de múltiples actores en nuevas arenas de diálogo a las que acuden libremente al reconocer las dependencias mutuas que existen entre ellos. En esas arenas todos tienen el mismo poder y muestran predisposición a escuchar y respetar al resto de los participantes. En el proceso se integra la experiencia y el conocimiento del lugar con el conocimiento científico y técnico, y se genera conocimiento y poder a través del aprendizaje colectivo y la capacidad de innovar. A través del mantenimiento de este compromiso creativo de manera sostenida en el tiempo, se crean nuevos marcos de referencia y se puede llegar a acordar intervenciones específicas en base a acuerdos duraderos. Si todas estas características o cualidades del proceso están presentes, un episodio colaborativo puede ser capaz de combinar la innovación creativa con la eficacia, para llevar a alcanzar una mayor capacidad de resolver los problemas que la que es propia de otras formas de política. Esta capacidad, nacida en el marco de un episodio específico, puede contribuir a una mayor construcción de la capacidad institucional (Ibídem). Para que esto sea así los actores presentes en el proceso tienen que ser representativos y los valores de justicia inclusiva y sostenibilidad tienen que mantenerse vigentes a lo largo del mismo. Si esto no se verifica, se darán procesos de participación que fracasarán, a pesar de los esfuerzos hechos para cambiar las formas de pensar y actuar, "pero el fracaso no es siempre negativo, y los pequeños logros no tienen por qué perderse en el flujo de la historia. Incluso el más estable de los sistemas de gobernanza de alguna manera está siempre transformándose y, a través de la movilización astuta, pueden abrirse "ventanas de oportunidad" y "grietas en la estructura" a través de las cuales otros modos de proceder pueden introducirse" (Healey, 2003: 117).

\footnotetext{
9 Traducción propia a partir de texto original en inglés.
} 


\subsection{El enfoque colaborativo para la transformación de la gobernanza en la Iniciativa Comunitaria URBAN}

Como se ha visto, la Planificación Colaborativa se propone como una alternativa a aplicar en procesos de planificación que operan en contextos complejos que, partiendo de la ausencia de diálogo o incluso del conflicto entre actores con diferentes posiciones en torno a un tema de política pública, se reconducen para derivar en la construcción de un proyecto común. La capacidad transformadora de los procesos colaborativos, el cambio hacia un modelo de gobernanza más inclusivo que señalan como objetivo todos los autores mencionados, y en particular la Profesora Healey, toma como criterio desde el que establecer un marco de análisis en las siguientes fases de esta investigación de los procesos colaborativos que se han dado en la implementación de las Iniciativas Comunitarias URBAN y URBAN II en España.

Se toma como referencia la propuesta desarrollada por Healey, ya que en la Planificación Colaborativa la participación de los actores locales y la comunidad se ubica dentro de las estructuras que constituyen los marcos de planeamiento. En el contexto de este trabajo se considera válida la aplicación de esa visión al enfoque colaborativo de la Iniciativa Comunitaria URBAN, dentro de la cual los programas de regeneración son considerados un instrumento que propicia el acercamiento entre el sector público, la comunidad y los actores locales para transformar las formas de gestión en las que las decisiones son tomadas por la administración sin tener en cuenta la complejidad y diversidad que se da en la realidad urbana en la que opera. El enfoque colaborativo de URBAN, como parte de una metodología para la mejora de ámbitos urbanos degradados, tiene que ver también con el entendimiento de que la calidad de un "lugar" va más allá del soporte físico, estando más relacionada con la calidad de las relaciones y las redes sociales que existen, con lo que Healey denomina "el flujo" de la vida urbana (Healey, 2004: 160).

Desde el lanzamiento de la Iniciativa URBAN la Comisión Europea ha insistido en ambos temas, manteniéndolos a lo largo de los años en los documentos en los que ha expresado sus puntos de vista respecto a la actuación en el medio urbano. La Comisión se reafirmó en esta postura al establecer en el año 2000 la gobernanza europea como un objetivo estratégico y publicar en 2001 la comunicación titulada La Gobernanza Europea. Un Libro Blanco (Comisión Europea, 2001), un documento en el que se expresaba la intención de transformar la gobernanza europea a través de distintos instrumentos, entre los que se encuentra la financiación de programas, actuaciones e iniciativas a través de los Fondos Estructurales.

En relación al segundo tema mencionado, las comunicaciones de la Comisión que hacen mención a la calidad del medio urbano también han apuntado la necesidad de mejorar la dimensión social de la ciudad desde el entendimiento de que sólo un fuerte entramado de relaciones y redes sociales pueden capacitar a los barrios y ciudades para afrontar las dinámicas negativas. En concreto el Marco de Actuación para el Desarrollo Urbano Sostenible en la Unión Europea de 1998 señalaba: "la cooperación es necesaria porque hay problemas urbanos complejos que no pueden resolver por sí solos instituciones u organismos públicos aislados. La resolución de problemas es una obligación común que requiere la intervención de todos los interesados. A nivel local, es importante vincular a los ciudadanos y a los sectores privado y comunitario para 
conseguir dar cabida a las aspiraciones de todos los principales intervinientes, responder a las necesidades de los beneficiarios locales (...), movilizar todos los recursos posibles y potenciar el sentido de "posesión" y el compromiso, incrementando así la legitimidad de la política y su aplicación efectiva" (Comisión Europea, 1998: 10). Esta visión se ha visto renovada en documentos sucesivos.

La contribución a la transformación de la gobernanza que podría haber hecho URBAN en el sentido planteado por Healey se habría operado en base a la oportunidad que los programas de regeneración urbana constituían para que la comunidad local participase en los mismos junto al sector público. Esta posibilidad podía "capacitar" a dichos actores para que transformasen el modo de relacionarse entre ellos, dando lugar a un proceso de conocimiento mutuo, interacción y creación de relaciones donde se tejerían redes fundadas en el entendimiento y la confianza mutua, que darían lugar a lo que Healey denomina relational resources. Esto, a su vez, podría derivar en la demanda de extender este tipo de actuaciones a otros ámbitos de política, dando lugar a un verdadero proceso de transformación de la gobernanza local mediante una transformación de las infraestructuras duras (instituciones, normas, etc.).

En base a lo anterior, URBAN también se habría constituido como un instrumento en torno al cual se habría intentado mejorar el diálogo entre los distintos niveles de gobierno con intereses y/o competencias en el ámbito de la mejora del medio urbano (la UE, los gobiernos nacionales, las regiones y las ciudades), contribuyendo a la mejora de la gobernanza multinivel (también denominada dimensión vertical de la gobernanza). Además, en base al enfoque integrado que la caracteriza y que es sustancial al carácter colaborativo de la misma, la Iniciativa habría contribuido a la coordinación entre los distintos departamentos o áreas municipales (medio ambiente, urbanismo, social, economía, participación, etc.) responsables de los ejes en los que han actuado los programas. En base a esto también habría contribuido a la mejora de la dimensión horizontal de la gobernanza urbana.

\section{FORMACIÓN Y LANZAMIENTO DE LA INICIATIVA COMUNITARIA URBAN EN EL CONTEXTO DE LA POLÍTICA URBANA DE LA UNIÓN EUROPEA}

A principios de los años noventa la Comisión Europea atendió la reivindicación de las ciudades, diferentes instituciones y entes que solicitaban una intervención directa de los Fondos Estructurales en las áreas urbanas a través de un instrumento específico, con el fin de frenar los procesos de degradación y generar dinámicas de renovación y desarrollo. Esta demanda se había basado en gran medida en la constatación de la especificidad de la problemática urbana, que hacía que muchas de las temáticas que tenían que afrontar las ciudades para alcanzar niveles adecuados de cohesión económica y social quedasen fuera de los contenidos que eran cofinanciables dentro de los programas comunitarios existentes.

Basándose en la experiencia obtenida en el desarrollo de la Política Regional durante la década de los ochenta, la Comisión Europea, el Parlamento Europeo y los gobiernos de los Estados miembros empezaron a dar forma de manera gradual a un marco de desarrollo urbano de escala comunitaria. El trabajo en este ámbito, junto a la experiencia obtenida a través de los Proyectos Piloto Urbanos (PPU), daría lugar en 
1994 al nacimiento de la Iniciativa Comunitaria URBAN, que surgió como respuesta a la mencionada demanda.

Este instrumento nació determinado por las políticas de regeneración urbana que habían sido desarrolladas con anterioridad por distintos países comunitarios y Estados Unidos, pero sobre todo estuvo influenciado por la experiencia británica, en cuyo contexto nacional se había lanzado en el año 1991 el programa City Challenge por parte del Department of Environment del Gobierno Major. Como se verá la Iniciativa Comunitaria URBAN iba a adoptar la metodología de City Challenge (a excepción de algunos aspectos de la misma).

City Challenge nació, como consecuencia del proceso de reflexión que se había iniciado en el contexto británico al final de la década de los ochenta en torno a los resultados de las iniciativas que se habían puesto en marcha durante esos años por parte del gobierno conservador en el ámbito de la regeneración urbana en el país (Urban Development Corporations, Enterprise Zones, Urban Development Grants, Inner City Enterprises, City Grant). City Challenge también aparecía influenciado por el New Public Management, de la mano del cual en Estados Unidos y Gran Bretaña empezaron a introducirse criterios y técnicas de gestión procedentes del ámbito empresarial a la administración pública con el fin de mejorar su eficacia.

En Gran Bretaña a partir de aquel momento el enfoque económico de las iniciativas para la regeneración urbana siguió teniendo un peso relevante, pero se dio cabida a las autoridades locales y también a las comunidades y los actores locales en los procesos, desde el entendimiento de que sólo el nivel local conoce en profundidad las problemáticas que afronta, por lo que es el único capaz de realizar diagnósticos realistas y diseñar y desarrollar estrategias eficaces. La participación de la comunidad y su implicación en los procesos se empezó a entender como un recurso para reducir el coste de los programas, aumentar su eficacia, y asegurar la durabilidad de las acciones que se emprendían a través de los programas de regeneración. A partir de la penetración de todos estos elementos en las políticas urbanas se dio de nuevo al nivel local la oportunidad de incidir en los procesos de regeneración en el contexto británico.

Una primera respuesta en el intento de adaptar los instrumentos de regeneración a las nuevas directrices de actuación adoptadas por el gobierno conservador en el cambio de década quedó plasmada en el Libro Blanco de 1990 People in Cities y en términos prácticos se materializó en el diseño y el contenido del programa City Challenge, en 1991. Los objetivos esenciales de City Challenge, fijados en las directrices establecidas por el Secretario de Estado de Medioambiente, Michael Heseltine, se resumían en la adopción de estrategias radicadas localmente que atrajeran inversión, estuvieran basadas en la creación de un clima de calidad ambiental y cultura empresarial, y en la formación de asociaciones entre las autoridades locales y todos los actores con intereses en el área de actuación (Faber, 1994). Los programas candidatos tenían que desarrollar estrategias dirigidas a áreas que presentasen oportunidades económicas relevantes, que estuvieran aquejadas de un declive significativo o ambas circunstancias. Dichas áreas tenían que tener una extensión limitada, lo que conllevaba la concentración de los recursos económicos y técnicos según un enfoque area-based. 
Para ser elegibles los programas tenían que desarrollar una asociación (partnership) entre las autoridades locales, el sector privado, la comunidad local, departamentos del gobierno central, la policía, etc. y tenían que estar planificados en base a un horizonte limitado y establecido de tiempo. Además tenían que presentar una estrategia a seguir, basada en los problemas existentes y los objetivos a alcanzar, y tenían que hacer mención al "efecto palanca" que se esperaba ejercer en otras áreas colindantes a través del desarrollo del programa en esa zona específica.

Si cumplían todas esas condiciones las ciudades podían presentar programas candidatos a través de un proceso novedoso, denominado competitive bidding, según el cual las distintas propuestas entraban en un proceso en el que competían entre sí, con el objetivo de que las mejores accedieran a la financiación. En este sistema de selección quedaba claramente plasmado el enfoque empresarial que Heseltine potenció en esos años en esta y otras políticas desde sus puestos en el Gobierno (para Heseltine City Challenge no tenía que financiar problemas, sino soluciones).

El profesor Michael Parkinson, desde el European Institute of Urban Affairs de Liverpool, había trabajado en el ámbito de la UE a partir de la elaboración y publicación del Informe Parkinson (Urbanization and the functions of cities in the European Community) de 1992 (EIUA, 1992). El enfoque plasmado en este documento, el debate existente en su país en relación a la acción en los barrios degradados y el cambio de posicionamiento del Gobierno constituían el contexto en el que venía trabajando. Sobre esta base, a petición de la Dirección General de Política Regional de la Comisión Europea, diseñó durante el periodo 1991-92 una nueva Iniciativa Comunitaria destinada a contrarrestar los procesos de degradación que se estaban registrando en muchos barrios de las ciudades europeas. Parkinson conocía de primera mano la metodología de City Challenge. Para dar respuesta al encargo de la Dirección General de Política Regional introdujo en la nueva Iniciativa Comunitaria dirigida a las áreas urbanas una metodología similar, que incluía los principales elementos definitorios del programa británico, aunque adaptándolos al contexto comunitario y evitando una trasposición literal (entrevista a Michael Parkinson, ver Anexo). Dichos elementos definitorios fueron:

i) Enfoque area-based.

ii) Desarrollo de una estrategia a lo largo de un periodo limitado de tiempo (5-6 años).

iii) Enfoque integrado.

iv) Implicación del sector público, privado y la comunidad local.

v) Enfoque colaborativo entre distintos niveles de gobierno y entre distintas instituciones o departamentos del mismo nivel de gobierno.

vi) Proceso de selección competitivo en base a criterios de calidad del programa y capacidad de cofinanciación.

Los objetivos esenciales de City Challenge se resumían en:

- Dar lugar a programas basados en estrategias radicadas localmente que atrajeran inversión.

- La creación de asociaciones entre las autoridades locales y todos los actores con intereses en el área de actuación (Faber, 1994). 
Mientras que los objetivos generales de URBAN, expresados en la Comunicación de la Comisión (Comisión Europea, 1994), eran los siguientes:

- Contribuir a la mejora de las zonas urbanas a través de actuaciones dirigidas a mejorar las infraestructuras y el medio ambiente, creando además un entorno favorable para la instalación de nuevas actividades económicas.

- "Promover el lanzamiento de nuevas actividades económicas mediante el establecimiento de talleres y la realización de actuaciones de apoyo a las empresas y al comercio locales" (Ministerio de Hacienda, 2000: 1).

- Dar lugar a la integración social de la población afectada mediante la puesta en marcha de planes de formación.

- Mejorar los servicios sociales, sanitarios y de seguridad.

- "Contribuir al aumento de la capacidad local a la hora de resolver problemas, estableciendo así las bases para la cooperación entre las organizaciones ciudadanas y agentes interesados" (ibídem).

De la comparación de los objetivos de ambos se desprende que en los dos instrumentos la revitalización económica de los barrios y la adopción de un enfoque colaborativo eran temas centrales. De ella también emerge la mayor orientación social adoptada por URBAN, derivada, según Parkinson, de sumar al modelo británico una tradición de acción en el medio urbano de base más social con peso en la Unión Europea a través de la influencia de países como Francia (entrevista a Michael Parkinson, ver Anexo). Esta circunstancia también es señalada por Atkinson, para quien a nivel de la Unión Europea el concepto de la exclusión social integró elementos del enfoque francés, que focalizaban en la exclusión social y cultural, con el enfoque británico, más concentrado en la desigualdad y la exclusión material (Atkinson, 2000).

Por otra parte, entre City Challenge y URBAN también se daban importantes diferencias. En base al objetivo de este trabajo es de interés señalar la adopción por parte del segundo de un concepto de participación sensiblemente distinto. Las diferencias principales en relación a la participación y la adopción de un enfoque más social por parte de URBAN estribaron en que:

- URBAN no incluyó la obligatoriedad de formar asociaciones a nivel local como condición para que los programas pudieran acceder a la Iniciativa. La formación de partnerships era recomendada pero no era un requisito obligatorio.

- La participación en URBAN se consideraba como una parte de la metodología de actuación, que favorecía la adopción de un enfoque integrado en los programas. Por otra parte, a través de la participación se pretendía introducir y consolidar en los contextos locales formas más democráticas de gestión local, donde se crearan arenas de diálogo y consenso en las que estuvieran presentes en igualdad de condiciones las autoridades locales, los agentes económicos y sociales de la ciudad, el tercer sector y la comunidad afectada por el programa de regeneración. Una revisión de la documentación emanada de las instituciones europeas en esos años permite interpretar la participación en URBAN en aplicación del Principio de Subsidiariedad que rige la política comunitaria como una vía a través de la cual 
perfeccionar la gobernanza local, devolviendo poder a la comunidad local para convertirla en agente activo en los procesos de toma de decisiones y su implementación.

- Como se ha apuntado, URBAN adoptó desde un primer momento un enfoque más social que City Challenge, aunque el enfoque económico también estaba presente y era central en la Iniciativa. Al contrario que el programa británico, URBAN no incluyó explícitamente como criterio para determinar la eligibilidad de las áreas el hecho de que estas presentasen potencialidades económicas relevantes, sino que fuesen áreas donde la acción era necesaria en base al proceso de degradación que presentaban.

- Otra diferencia es que URBAN no adoptó plenamente el proceso competitivo del ejemplo británico, dejando la decisión sobre el método y los criterios a utilizar en el proceso de selección a los Estados miembros, pero dando desde la Comunicación de la Comisión un peso equivalente a la necesidad de actuación y a la calidad de la propuesta de regeneración. En este sentido URBAN adoptó un enfoque más parecido al que luego introduciría en el contexto británico el Gobierno laborista de Tony Blair a partir del año 1997.

En el diseño de la Iniciativa se tuvo en cuenta la especificidad de la problemática urbana a afrontar, por lo que el instrumento resultante adoptó un enfoque estratégico adaptado a la escala del medio urbano en el que se pretendía actuar. Para ello adoptó el enfoque area-based de City Challenge y se dotó con recursos económicos procedentes del Fondo Europeo de Desarrollo Regional (FEDER) y del Fondo Social Europeo (FSE).

Durante el periodo 1989-1993 se habían lanzado los Proyectos Piloto Urbanos, que también ejercieron una importante influencia en la determinación de la metodología que se iba a plasmar a partir de 1994 en URBAN. Entre las novedades que introdujeron es relevante señalar la canalización de Fondos Estructurales hacia las áreas urbanas, ya que a través de la implementación de los 33 Proyectos Piloto Urbanos se asignaron por primera vez fondos procedentes del FSE y del FEDER a la regeneración de una zona urbana geográficamente delimitada. El resultado de dicha "fórmula" fue considerado positivo por la Comisión Europea (GHK, 2003). URBAN fue concebido también en continuidad con esta experiencia.

El lanzamineto de los PPU había coincidido con el cambio de tendencia que se dio en torno a 1990 en el contexto británico en relación a la mayor implicación del nivel local en las acciones de regeneración urbana. En base a esto se puede afirmar que el diseño de los PPUs, que coincide prácticamente en términos temporales con el diseño de City Challenge, respondió a la misma reflexión en el ámbito comunitario que había derivado en el lanzamiento de este último en el contexto británico. Este paralelismo responde también a la fuerte trasposición de enfoques que se dio entre estos dos contextos durante estos años, materializada a través de un fuerte liderazgo británico en el seno la Dirección General de Política Regional de la Comisión Europea (entrevista a Michael Parkinson, ver Anexo).

URBAN fue una de las 13 Iniciativas Comunitarias de la UE durante el periodo presupuestario 1994-1999. Las Iniciativas Comunitarias perseguían durante el 
mencionado periodo presupuestario la creación de métodos de acción de arriba abajo en los distintos Estados miembros, por lo que todas estuvieron basadas en enfoques colaborativos multinivel.

La materialización de un instrumento de regeneración urbana por medio de una Iniciativa Comunitaria permitía en aquel momento a la UE actuar sin tener competencias directas en este ámbito, ya que los Estados miembros no estaban obligados a implementar los contenidos de URBAN. La Comisión lanzaba la Iniciativa, y estos decidían voluntariamente presentar sus candidaturas. Si las presentaban y eran aprobadas por la Comisión, accedían a los recursos económicos puestos a disposición por el FEDER y el FSE, condicionados al cumplimiento de una serie de directrices de actuación y el cumplimiento de unos objetivos preestablecidos.

Desde instancias comunitarias se asumía que URBAN no podía resolver los problemas de las ciudades de la UE, por si sola, por lo que se proponía como un catalizador que actuara a través del desarrollo de planes clave para las zonas urbanas desfavorecidas.

Otro de los objetivos principales con los que se lanzó URBAN fue convertirla en un punto común de referencia en la discusión política sobre el futuro de la Ciudad europea. Este objetivo se cumplió, ya que la experiencia adquirida a través de la implementación de esta Iniciativa influenció notablemente los documentos producidos por la Comisión durante la década de los noventa (y también del 2000) en relación al desarrollo urbano sostenible.

En los periodos de programación de los Fondos Estructurales 1994-1999 y 20002006 se desarrollaron respectivamente las dos fases de esta Iniciativa Comunitaria: URBAN y URBAN II. Estuvo prevista su continuación para el siguiente periodo presupuestario (2007-2013), bajo el nombre de URBAN+, sin embargo finalmente no fue lanzada, al quedar las acciones de desarrollo urbano integradas en el mainstreaming comunitario a través de los Programas Operativos de los Estados miembros.

Esta situación ha generado un debate interno en las instituciones europeas en el que se presentan dos posiciones: las que consideran que la atención al tema urbano debe ser un mainstreaming en las políticas europeas y las que consideran que la reaparición de URBAN o un instrumento similar es necesaria, debido al carácter ejemplificador y la visibilidad que difícilmente incorporan las actuaciones a través del mainstreaming.

La política urbana de la UE durante el nuevo periodo presupuestario 2014-2020 prevé la continuación del mainstreaming de la misma en los Programas Operativos de los Estados miembros, por lo que hasta el momento presente la Iniciativa Comunitaria URBAN continua siendo el instrumento más específico y visible de la dimensión urbana de la política de la Unión Europea. 


\section{LA PRÁCTICA DE LA REgENERACIÓN URBANA EN ESPAÑA}

Las iniciativas de regeneración urbana en el país son recientes si se comparan con las de otros países de Europa Occidental o con Estados Unidos. Cuando en el año 1994 la Comisión Europea lanzó la Iniciativa Comunitaria URBAN, algunos Estados miembros de la UE contaban con una tradición consolidada de actuaciones de rehabilitación dirigidas a los barrios degradados, implementadas a través de marcos legislativos y políticas diseñadas para tal fin desde sus gobiernos nacionales, mientras que en España la experiencia en ese campo era más corta y no existía una política a escala nacional comparable.

Las principales razones que llevaron a que la experiencia en relación a este tema se desarrollara con retraso, tuvieron su origen en cuestiones históricas, ya que el aislamiento que supuso el periodo dictatorial dejó al país al margen por un tiempo de las dinámicas que se estaban desarrollando a nivel europeo en todos los campos y, por tanto, también en lo relativo a la práctica urbanística. La ideología conservadora y propagandística que se impuso, derivó en el ámbito del urbanismo en una vuelta a la disciplina académica que limitaba la apertura hacia la modernidad que se estaba verificando en otros países. La rehabilitación urbana fue un aspecto inexistente en las políticas del franquismo.

A las circunstancias señaladas se añadieron otras que determinaron el desarrollo de las políticas urbanas en España en el periodo inmediatamente posterior a la dictadura. La principal fue la profunda reforma del Estado que se dio en el año 1978 y que, en virtud de la Constitución, dejó atrás el modelo centralista para dar paso a una nueva organización a través de la creación de 17 Comunidades Autónomas, llevando a una distribución del poder cercana a la de un modelo que algunas contribuciones denominan cuasi-federal.

En relación al tema que nos ocupa, la reestructuración del Estado que se llevó a cabo tuvo importantes consecuencias, ya que las competencias en materia de urbanismo pasaron, de estar en manos del Gobierno Central, a recaer en las Autonomías y los nuevos Ayuntamientos democráticos ${ }^{10}$. El Gobierno Central mantuvo las competencias en materia de régimen de propiedad del suelo (y materias anexas), de infraestructuras, de vivienda, de medio ambiente y de telecomunicaciones. La Constitución le atribuyó también títulos competenciales en otros ámbitos relacionados con el urbanismo.

En este ámbito, en virtud de las nuevas competencias que les habían sido conferidas, tanto los Ayuntamientos como las Comunidades Autónomas tuvieron que llevar a cabo un proceso rápido de aprendizaje, al tener que hacer frente a unos cometidos que tenían que ser atendidos con urgencia debido al estado del medio urbano. Desde el punto de vista ambiental, las condiciones de deterioro que presentaban los centros de las ciudades, debido al largo periodo precedente de desatención y la concentración de actividades obsoletas, se habían acrecentado a finales de los años sesenta y durante la década de los setenta con los procesos de destrucción del patrimonio edificado, debido a operaciones de demolición y sustitución

\footnotetext{
10 Los Ayuntamientos las recibieron en 1979, tras las primeras elecciones municipales de la democracia, mientras que el proceso de transferencia a las Comunidades Autónomas se empezó en los primeros años de los 1980.
} 
de construcciones que tuvieron consecuencias ambientales negativas. También la aparición y difusión del automóvil constituyó un factor responsable de la pérdida de calidad ambiental en las ciudades. A todo ello se sumaba la problemática social que se traducía en la existencia de focos de pobreza urbana y exclusión.

En lo que concierne a las áreas periféricas, las operaciones que se habían llevado a cabo durante el periodo dictatorial habían consistido sobre todo en la construcción de nuevos barrios de vivienda barata para absorber el aumento de población urbana. Muchas de las periferias surgidas a partir de los años cincuenta y sobre todo durante los años sesenta y principios de los setenta del siglo $\mathrm{XX}$, a través de procesos caracterizados en ocasiones por la ausencia de planificación, nacieron con deficiencias.

Se sumaba a este escenario la existencia de áreas industriales localizadas en ubicaciones que, debido al crecimiento urbano, habían quedado en posiciones rodeadas por áreas residenciales consolidadas. Estas explotaciones empezaban a abandonarse a favor de otras localizaciones mejor posicionadas en relación a las infraestructuras de transporte, la disponibilidad de mayor espacio y el menor coste del suelo.

Por otra parte, los problemas de contaminación y la insostenibilidad del "metabolismo" urbano eran graves en las ciudades españolas, pero todavía no se habían introducido en la agenda política como problemas a resolver y tampoco había aún en el país una conciencia social extendida que reclamase atención hacia estos temas.

Fue durante la década de los ochenta cuando se llevaron a cabo los primeros Planes Generales de la democracia. Estos se caracterizaron por introducir acciones que intentaban paliar los problemas producidos por la escasa ordenación del crecimiento que había caracterizado el periodo anterior de desarrollo urbano acelerado. Los Ayuntamientos acudieron a los urbanistas en busca de respuestas, que quedaron plasmadas en esos primeros Planes Generales. Se trató de un periodo en el que, una vez superado el periodo de dictadura, se trabajó con ilusión ${ }^{11}$, tanto desde las instancias profesionales como desde las políticas, para afrontar la situación que presentaban las ciudades y empezar su trasformación, desde una reacción contra el resultado de los modelos desarrollistas de la dictadura que, según Ortega, se materializó "en propuestas compartidas por técnicos, partidos políticos y ciudadanos" (Ortega, 2003: 55).

Durante los últimos años del franquismo se había forjado una crítica constructiva sobre la situación general del país, en base a la cual durante los primeros años de la Transición los partidos democráticos lideraron una postura crítica que, entre otras cosas, contribuyó a que precipitasen las consignas del nuevo planeamiento de la década de los ochenta, reclamando una ciudad más justa y la participación de la población en el mismo. En un primer momento la rehabilitación urbana no fue considerada una tarea prioritaria por los Ayuntamientos, sin embargo las exigencias de las organizaciones sociales empujaron a estos a emprender acciones concretas a

\footnotetext{
${ }^{11}$ La palabra "ilusión" ha sido utilizada por varios de los expertos españoles entrevistados en el marco de la Tesis Doctoral en la que se enmarca este trabajo para caracterizar la práctica de los urbanistas en este periodo. La utilizan sobre todo los entrevistados de más edad.
} 
pesar de la escasez de recursos económicos. Este periodo se caracterizó por el surgimiento de una cultura democrática local que legitimó lo que se dio en llamar "urbanismo ciudadano" emergido dentro de los movimientos sociales urbanos (MSU).

Los MSU surgieron durante la década de los sesenta en las ciudades europeas y estadounidenses. En España su actividad empezó a ser relevante en los últimos años de esa década, durante la recta final de la dictadura y en el inicio de la construcción democrática, cuando desde una base vecinal ejercieron un papel de movilización política, tanto para hacer frente a las instituciones franquistas como para articular socialmente a los ciudadanos (Urrutia, 1992). En el plano del urbanismo reivindicaban la participación de la ciudadanía en la configuración del medio urbano en el que se desarrollaban sus vidas, como reacción a la degradación de los barrios o frente a actuaciones urbanísticas de alto impacto.

En este contexto, las primeras acciones de mejora urbana que llevaron a cabo los Ayuntamientos pretendieron ir dotando a las ciudades de los equipamientos y espacios verdes de los que carecían, instrumentalizándose a través de Planes Especiales o Planes de Actuación por barrios. Las actuaciones que se acometieron en este periodo se caracterizaron por un enfoque sectorial, donde predominó la dimensión física.

Además de los Ayuntamientos, también otros niveles de gobierno comenzaron a desarrollar en ese momento acciones dirigidas a mejorar los barrios degradados. Así, en virtud del mandato a todos los poderes públicos que se recoge en la Constitución, desde el inicio de la década de los ochenta se empezó a articular una serie de medidas de iniciativa pública desde el Gobierno Central en el ámbito de la mejora física de los barrios, dirigida a la protección de los edificios de vivienda, que reintrodujeron en el panorama español el concepto de rehabilitación del patrimonio urbano construido. En concreto en 1983 se estableció un marco legislativo estatal, apoyado por una dotación económica permanente, dirigido a la rehabilitación del patrimonio residencial, a través del Real Decreto 2329/1983 de Protección a la Rehabilitación del Patrimonio Residencial y Urbano de 1983.

Como se ha apuntado, el Estado traspasó las competencias en ordenación urbana y territorial a los Ayuntamientos y Comunidades Autónomas, por lo que desde entonces ha tenido que ejercer su acción contra la degradación urbana a través de políticas que no invadieran ámbitos de competencia que ya no le pertenecían. En este sentido, el mencionado Decreto Ley es el primer paso de la definición de una política de actuación del Gobierno Central para la mejora del medio urbano, desarrollada en virtud de sus competencias en el ámbito de vivienda, e instrumentalizada a partir de entonces través de los Planes de Vivienda plurianuales que se han sucedido hasta la actualidad. Desde entonces, la política de vivienda del Estado ha incidido en la mejora de la calidad de vida en el medio urbano en dos sentidos principales: desde el punto de vista físico ha derivado en la mejora ambiental de los barrios, mientras que desde el punto de vista social ha contribuido a que sobre todo la población con menos recursos haya podido acceder a la vivienda, contribuyendo a la cohesión social de las ciudades. Desde la línea de rehabilitación de la política de vivienda se ha llevado a cabo una mejora urbana visible (que en un primer momento se hizo notar más en los centros urbanos). 
En la segunda mitad de los ochenta la situación económica del país empezó a mejorar, lo que permitió a los Ayuntamientos una mayor disponibilidad de recursos que dedicar a la rehabilitación urbana. Fue, por otra parte, el momento de consolidación democrática de las Corporaciones Locales y la redacción de Planes Generales de Ordenación Urbana en los que empezaban a incluirse directrices de conservación y rehabilitación del patrimonio urbano de manera sistemática. Las actuaciones de rehabilitación de los centros históricos siguieron instrumentalizándose a través de los Planes Especiales. Estos, además de la dimensión físico-ambiental, incluían la dimensión económica en las estrategias de revitalización, al constituir la reactivación económica de los barrios (sobre todo los centrales) uno de los objetivos prioritarios que estaban en la base de las actuaciones. La dimensión social era predominantemente objeto de políticas independientes, implementadas por las consejerías de Asuntos Sociales de los diferentes niveles de gobierno. En este sentido se puede afirmar que la política social ha sido la otra gran vía de política, complementaria a la de rehabilitación física, a través de la que se ha instrumentalizado la acción contra el declive urbano, mejorando las perspectivas de integración, laborales y formativas de los habitantes de las áreas más vulnerables.

Sobre ese aprendizaje y como consecuencia de la llegada de las recomendaciones internacionales a favor del desarrollo urbano sostenible, durante los años ochenta se produjo en el país el debate sobre la integración de las políticas sectoriales (Ortega, 2003). Esto propició que durante los años noventa algunas ciudades (sobre todo de pequeño tamaño) empezasen a ser objeto de nuevos modelos de rehabilitación.

En aquel momento los enclaves urbanos seguían arrastrando problemas no resueltos a los que se sumaba la aparición de otros nuevos. En relación a los barrios vulnerables se observaba como las altas tasas de paro que los habían caracterizado persistían, derivando en su consolidación como zonas en declive, abandonadas por la inversión privada y con inversiones públicas limitadas a la oferta de servicios. Por otra parte, los movimientos sociales urbanos que habían sido capaces de condicionar la actuación de los primeros Ayuntamientos democráticos durante el inicio de los años ochenta, sufrieron durante este periodo una transformación que los hizo perder vigor paulatinamente para estancarse en la década de los noventa. Además de las trabas que el tejido asociativo encontraba para lograr interactuar con la Administración, se dio un sentimiento de desesperanza por parte de amplios sectores de la población, al constatar su incapacidad de incidir sobre las decisiones que determinaban el devenir de sus barrios a través de formas de representación democráticas y de procesos de participación.

La intervención de los ciudadanos durante estos años se circunscribió en líneas generales a la fase de información pública y presentación de alegaciones que incluían los instrumentos de planeamiento. La falta de participación (ciudadana y de los actores locales) se conformó a partir de los años noventa como una de las constantes que caracterizó los procesos de toma de decisiones sobre la transformación de las áreas urbanas en España. Borja señala, como uno de los factores que frenaron el desarrollo de la democracia local participativa en aquel momento (sobre todo en ciudades grandes y medias) las "organizaciones partidarias que tienden al monopolio de la vida política local, en su vertiente institucional" (Borja, 2001), que limitaron y minimizaron los mecanismos participativos que facilitaban la presencia de actores no institucionales. 
Es importante destacar en este punto que durante este periodo tuvo lugar la entrada de España en la Comunidad Europea (año 1986). Esta circunstancia iba a tener consecuencias relevantes en la mejora del medio urbano, ya que a partir de ese momento el país fue receptor de los Fondos Estructurales (que en gran medida recaerían en actuaciones dentro de las ciudades).

Por otra parte, en aquel momento la acción del Ministerio de Obras Públicas, Transporte y Medio Ambiente (MOPTMA) constituyó una de las primeras iniciativas que, más allá de los planes de vivienda, supuso el lanzamiento de una política de rehabilitación del medio urbano por parte de la Administración Central. Esta nació englobada en el Plan Director de Infraestructuras 1993-2007 (PDI) aprobado en 1993, un instrumento de planificación para el desarrollo de las infraestructuras de competencia estatal. Desde el punto de vista urbano el plan proponía un conjunto integrado de actuaciones que constituían una estrategia de consolidación de la red española de ciudades, integradas en su región, que respondía a una jerarquización y una distribución territorial equilibrada (Fernández Lafuente, 1994). Entre las actuaciones que se proponían dentro de este objetivo estaba la actuación de mejora en el medio urbano en colaboración con las Comunidades Autónomas y los Ayuntamientos. Desde este punto de vista el plan partía del convencimiento de que sólo desde el entendimiento con ambos niveles de gobierno podría el Estado ejercer actuaciones en las ciudades, por lo que buscaba su implicación en los proyectos.

Desde el PDI se dio un intento por parte del Estado de ayudar a las ciudades y las Comunidades Autónomas a desarrollar acciones de rehabilitación de gran escala relacionadas con las infraestructuras de transporte. Además desde este instrumento se hizo un esfuerzo por hacer de la concertación multinivel un modo de actuar que pudiera ser transpuesto a otros ámbitos de política. EI PDI se puede interpretar como el intento de iniciar la concertación en ámbitos de competencias compartidas entre los distintos niveles de la Administración, desde el entendimiento de que la concertación interinstitucional no sólo era necesaria, sino también inherente al Estado de las Autonomías. Esta visión no iba a gozar de continuidad en la legislatura siguiente, en base a un cambio de partido en el Gobierno.

Más allá de esta importante aportación, el Gobierno Central siguió incluyendo dentro de su política de vivienda una vía de acción contra el deterioro físico en las ciudades a través de la actuación en la edificación residencial, instrumentalizándola por medio de Reales Decretos que trataban de manera conjunta temas de de vivienda, suelo y rehabilitación urbana. Así en1992 se aprobó el Plan de Vivienda 1992-1995 del Ministerio de Obras Públicas, Transportes y Medio Ambiente. A través de dicho Plan la política de vivienda del Gobierno Central pasó a tener un carácter más social. El Plan de 1992 fue objeto de cambios en 1993, a través de la aprobación del Real Decreto 726/1993. El cambio sustancial en relación al tema fue la introducción de un artículo titulado "De las actuaciones en Área de rehabilitación" en el que se introducía y definía el concepto de Área de Rehabilitación o Área de Rehabilitación Integrada (ARI).

Esta novedad apareció en el marco de una reflexión sobre la rehabilitación en España, que ponía en evidencia que la analogía de la política de ayuda a la rehabilitación con las ayudas para actuaciones de nueva construcción no había "resultado eficaz a efectos de estimular la rehabilitación" en el país (Real Decreto 
726/1993) y constataba lo insuficiente de las ayudas y las formas que estas habían adoptado. Como resultado se reorientó la ayuda a la rehabilitación desde la mejora puntual de los edificios residenciales hacia actuaciones que comprendieran la mejora ambiental de áreas urbanas degradadas. Esto se instrumentalizó a través de la definición de las Áreas de Rehabilitación Integral (ARI).

El análisis de este instrumento de política lanzado por el Gobierno Central, pone de manifiesto la existencia de algunos elementos novedosos en la escena española, que presenta similitudes con los métodos de acción que en ese momento (1993) se estaban intentando extender a todos los países comunitarios desde la UE (recuérdese que en 1989 se habían lanzado los PPU y que en 1990 la Comisión había publicado el Libro Verde del Medio Ambiente Urbano) y que un año después se plasmarían en la Iniciativa Comunitaria URBAN. A su vez, como se ha visto, la UE, a través de la Dirección General de Política Regional, estaba integrando las enseñanzas y experiencia procedente sobre todo de la escena británica, donde en ese momento estaba desarrollando el programa City Challenge. La definición de Área de Rehabilitación Integral implicó sobre todo un cambio de escala en el ámbito de la rehabilitación, desde el edificio puntual a la zona urbana homogénea en proceso de degradación.

Como había sucedido en el caso de los planes anteriores, la acción financiadora del Plan de Vivienda siguió teniendo un fuerte carácter redistributivo. En ese contexto, en el marco del Plan de Vivienda 1992-1995 se empezaron a poner en marcha proyectos de rehabilitación urbana a gran escala en las ciudades españolas. La vigencia de este marco legislativo se amplió para el periodo 1996-199912, aunque llevando a cabo una serie de modificaciones que buscaban la eficacia social de las actuaciones.

Como consecuencia de este y otros ejes de actuación, durante este periodo se produjo una mejora ambiental y social en las ciudades, que derivó también en una dinamización económica, propiciada por las acciones quese empezaron a implementar con recursos económicos públicos procedentes de los Ayuntamientos, las Comunidades Autónomas, el Gobierno Central y la Unión Europea.

A pesar de los pasos dados, en ese momento la insuficiente atención prestada a la rehabilitación urbana por parte del Gobierno Central se hacía patente en la falta de estudios realizados por las Administraciones Públicas que analizaran cualitativa y cuantitativamente la situación de los barrios desfavorecidos de las ciudades españolas. Además faltaba una reflexión sobre el tema de la Ciudad que trasponer a las políticas autonómicas y locales. Esta laguna sólo se ha salvado parcialmente en el momento presente.

En 1994, cuando la Iniciativa Comunitaria URBAN se lanzó, no existía en el país ninguna experiencia similar que comprendiera actuaciones integradas que afrontaran el declive urbano desde el entendimiento de la ciudad como un todo y no a través de la suma de problemáticas a abordar por medio de políticas sectoriales, implementada en base a un enfoque colaborativo entre los diferentes niveles de gobierno, con la participación de la ciudadanía y los actores locales, y lanzada a escala nacional.

${ }^{12}$ A través del Real Decreto 2190/1995 de 28 de diciembre, sobre medidas de financiación de actuaciones protegibles en materia de vivienda y suelo para el periodo 1996-1999. 
En 1996, bajo el título de La construcción de la ciudad sostenible, se publicó el Primer Catálogo Español de Buenas Prácticas (Ministerio de Obras Públicas, Transporte y Medio Ambiente, 1996). En él se recogían un conjunto de experiencias urbanas consideradas exitosas y, a través de su análisis, se llegaba a una serie de conclusiones relacionadas con la sostenibilidad urbana en el país. Su aportación, además de poner el acento en las acciones positivas que se estaban experimentando en algunas ciudades españolas, radicó en la revisión de la situación general en la que se encontraban las ciudades desde el punto de vista de la sostenibilidad y los sistemas de gestión e implementación de las acciones.

Por la cercanía temporal, el estado de las ciudades que describe el Primer Catálogo Español de Buenas Prácticas, puede considerarse la situación en la que se encontraban estas cuando URBAN empezó a operar en el país (el Catálogo es de 1996, mientras que URBAN se lanzó en 1994). La situación que describe el Catálogo es la siguiente:

- En relación al concepto de sostenibilidad se pone en evidencia que, salvo casos muy aislados, en España en 1996 no existía aún una conciencia institucional y social arraigada sobre los problemas medioambientales y la sostenibilidad urbana y territorial. (MOPTMA, 1996).

- En el Catálogo también se llegaba a conclusiones en el ámbito de los instrumentos y sistemas de planeamiento. En este sentido se detectaba una insuficiente innovación cultural e instrumental de las herramientas para la intervención en las ciudades.

- Se favorecía de manera generalizada el crecimiento urbano en aras del desarrollo económico (Ibídem).

A pesar del citado retraso en acometer acciones de mejora urbana, en ese momento ya se detectaba un incipiente interés por rehabilitar los barrios degradados, tal y como deriva de las acciones escogidas como Buenas Prácticas en el mismo Catálogo, pudiéndose afirmar que en ese momento la rehabilitación urbana había entrado ya en la agenda política de buena parte de las administraciones locales.

En este contexto, la llegada de URBAN a España constituyó el primer contacto sistemático que los Ayuntamientos, algunas Comunidades Autónomas y el Gobierno Central tuvieron con acciones integradas que formaban parte de un programa diseñado ad hoc para dar respuesta de manera específica a la degradación urbana, sólo precedido por la experiencia de menor relevancia de los PPU.

Como se explica a continuación, la primera fase de los proyectos URBAN conllevó el desarrollo de 29 proyectos. Aunque la valoración de sus resultados se recoge más adelante, baste decir aquí que la introducción de esta Iniciativa Comunitaria supuso una "perturbación" positiva y una semilla de transformación de la práctica dominante que, como se verá, ha tenido consecuencias relevantes. 


\section{LA INICIATIVA COMUNITARIA URBAN EN ESPAÑA}

La Iniciativa Comunitaria URBAN fue lanzada por la Comisión Europea en 1994 a través de la Comunicación de la Comisión Europea a los Estados Miembros por la que se fijan las orientaciones para los programas operativos elaborados dentro de la Iniciativa URBAN (Comisión Europea, 1994b). La Comunicación establecía el ámbito de acción, los objetivos, las zonas seleccionables, las medidas a implementar y las condiciones de financiación. En virtud de la misma cada Estado miembro optaba voluntariamente a obtener cofinanciación comunitaria para desarrollar programas de regeneración urbana. Cada programa se estructuraba en base a una serie de ejes a los que daban contenido las medidas que, a su vez, se plasmaban en base a acciones concretas. El conjunto de esos elementos estaba basado en una estrategia de desarrollo urbano sostenible que se tenía que aplicar durante el periodo 1994-1999 en el área en cuestión, con el fin de invertir la tendencia de degradación existente y dar lugar a capacidad local.

Para optar a formar parte de la Iniciativa cada Estado miembro de la UE tuvo que designar una Autoridad de Gestión que liderase el desarrollo de la misma y que llevase a cabo la difusión, seguimiento, control, coordinación y apoyo técnico a los programas. En el caso de España se designó como tal al Ministerio de Economía y Hacienda, en concreto a la Dirección General de Fondos Comunitarios y Financiación Territorial. Este ente se eligió en base a la experiencia que tenía como administrador del FEDER.

La Dirección General de Fondos Comunitarios difundió la Comunicación de la Comisión Europea, haciéndola llegar a las instituciones y actores locales potencialmente interesados en acceder a la Iniciativa. La convocatoria se envió a todas las ciudades que tenían más de 100.000 habitantes a través de una carta y un folleto explicativo preparados para tal fin (De Gregorio y Kocewicz, 2007). La Comunicación de la Comisión por la que se lanzó URBAN era del 15 de junio de 1994 y el Estado Español presentó su solicitud de ayuda comunitaria para el Programa Operativo URBAN el 3 de noviembre de ese mismo año. Esto significa que en cuatro meses y medio la Autoridad de Gestión hizo pública la convocatoria a las ciudades españolas, estas desarrollaron sus propuestas, se llevó a cabo el proceso de selección y se efectuaron las modificaciones pertinentes en los programas seleccionados para, a continuación, presentárselos a la Comisión como candidatos a la Iniciativa.

Como resultado, el periodo de tiempo que las ciudades tuvieron para desarrollar las propuestas fue escaso lo que, sumado a la falta de experiencia que las instituciones locales tenían en el desarrollo de proyectos de esta índole, derivó en la presentación de proyectos que no fueron del todo coherentes con los presupuestos de la Iniciativa, no asumiendo el enfoque integrado y colaborativo en el grado recomendado por la Comisión. Esta circunstancia determinó desde el principio el desarrollo de URBAN en España, limitando los resultados alcanzados por los programas.

Dada la rapidez con la que se presentaron las propuestas y la falta de experiencia, los indicadores de degradación o vulnerabilidad que las ciudades utilizaron para justificar la elegibilidad del área que proponían como zona de actuación no fueron siempre los más adecuados. Además fueron heterogéneos entre los diferentes 
proyectos, lo que hizo difícil utilizarlos como criterio de selección y comparación entre las propuestas. Una consecuencia de esto fue que en España el grado de declive de las zonas URBAN fue un elemento que no pudo tenerse suficientemente en cuenta en la elección de los programas, porque no se contó con un sistema de evaluación común del nivel de degradación de los distintos barrios aspirantes a acceder a URBAN. Como consecuencia, las áreas en las que se actuó no fueron siempre aquellas que más lo necesitaban.

El proceso de selección de los programas se llevó a cabo en base a criterios técnicos, políticos y económicos. Los programas finalmente seleccionados fueron los de Badajoz, Badalona, Barakaldo, Cádiz, Cartagena, Huelva, La Coruña, Langreo, Madrid, Málaga, Sabadell, Salamanca, Sevilla, Toledo, Valencia, Valladolid y Vigo (ver Figura 01).

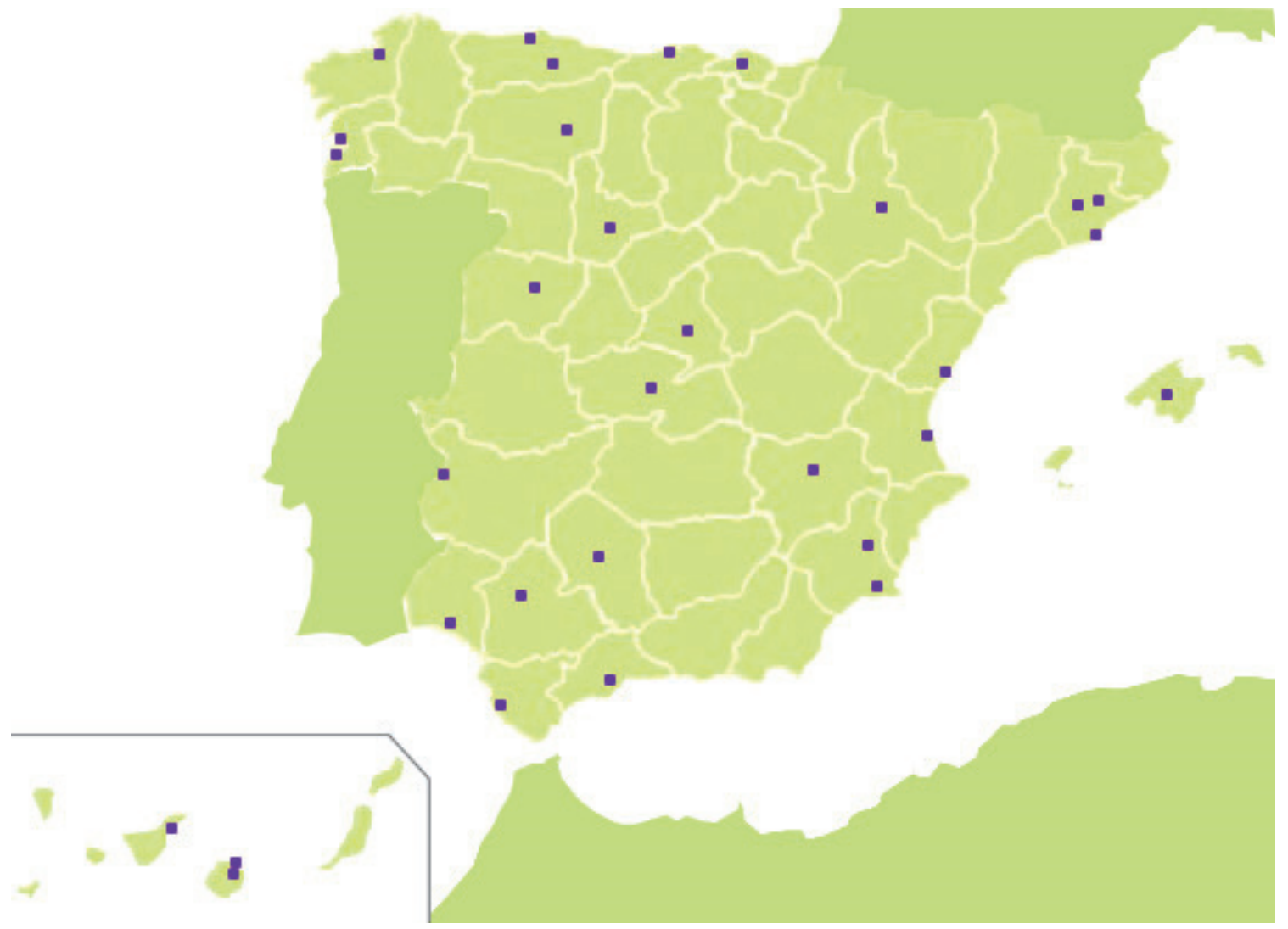

Figura 1. Ubicación de los 29 programas URBAN y los dos programas REGIS desarrollados en España.

Fuente: Elaboración propia

La financiación europea fue de 162.599.000 $€$, de los que 14.663.000 $€$ procedieron del Fondo Social Europeo (FSE) y 144.936.000 $€$ del FEDER (Ministerio de Hacienda, 2003).

En octubre de 1995 la Comisión decidió el reparto de la reserva presupuestaria de las Iniciativas Comunitarias. Esto derivó en una ampliación de la Iniciativa, a través 
de una nueva Comunicación ${ }^{13}$ de julio de 1996. En respuesta a esta el Gobierno español presentó en enero de 1997 una solicitud de ayuda comunitaria al FEDER y FSE para la Iniciativa Comunitaria URBAN 1997-1999, en base a la cual la Comisión aprobó la realización de 12 nuevos proyectos URBAN ${ }^{14}$. Los programas contaron con un presupuesto de 77.331.000 $€$, de los que $67.108000 €$ fueron aportados por el FEDER y $10.222 .000 €$ por el FSE. Las ciudades que accedieron a la Iniciativa en aquel momento fueron: Albacete, Avilés-Corvera, Castellón, Córdoba, León, Murcia, Palma de Mallorca, Pontevedra, Santa Coloma de Gramanet, Santander, Telde y Zaragoza.

El proyecto de Avilés-Corvera tuvo la particularidad de proponer actuar en estas dos ciudades limítrofes. En todos los demás casos el área de actuación de los programas estuvo situada íntegramente dentro del término municipal de las ciudades mencionadas.

Estos 12 programas iniciaron oficialmente su funcionamiento en marzo de 1998, cuando fueron aprobados por la Comisión. Al igual que los programas que habían sido aprobados en 1995 su periodo de vigencia finalizaba el 31 de diciembre de 1999 (plazo máximo para contratar y adquirir los compromisos con cargo al programa URBAN) y tenían un plazo límite de gasto establecido en diciembre de 2001. Como consecuencia contaron con muy poco tiempo para implementarse. Esta circunstancia constituyó una importante limitación que dificultó la consecución de resultados (Ministerio de Hacienda, 2003b).

Finalmente dentro de la Iniciativa Comunitaria REGIS ${ }^{15}$, se desarrollaron dos programas URBAN en las capitales de provincia de las Islas Canarias. Del total de los programas, el $62 \%$ se implementaron en cascos históricos o áreas centrales, mientras que el $38 \%$ se desarrollaron en barrios residenciales de la periferia.

Aunque, como se ha apuntado, la Autoridad de Gestión, que desempeñó la labor de nexo de unión entre Bruselas y el contexto español, fue la Subdirección General de Fondos Comunitarios y Financiación Territorial del Ministerio de Economía y Hacienda, en un primer momento hubo otro organismo implicado en el seguimiento de URBAN: se trató de la Dirección de Actuaciones Concertadas en las Ciudades, que formaba parte desde los primeros años noventa del Ministerio de Obras Públicas, Transporte y Medio Ambiente. La implicación en URBAN de dos entes a nivel nacional respondía a la esencia misma de la Iniciativa: por una parte estaba presente una institución que coordinaba con la UE la llegada y gestión de los fondos procedentes del FEDER y, por otra, una institución que tenía experiencia para implementar URBAN en función de su contenido urbano y de concertación entre distintos niveles de gobierno.

La labor de la Dirección General de Actuaciones Concertadas en las Ciudades fue relevante en el proceso de preparación de las candidaturas y su adecuación al "formato" URBAN, ya que se ocupó de ayudar a las autoridades locales (Ayuntamientos y Comunidades Autónomas) a concebir programas basados en un enfoque integrado. Fueron también sus funciones asesorar a las ciudades durante el proceso de implementación y la asistencia al Comité de Seguimiento (ver más abajo).

\footnotetext{
13 Decisión 96/C/200/04.

14 Decisión C(98) 472 de marzo de 1998.

15 La Iniciativa Comunitaria REGIS tenía por objeto apoyar una mayor integración de las regiones ultraperiféricas en las Iniciativas Comunitarias.
} 
Aún así, hay que señalar que su función en este ámbito fue limitada. Por ejemplo, no pudo ejercer una función "correctora" sobre la metodología presentada por los programas en el ámbito de la participación de la comunidad local y otros aspectos colaborativos. La desaparición en 1996 de la Dirección General de Actuaciones Concertadas en las Ciudades, y su consiguiente salida de la gestión de URBAN cuando la Iniciativa estaba aún arrancando, tuvo consecuencias en el desarrollo de los programas y en los resultados que consiguieron. La gestión de los 17 proyectos que accedieron en 1994 a la Iniciativa corrió predominantemente a cargo de los Ayuntamientos de las ciudades seleccionadas.

En los casos de los programas de Langreo y Valencia la gestión corrió a cargo del Principado de Asturias y la Comunitat Valenciana respectivamente, mientras que en el caso de Madrid la gestión del programa fue compartida entre el Ayuntamiento y la Comunidad Autónoma. En el caso del programa de Barakaldo la gestión corrió a cargo de un ente mixto denominado Bilbao Ría 2000 (que englobaba a las Administraciones Central y Vasca) y del Ayuntamiento. En el caso de los 12 programas que accedieron a la ampliación de la Iniciativa de 1997, la gestión de los proyectos corrió exclusivamente a cargo de los Ayuntamientos. El Reglamento de la CEE ${ }^{16}$ había establecido que para garantizar un buen desarrollo de los programas y evitar desviaciones se formaría un Comité de Seguimiento (CdS) para la Iniciativa Comunitaria URBAN en cada Estado Miembro. El CdS en España tendría que estar formado por los responsables de cada programa URBAN (Ayuntamiento o Comunidad Autónoma correspondiente), las autoridades de la Administración General del Estado (Subdirección General de Fondos Comunitarios y Financiación Territorial y, hasta 1996, la Dirección General de Actuaciones Concertadas en las Ciudades) y representantes de los servicios de la Comisión Europea. El CdS hacía el seguimiento de los programas y gestionaba las modificaciones a los contenidos iniciales.

En relación a la tarea desempeñada por el Comité de Seguimiento, en la Evaluación Intermedia del Programa Operativo 1997-1999 se valoraba particularmente el papel que este foro había jugado como arena de aprendizaje e intercambio de información entre los gestores de los programas (Ministerio de Hacienda, 2003b). Constituyó también el instrumento a través del cual se formaron redes informales de apoyo e intercambio de experiencia entre los técnicos participantes. Cada uno de los programas españoles estuvo basado en una estrategia de regeneración para el área elegible en cuestión, que se desarrollaba en base a medidas incluidas en los siete subprogramas o ejes siguientes:

1. Mejora del medio ambiente.

2. Desarrollo del tejido económico.

3. Dotación de equipamientos sociales y culturales.

4. Dotación de centros de formación.

5. Evaluación y gestión.

6. Programas sociales.

7. Programas de formación profesional.

Cada uno de estos ejes incluía medidas que, a su vez, se desarrollaban en base a las acciones concretas. La inclusión de medidas dentro de todos los ejes perseguía la

\footnotetext{
${ }^{16}$ Reglamento (CEE) no 2082/93, artículo 25, apartado tercero.
} 
plasmación del método integrado en la práctica de los programas, pero las ciudades podían elegir, en función de la estrategia adoptada, los ejes en los que integraban acciones, no teniendo que dar contenido a todos ellos si no lo consideraban oportuno. Así, todos los URBAN lanzados en 1995 incluyeron medidas de mejora física (eje 1). Casi todos introdujeron medidas de desarrollo del tejido económico (eje 2), de dotación de equipamientos sociales y culturales (eje 3), de desarrollo de programas sociales (eje 6) y de puesta en marcha de programas de formación profesional (eje 7). El único subprograma en el que una minoría de ciudades incluyó medidas fue la dotación de centros de formación (eje 4). Todas las ciudades que accedieron a la Iniciativa en 1997 incluyeron medidas de mejora física (eje 1), de evaluación y gestión (eje 5) y de dotación de equipamientos sociales y culturales (eje 3). La mayoría introdujeron medidas en el resto de los subprogramas.

\subsection{El enfoque colaborativo de los programas}

El enfoque colaborativo de los programas URBAN desarrollados en España se ha analizado en base a su capacidad para dar lugar a la transformación de la gobernanza a través de la construcción de capacidad local y de su contribución a la introducción de prácticas capaces de propiciar la evolución de los modelos de gobierno y gestión pública hacia modos de actuación más inclusivos en el sentido apuntado por Healey, observándolos desde su capacidad de dar lugar a redes relacionales y procesos de gestión capaces de transformar las estructuras y prácticas existentes. El análisis de esta dimensión de la Iniciativa se ha estructurado en base a las tres dimensiones de gobernanza: la dimensión multinivel, la dimensión horizontal y la dimensión participativa.

\section{Dimensión multinivel}

El modo en el que se plasmó la dimensión multinivel de la componente colaborativa de URBAN en España quedó determinado por una de las primeras decisiones que se tomó a nivel del Gobierno Central respecto a la Iniciativa: el hecho de no asignar a las Comunidades Autónomas un papel durante el proceso de gestión (lo que sí hicieron otros países con estructuras estatales descentralizadas como Alemania o Bélgica). Esto conllevó que las posibilidades de participación de las CCAA se limitaran a su entrada como entes ejecutores de los programas (lo que sucedió sólo en el caso de los programas de Madrid, Langreo, Valencia y Barakaldo) o a su implicación como un actor más en los programas a través de la firma de convenios con los órganos gestores (por ejemplo en el caso de Cádiz, Valladolid, Avilés-Corvera) en la implementación de actuaciones concretas.

Como consecuencia se redujo de partida el potencial de la dimensión colaborativa multinivel de la Iniciativa, ya que el nivel regional estuvo infra representado, por lo que la relación entre los distintos niveles de gobierno se concentró principalmente entre el Gobierno Central y las ciudades. Esta circunstancia minimizó los resultados intangibles que potencialmente podían haberse alcanzado, sobre todo si se tiene en cuenta el importante papel que las Comunidades Autónomas juegan en el ámbito del urbanismo en España, al contar con competencias compartidas con las ciudades y el necesario acercamiento que en el contexto español tiene que darse entre el Gobierno 
Central y las Comunidades para dar lugar a un marco de referencia en relación a la regeneración urbana y el desarrollo urbano sostenible, tal y como recomienda la Carta de Leipzig (Reunión Informal de Ministros sobre Desarrollo Urbano y Cohesión Territorial, 2007a).

La relación entre distintos niveles de gobierno en el marco de la Iniciativa se materializó principalmente en la que tuvo lugar entre la Autoridad de Gestión y los entes ejecutores de los programas. Dicha relación se fundamentó en que el Ministerio de Hacienda, en base a su papel de Autoridad de Gestión, seguía y coordinaba las acciones que se desarrollaban en el marco de los diferentes programas. Esta relación presentó dos dimensiones de interés para este estudio: i) la relativa al aspecto económico y normativo de la Iniciativa; ii) la relativa al contenido metodológico de acción en el medio urbano degradado, es decir, la plasmación del "método URBAN" en las estrategias de los programas.

La primera dimensión estuvo fuertemente determinada por la normativa de los Fondos Estructurales y de la Iniciativa Comunitaria URBAN y conllevó el cumplimiento de las normas de funcionamiento. Una de las mayores dificultades que afrontaron los entes ejecutores de los programas se situó en este ámbito, debido a la falta de familiaridad con la normativa europea y la complejidad de los procedimientos a seguir en relación a la implementación, seguimiento y control de los programas. También les resultó compleja la gestión económica. La Autoridad de Gestión jugó un papel relevante para intentar facilitar esa labor a los entes ejecutores y para asegurar la consistencia del trabajo del Comité de Seguimiento, en el marco del cual se desarrollaba gran parte del asesoramiento técnico.

La relación entre la Dirección General de Fondos Comunitarios y los entes ejecutores en relación al tema económico y el cumplimiento de la normativa comunitaria, se centró en el intercambio de información y justificaciones, en los pagos y en la prestación de asistencia técnica por parte de la primera. En el caso español, tal y como se desprende del análisis, la relación entre la Autoridad de Gestión y los entes ejecutores en cuanto a los aspectos administrativos y normativos de la Iniciativa fue fluida y supuso un aprendizaje para todos los actores involucrados.

En cuanto al segundo aspecto de la relación entre la Autoridad de Gestión y los entes ejecutores, a ojos de este trabajo interesa entender si la primera ejerció un papel activo para que los entes ejecutores introdujeran o reforzaran el enfoque colaborativo en las estrategias que presentaron, tanto en el documento proyectual como durante el proceso de implementación del programa.Una revisión del contenido inicial de los programas URBAN ${ }^{17}$ pone de relieve que el carácter colaborativo de la Iniciativa no quedó introducido suficientemente en las estrategias de acción definidas. La posible acción del Ministerio para reorientar la acción de los entes ejecutores durante la implementación de los programas con el fin de reforzar la dimensión colaborativa no se dio. Esta circunstancia no se debió a una mala interpretación de

\footnotetext{
17 Los de las ciudades que accedieron a la Iniciativa en 1994 fueron recogidos en el documento del Ministerio de Hacienda: Programación inicial del Programa Operativo de la Iniciativa Comunitaria URBAN 1994-1999 (Ministerio de Hacienda, 1994a). También se describían de manera resumida en el documento Programa Operativo URBAN 1994-1999 (Ministerio de Hacienda, 2003). Los de las ciudades que accedieron a la Iniciativa en 1997 se describían en el documento Programa Operativo URBAN 19971999 (Ministerio de Hacienda, 2003).
} 
las responsabilidades de la Autoridad de Gestión, sino a que en el caso español no se había establecido entre los objetivos explícitos de la Iniciativa la introducción de la dimensión colaborativa (la revisión de la documentación elaborada en el marco del programa por el Ministerio de Hacienda pone de manifiesto que la misma no fue señalada como parte de la metodología y los objetivos a alcanzar).

\section{Dimensión horizontal}

La dimensión horizontal del enfoque colaborativo en URBAN se materializó en las relaciones que en el marco de la gestión e implementación de los programas se establecían entre organismos y entes de la administración, ya fueran directamente las áreas o consejerías de los Ayuntamientos, ya fueran entes que dependieran orgánicamente del Ayuntamiento o la Comunidad Autónoma en cuestión.

La aplicación del enfoque integrado hacía necesario que los programas actuasen en todas las dimensiones de la degradación urbana y esto hacía que, en función de la modalidad organizativa adoptada por los entes ejecutores para gestionar los URBAN, se diese, o no, un aprendizaje por parte de los Ayuntamientos y las Comunidades Autónomas en la implementación del enfoque integrado.

La mayor parte de los Ayuntamientos decidieron que la gestión del programa se hiciera desde sus propias estructuras administrativas y por parte del personal ya presente en las mismas (de los 22 programas con los que se cuenta con información 15 optaron por esta solución ${ }^{18}$ ). En algunos casos las estructuras existentes se reforzaron con la contratación de personal técnico externo, elegido específicamente para proveer perfiles profesionales que no estaban presentes entre el personal municipal. Esta modalidad derivó en una mayor flexibilidad en la coordinación de los trabajos y en que la mejora de la coordinación entre distintas áreas municipales quedara interiorizada en el Ayuntamiento. En todo caso dicha coordinación no fue fácil para los Ayuntamientos. Entre las principales dificultades a vencer estuvo el tener que hacer trabajar bajo la coordinación de un área municipal a otras áreas que en el organigrama del Ayuntamiento estaban en su mismo nivel jerárquico.

Otros entes de ejecución prefirieron establecer una oficina de gestión independiente de la estructura municipal existente, creada ad hoc para tal fin. Para ello contrataron personal externo al Ayuntamiento (de los 22 programas con los que se cuenta con información 7 optaron por esta solución). Esta modalidad de gestión tuvo tres consecuencias principales: en primer lugar la coordinación de las áreas municipales implementadoras de las acciones fue más fácil, pues esta acción venía de un ente "temporal" ligado a la vida del programa, no de otra área municipal que al asumir esta labor perturbase la jerarquía organizativa del Ayuntamiento. En segundo lugar, la externalización de la coordinación hizo que el aprendizaje que llevaron a cabo los técnicos implicados en esa tarea se perdiera una vez que el

\footnotetext{
18 No se cuenta con información sobre siete de los programas lanzados en 1997 (Santander, Castellón de la Plana, Pontevedra, Telde, Zaragoza, Santa Coloma de Gramanet y Palma de Mallorca). Esta circunstancia no se ha considerado un obstáculo que invalide el análisis, ya que esos programas contaron con tan poco tiempo para desarrollarse, que la metodología colaborativa auspiciada por URBAN difícilmente pudo implementarse. Por esta razón es posible afirmar que, adoptaran una u otra de las opciones de gestión detectadas, la experiencia adquirida por los entes ejecutores habría difícilmente logrado producir cambios en la gestión local y la dimensión horizontal de la gobernanza.
} 
programa finalizó. En tercer lugar, en algunos casos la creación de una oficina URBAN hizo que se diera una mayor cercanía entre esta y la población beneficiaria que en los casos en los que la gestión corrió a cargo del Ayuntamiento.

En relación a los programas que se desarrollaron en esta primera fase de URBAN hay que apuntar que, tanto la revisión de sus contenidos, como el seguimiento de la implementación de los mismos a través de la documentación generada en el marco de la Iniciativa, revela el bajo grado de experiencia que las ciudades españolas tenían en ese momento y los problemas que tuvieron que afrontar para desarrollar proyectos de la complejidad administrativa y metodológica que requería URBAN. Como resultado, las estrategias no siempre guardaron coherencia interna y el enfoque integrado fue sustituido por una suma de acciones sectoriales.

Una de las principales dificultades con las que las administraciones locales se encontraron a la hora de aplicar la metodología de URBAN fue la necesidad de establecer una visión de futuro para la zona en cuestión, en base a la cual generar una estrategia unitaria que después se estructurase en los ejes del programa. Las ciudades no pudieron "interiorizar" en el tiempo que se les dio para preparar las propuestas esa forma de abordar la regeneración urbana. Como consecuencia afrontaron el diseño y gestión de los programas asumiendo la estructura pero no el enfoque metodológico. Esta es la causa de que del análisis de los programas que las ciudades presentaron en 1994 y 1997 se trasluzca la falta de sinergias entre distintos ejes o subprogramas, una permanencia de la sectorialidad que venía caracterizando la acción en el medio urbano en España.

\section{Dimensión de participación}

La tercera de las dimensiones en base a las cuales se analiza la transformación de la gobernanza introducida por la Iniciativa URBAN en España en base a su carácter colaborativo consistió en la participación entre los entes ejecutores y la comunidad local, tanto en el proceso de diseño de las estrategias de actuación como en la gestión de las acciones programadas y su seguimiento.

La colaboración entre los entes ejecutores y la comunidad local era recomendada por la Comisión en la Comunicación de lanzamiento de URBAN. La metodología de acción que se proponía había sido resultado de un proceso largo de aprendizaje en el contexto inglés, y llegó a España a través de URBAN en 1994 sin un proceso de aprendizaje previo. La experiencia con la que el país contaba en ese momento en relación a la participación en políticas urbanas era baja. En los procesos de regeneración los ciudadanos y los actores locales (a excepción de los actores económicos en algunos casos) eran tradicionalmente objetos pasivos de las políticas que se ponían en marcha. Tampoco existía una inquietud relevante por parte de la sociedad en relación a los procesos de toma de decisiones de las políticas urbanas.

Las demandas de participación existentes en algunos barrios no eran sintomáticas de una reivindicación generalizada de cambio. Al darse la adaptación de la metodología propuesta por URBAN a la realidad española este aspecto quedó cercenado. Es significativo que en un documento del Ministerio de Hacienda en el que se hacía una primera presentación de la Iniciativa URBAN (titulado Programa Operativo URBAN 1994-1999 (Ministerio de Hacienda, 1994)), no se hacía mención a 
este tema cuando se hablaba de los objetivos o de las actuaciones que tenían que incluirse en los programas. Dentro de la estructura de los programas las medidas relativas a la participación de la comunidad y los actores locales recaían, de existir, en el eje 5 "Gestión, seguimiento, evaluación y asistencia técnica". La revisión efectuada pone en evidencia que la mayor parte de estos no incluyeron acciones de participación de la comunidad dentro de dicho eje, y cuando lo hicieron entendieron que los procesos de participación consistían principalmente en la puesta en marcha de procesos de información (reuniones informativas o difusión) que asignaban a los actores no institucionales una función pasiva.

Del análisis pormenorizado de los procesos de participación desarrollados en el marco de los programas, deriva que de los 23 programas de los que se cuenta con información en relación a este tema, en nueve no se implementaron procesos participativos o de información directa. En 12 se celebraron reuniones que dieron a la ciudadanía y los entes locales la posibilidad de conocer los programas y reaccionar respecto a los mismos (aunque esta última posibilidad siempre fue limitada debido a que la toma de decisiones siempre recayó en el ente gestor). Sólo en un caso, Huelva, se puso en marcha un proceso de participación estructurado y dirigido por expertos (en este también la capacidad de decisión quedó en el Ayuntamiento). En el caso de Telde la incentivación de la participación se incluyó, pero como una medida sectorial dirigida sólo a la ciudadanía y las asociaciones vecinales por lo que, aunque fue una acción potenciadora de la capacidad local, no respondía plenamente a los objetivos que establecía la Iniciativa.

La falta de un planteamiento común a todos los programas y la heterogeneidad de las estrategias de participación adoptadas apuntan a que en la mayor parte de los casos estas últimas fueron entendidas como una obligación formal, que se abordó desde posicionamientos que no desplegaron los mecanismos necesarios para desarrollar procesos de participación real. La implicación de la comunidad local en el proceso de diseño de la iniciativa fue insuficiente o inexistente en la mayor parte de los programas y sólo se pudo dar de manera real cuando ésta estaba ya organizada previamente, es decir había adquirido aprendizaje (construcción de la capacidad local) a través de procesos anteriores a URBAN (en el caso de Huelva), que la habían llevado a formar asociaciones $u$ otros entes de servicio social.

En algunos casos en la documentación revisada se hace mención al enriquecimiento del tejido asociativo a través de una dinamización de la comunidad local derivada de la implementación de los programas. Los procesos de participación puestos en marcha, aunque insuficientes y limitados en el tiempo, acercaron a las comunidades y los actores locales a las administraciones, enseñándoles que era posible interactuar con estas, e iniciándoles en un camino de colaboración que hasta entonces les era desconocido. Los entes que colaboraron con los Ayuntamientos o las CCAA en la implementación de actuaciones fueron en todos los casos organizaciones sociales o económicas ya existentes, que contaban con experiencia previa en la prestación de servicios en el área de actuación. En este sentido es interesante señalar que, tanto los programas que incluyeron la participación de la ciudadanía y los entes locales, como aquellos que no lo hicieron, desarrollaron acuerdos de colaboración con las organizaciones sociales activas en la zona para el desarrollo de las medidas de carácter social o de formación. 
Como se ha apuntado, hay que destacar que a pesar del bajo nivel participativo de los programas, estos contaron con la colaboración de actores institucionales, sociales y económicos para implementar algunas de las medidas incluidas en los mismos. Este fue uno de los ámbitos en los que el enfoque colaborativo presentó mejores resultados en el caso español.

\section{LA INICIATIVA COMUNITARIA URBAN II EN ESPAÑA}

El lanzamiento de la Iniciativa Comunitaria URBAN II tuvo lugar el 19 de mayo del año 2000 a través de la Comunicación de la Comisión a los Estados miembros por la que se fijan las orientaciones de una Iniciativa comunitaria relativa a la regeneración económica y social de las ciudades y de los barrios en crisis con el fin de fomentar un desarrollo urbano sostenible - URBAN II (Comisión Europea, 2000). Los objetivos fijados para URBAN II seguían las líneas generales que su predecesora, URBAN, había establecido seis años antes aunque, en esta nueva convocatoria se ponía el acento en la innovación a favor de la regeneración económica y social sostenible y en la difusión e intercambio de buenas prácticas de desarrollo urbano sostenible en la Unión Europea.

En España, al igual que durante el desarrollo de los proyectos URBAN entre 1994 y 1999, se designó como Autoridad de Gestión del Programa de Iniciativa Comunitaria URBAN II a la Dirección General de Fondos Comunitarios y Financiación Territorial de la Secretaría de Estado de Presupuestos y Gastos del Ministerio de Hacienda. Esta podía ejercer sus funciones directamente o a través de la Subdirección General de Administración del FEDER. En este periodo, al contrario que en la convocatoria precedente, no hubo participación de otro ente a nivel nacional en algún momento del desarrollo de la Iniciativa.

En el caso español no se llevó a cabo una reflexión sobre los programas URBAN que se habían desarrollado durante el periodo 1994-1999, con el fin de reorientar o introducir cambios en la metodología aplicada en esa primera fase que contribuyeran a alcanzar los en mayor medida los objetivos de la Iniciativa.

Para dar a conocer la nueva convocatoria de URBAN, la Dirección General de Fondos Comunitarios y Financiación Territorial del Ministerio de Economía y Hacienda, a través de sus servicios técnicos, elaboró un folleto informativo. Este fue remitido a todos los Ayuntamientos de las capitales de provincia y ciudades españolas que cumplieran la condición de contar al menos con 20.000 habitantes. Además de servir de instrumento de difusión, el folleto preparado por la Dirección General de Fondos Comunitarios tenía el objetivo de facilitar a los Ayuntamientos la preparación de las solicitudes de acuerdo a los requisitos establecidos por la Comisión Europea en la Comunicación a los Estados miembros. En él se fijaba el plazo para la presentación de solicitudes al Ministerio (que se extendió hasta el 15 de septiembre de 2000), por lo que las ciudades tuvieron unos tres meses para preparar las propuestas.

Al contrario que en el periodo presupuestario anterior, no tuvieron prioridad las ciudades situadas en zonas Objetivo 1 y 2 de los Fondos Estructurales, pudiendo todas las ciudades de la UE acceder a la Iniciativa. Esto constituyó un cambio importante en el modo de entender URBAN: si en la primera fase la Iniciativa había estado dirigida especialmente a los barrios en declive de las zonas menos prósperas de la UE, en esta 
segunda fase se abría a los barrios en crisis de todas las ciudades, independientemente de su economía, desde el entendimiento de que incluso las ciudades más prósperas afrontan problemas severos de degradación urbana en algunos de sus barrios. Se estableció, sin embargo, como condición para que las ciudades pudieran acceder a URBAN II que las áreas de actuación presentasen al menos tres de las siguientes realidades:

- Alto índice de desempleo de larga duración

- Débil tasa de actividad económica

- Alto nivel de pobreza y exclusión

- Necesidad de reconversión resultante de dificultades económicas y sociales

- Elevado número de inmigrantes, minorías étnicas o refugiados

- Bajo nivel educativo, importante déficit de formación y elevado índice de abandono escolar

- Nivel elevado de criminalidad y delincuencia

- Tendencias demográficas precarias

- Degradación ambiental

De esta manera se fijaban los criterios de acceso a la Iniciativa en base a los aspectos de degradación social, económica y física de los barrios. Cada ciudad pudo elegir los indicadores que consideró más representativos para justificar el grado de vulnerabilidad del área a regenerar. Esta manera de valorar el grado de declive de los barrios volvió a producir una falta de homogeneidad en los indicadores elegidos por los programas españoles, ya que cada uno incluyó los que consideró más relevantes para justificar la elección de su área de actuación.

En todo caso la heterogeneidad entre los indicadores utilizados fue menor que la que había existido en la primera fase de la Iniciativa. En efecto, aunque las ciudades justificaron y evaluaron la realidad de los barrios de manera distinta, la uniformidad del formato de propuesta, organizado según una estructura común para todas las ciudades europeas que se presentaban a la Iniciativa, la obligatoriedad de incluir una evaluación ex ante (basada en un conjunto de indicadores que justificase consistentemente la elección del área en cuestión) y un estudio DAFO (debilidades, amenazas, fortalezas y oportunidades), facilitó la comparación entre los proyectos durante la fase de selección.

En España como respuesta a la convocatoria difundida por el Ministerio de Economía y Hacienda un total de 86 Ayuntamientos presentaron una propuesta de acceso a la Iniciativa.

En el caso español se estableció que 10 ciudades accederían a URBAN II. Una vez seleccionadas los 10 proyectos candidatos, los representantes del Ministerio de Economía y Hacienda mantuvieron una reunión con los representantes de cada programa durante los meses de octubre y noviembre del año 2000, con el fin de adecuar mejor las propuestas a los requisitos de la Comisión (Ministerio de Hacienda. 2005j). Las ciudades elegidas finalmente para formar parte de la Iniciativa 
Comunitaria URBAN II en España fueron: Cáceres, Gijón, Granada, Jaén, Orense, Pamplona, San Adriá de Besós, San Sebastián-Pasaia, San Cristóbal de la Laguna y Teruel (ver Figura 2). Como consecuencia de esa selección, ninguna de las ciudades españolas que anteriormente habían participado en la Iniciativa consiguió volver a entrar en ella. Esto sí sucedió en otros Estados miembros.

En el caso del programa de San Sebastián-Pasaia el área de actuación comprendía varios términos municipales: San Sebastián (barrios del Este), Pasaia, Errentería, Lezo y Oiartzun. En todos los demás casos el área de actuación estuvo situada íntegramente dentro del término municipal las ciudades enumeradas.

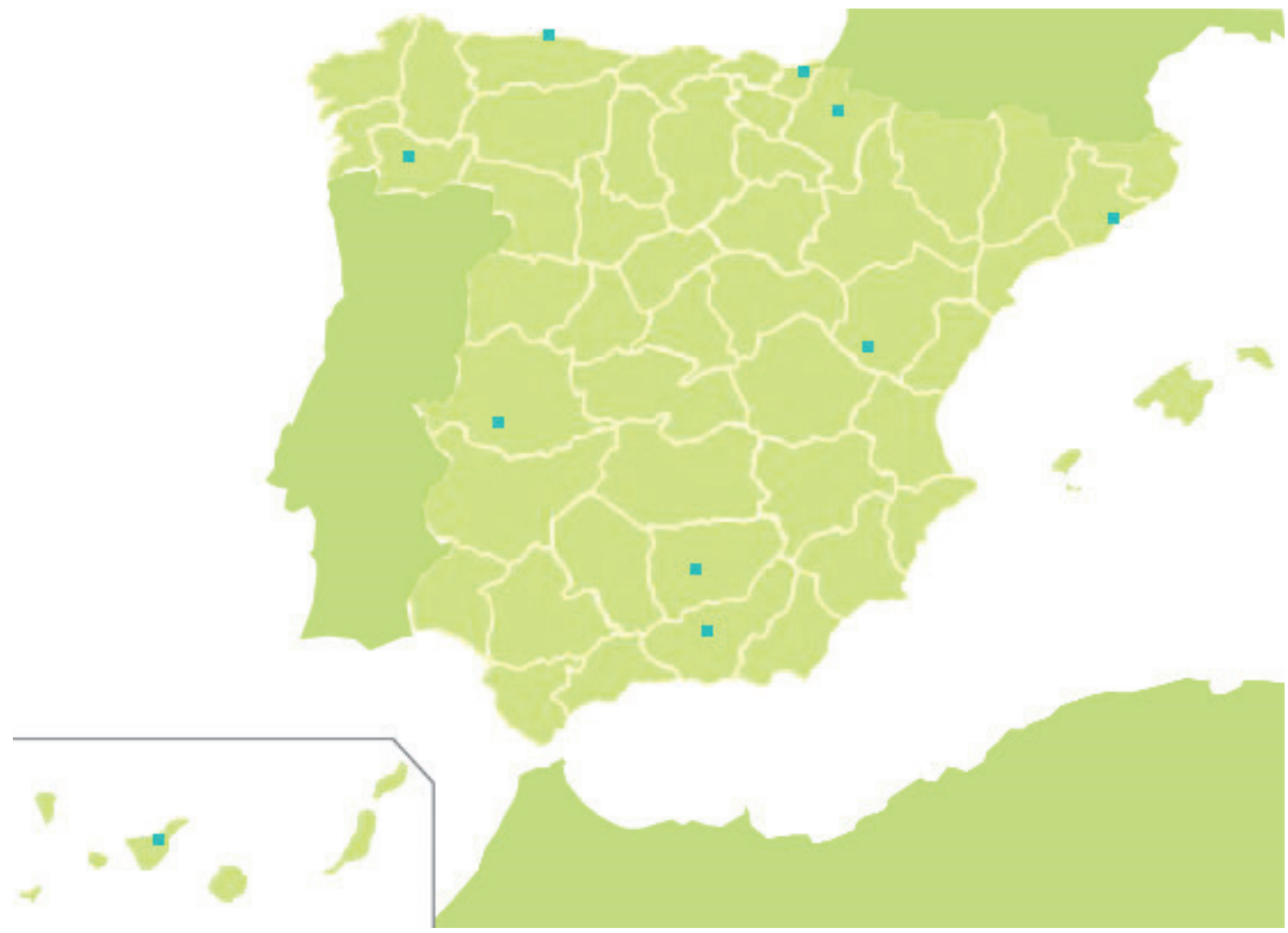

Figura 2. Ubicación de las ciudades que accedieron a la Iniciativa Comunitaria URBAN II (2000-2006).

Fuente: Elaboración propia.

La cofinanciación prevista por la Iniciativa Comunitaria a través del FEDER para el Estado español fue de 112,6 millones de euros. Como consecuencia de las modificaciones que la Comisión Europea llevó a cabo con el fin de simplificar la aplicación de los requerimientos administrativos en la segunda fase de la Iniciativa no se contó con financiación procedente del FSE.

En los programas URBAN II no se dio cofinanciación de las actuaciones contenidas en los programas por parte de las Comunidades Autónomas. En cuanto a la financiación estatal, esta se concentró dentro del eje 7 (medias 7.4 y 7.5, ver más abajo). Las cantidades aportadas fueron aproximadamente del mismo orden para 
todos los programas, variando entre los $6.255 €$ de Granada y Jaén y los $15.500 €$ de Pamplona y Sant Adrià de Besòs.

En el caso español la mayor parte de los programas no contaron con cofinanciación directa procedente del sector privado. Tan sólo el proyecto de Orense recibió financiación privada en medidas de los ejes 1 y 3. Como consecuencia, se puede afirmar que los programas no consiguieron integrar recursos económicos procedentes del sector privado tampoco en esta fase de la Iniciativa.

Durante el año 2004 la Comisión Europea informó sobre la indexación de precios de la Iniciativa Comunitaria URBAN al Estado Español para el periodo de programación de las anualidades 2004-2006. En base a esto al Estado Español le correspondieron 1.702.072 $€$ que el Ministerio de Economía y Hacienda distribuyó entre los 10 proyectos URBAN con el mismo criterio que había seguido la Comisión Europea anteriormente.

La distribución de los programas según zona de intervención fue la siguiente: el $60 \%$ se implementó en cascos históricos o áreas centrales, mientras que el $30 \%$ lo hizo en barrios residenciales de la periferia y sólo el $10 \%$ en un área prevalentemente industrial. En base a esto primaron, al igual que durante la primera fase, los proyectos de mejora de los cascos históricos, lo que sugiere que en el país seguía identificándose la regeneración urbana con acción en las áreas centrales de la ciudad, dando menor peso a la intervención en áreas periféricas o industriales. Las áreas de actuación de los programas de Cáceres, Granada, Jaén, Orense, Pamplona y Teruel integraron los cascos urbanos, focalizando sus actuaciones en redinamizar las áreas más antiguas. En ninguna de ellas se actuó sobre ensanches de los siglos XIX o XX. En el caso de Pamplona se actuó también en un barrio de antigua industrialización que estaba en el camino de consolidar su reconversión a área predominantemente residencial.

Durante esta segunda fase el ente ejecutor de los programas fue en casi todos los casos el Ayuntamiento de la ciudad en cuestión, asumiendo la gestión de manera directa (a través de la integración de la misma dentro de la estructura de la administración municipal) o creando un ente ad hoc. Se dieron dos casos en los que los entes ejecutores de los programas no fueron los Ayuntamientos de las ciudades implicadas, sino entes creados con anterioridad a URBAN II, que venían trabajando por la regeneración del área respectiva desde hacía tiempo. Esto sucedió en los URBAN de San Sebastián-Pasaia y San Adrià de Besòs, en los que los entes ejecutores fueron la Agencia para la Renovación Urbana de la Bahía de Pasaia BadiaBerri, S. A. y el Consorcio del Barrio de La Mina. A diferencia de la primera fase, durante la segunda fase de la Iniciativa ninguna Comunidad Autónoma estuvo involucrada como órgano de gestión de los proyectos. En los casos de San Sebastián-Pasaia y San Adriá de Besòs el Gobierno Vasco y la Generalitat de Cataluña participaron en los programas porque estaban presentes en los órganos mixtos que gestionaron los programas URBAN II de esas ciudades.

Se dieron cuatro modalidades generales de gestión de los programas: la integración total de las tareas de coordinación en la administración municipal (Pamplona), la coordinación del programa por parte de un ente supramunicipal (San Sebastián-Pasaia y San Adrià de Besòs), la creación de un departamento u oficina técnica de gestión integrados en el Ayuntamiento (Cáceres, Gijón, Jaén, San Cristóbal de la Laguna) y la coordinación del programa por parte de un ente externo a la 
administración municipal (Oficina URBAN, Sociedad Anónima, etc., puestas en marcha en el resto de los casos).

De la revisión de la documentación producida en el marco de los programas y los cuestionarios (ver Anexo) se trasluce que el Comité de Seguimiento funcionó de manera parecida a la de la primera fase de la Iniciativa. Se estableció que todos los Comités de Seguimiento de los proyectos URBAN II que estaban desarrollándose en España tenían que reunirse en Comités de Seguimiento conjuntos en alguna de las áreas urbanas donde se estaban desarrollando los proyectos al menos dos veces al año. La intención de estas reuniones era dar continuidad al foro de intercambio de experiencia que durante la primera fase había dado buenos resultados, al haber funcionado como una verdadera red de transmisión de conocimiento y difusión de prácticas durante el periodo 1994-1999. Este foro fue muy bien valorado por parte de los entes gestores de los programas.

Durante esta segunda fase, en cumplimiento del Reglamento del Consejo sobre los Fondos Estructurales y de las disposiciones de aplicación de los Programas de la Iniciativa Comunitaria URBAN II, se estableció que en el CdS pudieran participar además de los miembros permanentes, representantes de los interlocutores económicos y sociales y organizaciones no gubernamentales, y representantes del sector medioambiental. De esta manera todos estos actores quedarían asociados al seguimiento del programa. El ente ejecutor tenía que convocar una reunión informativa con los interlocutores antes mencionados después de cada reunión del Comité de Seguimiento, en las que debían proveer información sobre los temas tratados. Al mismo tiempo el ente de ejecución tenía que informar al Comité de los resultados de las reuniones mantenidas con los interlocutores sociales y económicos, para que este tuviera en cuenta sus propuestas y demandas en la implementación sucesiva del proyecto.

La necesidad de potenciar en mayor medida la implicación de los actores locales durante el desarrollo de la nueva fase de la Iniciativa constituyó una novedad relevante desde el interés de este trabajo. La presencia de los mencionados actores en el CdS y su vinculación al programa permitía aumentar el carácter participado de este foro y potenciar la creación de redes locales, al tiempo que se mejoraba la transparencia y la rendición de cuentas.

Como se desprende de la información relativa a los contenidos tratados en las reuniones, el Comité de Seguimiento siguió centrándose en seguir la ejecución de los programas, los cambios que se introducían, y la financiación. No llevó a cabo una tarea relevante en velar por el cumplimiento metodológico de los programas y en particular por su aspecto colaborativo. En todo caso, el Comité de Seguimiento jugó un papel clave en el desarrollo de la participación colaborativa de la Iniciativa URBAN II como foro de encuentro y diálogo entre los actores institucionales implicados.

La Iniciativa estableció que las propuestas de regeneración de las áreas URBAN II tenían que estructurarse según 7 ejes que, a su vez, contenían un conjunto de medidas, dentro de las cuales se ubicaban las acciones concretas que daban forma a la estrategia del proyecto. Los ejes y medidas establecidos eran los que aparecen en la tabla siguiente: 


\begin{tabular}{|c|c|}
\hline EJE 1 & $\begin{array}{l}\text { Utilización mixta y reurbanización de terrenos abandonados de modo compatible con el } \\
\text { medio ambiente }\end{array}$ \\
\hline Medida 1.1 & $\begin{array}{l}\text { Recuperación de solares abandonados y terrenos contaminados. Rehabilitación de espacios públicos, incluidas } \\
\text { zonas verdes }\end{array}$ \\
\hline Medida 1.2 & $\begin{array}{l}\text { Construcción, renovación y dotación de edificios para acoger actividades sociales, cuilturales, de ocio y } \\
\text { deportivas }\end{array}$ \\
\hline Medida 1.3 & Conservación y valoración del patrimonio histórico y cultural \\
\hline Medida 1.4 & $\begin{array}{l}\text { Aumento de la seguridad y la prevención de la criminalidad incluyendo la participación de los vecinos en el } \\
\text { diseño de la vigilancia urbana, mejora del alumbrado público, vigilancia mediante circuito cerrado de televisión. } \\
\text { Asesoramiento sobre seguridad y prevención }\end{array}$ \\
\hline Medida 1.5 & Eliminación de barreras arquitectónicas para facilitar el acceso a personas discapacitadas \\
\hline EJE 2 & Empresariado y pactos a favor del empleo \\
\hline Medida 2.1 & $\begin{array}{l}\text { Apoyo a la actividad empresarial, comercial, artesanal, economía social, a las cooperativas, mutuas y servicios } \\
\text { para pequeñas y medianas empresas }\end{array}$ \\
\hline Medida 2.2 & $\begin{array}{l}\text { Mejora de la competitividad del tejido empresarial existente, creación de centros de servicios, fomento de } \\
\text { sistemas para transferencias de tecnologia, potenciación del asociacionismo, etc. }\end{array}$ \\
\hline Medida 2.3 & $\begin{array}{l}\text { Apoyo a nuevos emprendedores, creación de incubadoras y centros de desarrolio y capacitación, instrumentos } \\
\text { de financiación para nuevos emprendedores }\end{array}$ \\
\hline Medida 2.4 & Ayudas al empleo y autoempleo \\
\hline lodi & $\begin{array}{l}\text { Creación y mejora de servicios de asistencia sanitaria y otros servicios sociales, en particular ancianos y niños } \\
\text { (guarderias) y otros colectivos desfavorecidos }\end{array}$ \\
\hline Medic & $\begin{array}{l}\text { Dotación de equipamientos de apoyo que contribuyan al desarroilo de actividades empresariales y a la } \\
\text { consolidación de las existentes }\end{array}$ \\
\hline Medida 2.7 & $\begin{array}{l}\text { Acciones de formación a colectivos desempleados y trabajadores en activo para actualización de su } \\
\text { capacitación y su adaptación a nueva organización del trabajo y técnicas de información y comunicación, dando } \\
\text { prioridad a itinerarios integrados de inserción profesional y al desarrollo de nuevas fuentes de empleo }\end{array}$ \\
\hline EJE 3 & Integración de marginados y acceso a servicios básicos \\
\hline Medida 3.1 & $\begin{array}{l}\text { Planes de educación y formación integrada y personalizada para la reinserción de colectivos desfavorecidos y } \\
\text { marginados, formación lingüistica personalizada, orientados particularmente a las necesidades específicas de } \\
\text { las minorias }\end{array}$ \\
\hline Medida 3.2 & Planes de experiencia laboral sobre proyectos locales de rehabilitación \\
\hline Medida 3.3 & $\begin{array}{l}\text { Inversiones en servicios educativos y sanitarios (incluidos centros de rehabilitación para drogadictos) a una } \\
\text { escala adecuada para el desarrollo y el empleo locales }\end{array}$ \\
\hline Medida 3.4 & $\begin{array}{l}\text { Creación y mantenimiento de estructuras de apoyo, información, sensibilización y orientación, que resulten } \\
\text { necesarias para garantizar la efectividad de las actuaciones que se ponen en marcha }\end{array}$ \\
\hline Medida 3.5 & Creación de escuelas taller y centros de formación. Acondicionamiento y mejora de los existentes \\
\hline EJE 4 & Integración de transporte público y comunicaciones \\
\hline Medida 4.1 & $\begin{array}{l}\text { Mejora y reordenación de los sistemas de transporte, incluyendo la integración de la red de transportes, } \\
\text { introducción del cobro por uso de las vias urbanas, creación de zonas sin tráfico rodado, sistemas de control } \\
\text { del tráfico inteligente y aparcamientos disuasorios }\end{array}$ \\
\hline Medida 4.2 & $\begin{array}{l}\text { Mejora del transporte público, de su seguridad, de los servicios de información, reservas y pagos por ordenador } \\
\text { para viajeros. Adquisición o modificación de vehículos de bajo consumo energético }\end{array}$ \\
\hline Medida 4.3 & y paseos en zonas verdes seguros y atractivos para peatones y ciclistas \\
\hline
\end{tabular}




\begin{tabular}{|c|c|}
\hline EJE 5 & $\begin{array}{l}\text { Reducción y tratamiento de residuos; gestión eficiente del agua y reducción del ruido; } \\
\text { reducción del consumo de energías a base de hidrocarburos }\end{array}$ \\
\hline Medida 5.1 & Fomento de la reducción de residuos, reciclado total, recogida y tratamiento selectivo \\
\hline Medida 5.2 & Control de la calidad del aire y reducción de la contaminación acústica (planes de acción local) \\
\hline Medida 5.3 & $\begin{array}{l}\text { Acciones para reducir el consumo de agua y fomentar el aprovectamiento de agua de iluvia y una gestión } \\
\text { eficaz de los residuos hidricos }\end{array}$ \\
\hline Medida 5.4 & Fomento de la eficiencia energética y de la reducción del consumo y de las fuentes de energías renovables \\
\hline EJE 6 & Desarrollo del potencial de las tecnologías de la sociedad de la información \\
\hline Medida 6.1 & $\begin{array}{l}\text { Fomentar el uso y acceso de las tecnologías de la información y comunicación entre los ciudadanos, } \\
\text { preferentemente con fines de formación, empleabilidad, educación y cultura }\end{array}$ \\
\hline Medida 6.2 & $\begin{array}{l}\text { Desarrolio de servicios de interés público, sobre todo en los ámbitos de educación y formación, asistencia } \\
\text { sanitaria, información sobre medio ambiente y apoyo a las PYMEs, en particular para el comercio electrónico y } \\
\text { los servicios de proximidad }\end{array}$ \\
\hline Medida 6.3 & $\begin{array}{l}\text { Apoyo a las autoridades locales para la transferencia de conocimientos especificos y tecnológicos adquiridos } \\
\text { con las experiencias realizadas en las ciudades de la Comunidad Europea }\end{array}$ \\
\hline EJE 7 & Evaluación, gestión y seguimiento. Mejoras en el gobierno urbano \\
\hline Medida 7.1 & $\begin{array}{l}\text { Fomento de las estructuras de gestión urbana nuevas y modernas, formación de personal. Estudios y peritajes } \\
\text { sobre la reorganización y mejora de los servicios públicos }\end{array}$ \\
\hline Medida 7.2 & $\begin{array}{l}\text { Campañas de información y publicidad, medidas para mejorar el acceso a la información, principalmente en } \\
\text { materia de medio ambiente y participación de los ciudadanos en los procesos de decisión }\end{array}$ \\
\hline Medida 7.3 & Desarrollo de actuaciones de difusión del programa y de intercambio de los conocimientos adquiridos \\
\hline Medida 7.4 & $\begin{array}{l}\text { Realización de evaluaciones de programa, tanto ex ante como ongoing que permitan contar con el máximo de } \\
\text { elementos de información a la hora de realizar la evaluación ex post }\end{array}$ \\
\hline Medida 7.5 & Gastos derivados de las tareas de gestión, seguimiento y control del programa \\
\hline
\end{tabular}

Figura 3. Ejes prioritarios de la Iniciativa Comunitaria URBAN II y medidas contenidas en ellos.

Fuente: Elaboración propia a partir de diferentes documentos de la Unión Europea

Los entes ejecutores tenían que organizar sus programas en función de esos ejes y medidas. Para ello podían incluir acciones en todos ellos o sólo en los que consideraban necesarios para desarrollar su estrategia de regeneración urbana. Además de desarrollar acciones según los ejes prioritarios y las medidas mencionados, al ser actuaciones cofinanciadas por el FEDER los proyectos tuvieron que atenerse al Reglamento (CE) 1685/200019 para que los gastos que comportaban pudiesen ser elegibles. Como consecuencia tuvieron que considerar los siguientes aspectos:

- La actuación en el ámbito de vivienda (construcción o rehabilitación) estaba excluida.

- Los trabajos relacionados con la construcción o rehabilitación de un edificio para albergar un equipamiento sólo eran elegibles si iban ligados a una estrategia de desarrollo de actividades económicas y/o de formación profesional.

- La cofinanciación de los servicios públicos ya existentes no era elegible.

19 DOCE I193 del 29 de julio de 2000 
- Las actividades de mantenimiento y limpieza de espacios públicos y privados no eran elegibles.

- Los gastos corrientes de funcionamiento de infraestructuras y espacios públicos no eran elegibles.

Como consecuencia las estrategias implementadas en los programas URBAN II fomentaron en mayor medida que en la primera fase la adicionalidad y el carácter innovador de los programas, observándose que las actuaciones introducidas se alejaron de las acciones sin valor añadido que los Ayuntamientos llevaban a cabo en su práctica habitual.

En general, los programas alcanzaron los objetivos tangibles establecidos. En esto tuvo mucho que ver la tarea de control y soporte técnico llevada a cabo por el Ministerio de Hacienda como Autoridad de Gestión y el compromiso de los entes ejecutores. La implementación de los programas supuso mejorar el medio físico y la cohesión económica y social de las áreas de actuación y de las ciudades donde se implementaron, ya que en general se cumplieron los objetivos tangibles previstos en 2001. A continuación se valora el cumplimiento de los objetivos intangibles.

\subsection{El enfoque colaborativo de los programas}

El acercamiento a esta dimensión de los programas URBAN II se ha llevado a cabo a través de diez estudios de caso (ver Metodología). Estos se han desarrollado en base a una ficha o protocolo basado en categorías analíticas que han permitido obtener resultados en función de las tres dimensiones de la gobernanza.

\section{Dimensión multinivel}

En relación a la gobernanza multinivel la segunda fase de la Iniciativa tampoco implicó a las Comunidades Autónomas en la gestión de la misma. Sólo dos de ellas estuvieron presentes en el proceso, gracias a que formaron parte de los entes mixtos que ejercieron como entes de ejecución de los programas de Sant Adrià de Besòs y San Sebastián-Pasaia ${ }^{20}$. La no implicación de las Comunidades Autónomas en la gestión de la Iniciativa en algún grado, denota que no se llevó a cabo en el marco español una reflexión en este sentido respecto al periodo anterior.

A ojos de esta investigación, la no implicación de las Comunidades Autónomas en el proceso de gestión de la Iniciativa fue una de las principales carencias que presentó el desarrollo de la misma en España, ya que imposibilitó que el nivel de gobierno regional llevara a cabo un aprendizaje en relación a la regeneración urbana que le permitiera abordar esta competencia en su territorio.

La no presencia de las Autonomías en los Comités de Seguimiento de URBAN II, derivó en que la colaboración multinivel no pudiera desarrollarse plenamente al faltar

\footnotetext{
20 Las Comunidades Autónomas de Cataluña y el País Vasco participaron en los programas al estar integradas en los entes mixtos que ejecutaron los programas URBAN II de Sant Adrià de Besòs y San Sebastián-Pasaia.
} 
uno de los niveles institucionales básicos del escenario español en el ámbito del urbanismo.

Siguiendo con la dimensión de la gobernanza multinivel, en cuanto a la relación entre la Comisión Europea, el Gobierno Central (a través del Ministerio de Hacienda) y los entes ejecutores, la información derivada de la revisión de la documentación institucional, las evaluaciones intermedias y las respuestas de los técnicos de las Oficinas URBAN ponen de relieve que esta fue fructífera y fluida. Tanto la Comisión como el Ministerio cumplieron con su papel de apoyo y asesoramiento técnico de manera eficaz a juzgar por dichas respuestas. Dicha revisión también pone en evidencia que la relación con la Comisión fue cultivada principalmente por la Autoridad de Gestión. La relación de los representantes de la Comisión con los representantes de los programas se circunscribió principalmente a encuentros en el marco del Comité de Seguimiento.

\section{Dimensión horizontal}

La dimensión horizontal de la gobernanza siguió dando frutos en la línea que había sido señalada por la Autoridad de Gestión respecto a la primera fase de la Iniciativa. Salvo en los casos de Sant Adrià de Besós y San Sebastián-Pasaia, los programas fueron gestionados por entes ejecutores que coordinaban la acción de las áreas municipales que implementaban las acciones de su competencia.

Esta circunstancia puso a dichas áreas a trabajar juntas, asumiendo una metodología de actuación que superaba la sectorialidad con la que habían venido operando sobre la realidad urbana hasta ese momento. Esto potenció el enfoque integrado de los programas. En efecto este hecho y otros factores mencionados (que incidieron en la mejora de las estrategias de actuación), derivaron en que los diferentes programas consiguieran poner en marcha estrategias que perfeccionaron la aplicación del enfoque integrado respecto a la primera fase de la Iniciativa.

El análisis de los programas pone de manifiesto que el modo en el que el enfoque integradoque se puso en práctica en las distintas ciudades revela modos de hacer todavía relacionados con la inercia de la práctica habitual. Esta circunstancia se detecta en las respuestas a los cuestionarios de algunos de los técnicos que estuvieron implicados en los programas (ver Anexo). También se pone de relieve en la fuerte dotación económica que en casi todos los casos se dedicó al eje 1 de mejora física (una media del $55,42 \%$ del gasto elegible recayó en este eje) y en la descripción de los procesos de regeneración que habían sido puestos en marcha por los Ayuntamientos hasta el año 2000 (Ministerio de Hacienda, 2001j).

En algunos casos las estrategias desarrolladas por los programas se diseñaron sumando a las actuaciones físicas (que los Ayuntamientos o entes gestores ya tenían en su agenda y en ocasiones previstas por sus Planes Generales de Ordenación Urbana) actuaciones en el ámbito social y económico. En todo caso, se detecta que 
el enfoque integrado estuvo más presente en los programas españoles de la Iniciativa URBAN II que en su antecesora. Dos de las razones en la base de esta evolución son:

i) el diálogo que había tenido lugar en el momento de plantear la estrategia de actuación entre los entes ejecutores y la comunidad local en aplicación de la normativa comunitaria

ii) la mayor calidad de las propuestas, debida a los requerimientos introducidos por la normativa comunitaria para los Fondos Estructurales en este periodo presupuestario. También fue un factor el conocimiento de la metodología que había introducido la fase anterior de la Iniciativa en el marco nacional.

En relación con lo anterior, el hecho de que todos los programas priorizaran el gasto en el eje 1 físico tiene su primera explicación en la concepción más extendida de la regeneración urbana en el país, que tiende a identificar la acción en un área a redinamizar con la mejora física.

Es destacable el hecho de que todos los programas menos dos pusieran en el segundo nivel de dotación económica el eje de redinamización económica (eje 2), que en casi todos esos casos se sitúa muy por delante del eje de actuación en el ámbito social (eje 3). También es de interés observar el bajo porcentaje de financiación que los programas dedicaron en general a los ejes 4, 5 y 6 , orientados la mejora de la movilidad; a la introducción de energías renovables, la gestión del agua, la gestión del ruido y los residuos; y a la introducción de las tecnologías de la información (ver figura 4).

Desde el punto de vista de la integración de las medidas en función de la modalidad de gestión adoptada, no se ha detectado la existencia de diferencias relevantes. Aunque a lo largo del desarrollo de todos los programas se dieron problemáticas que derivaron en modificaciones, estas no afectaron de manera significativa a la estrategia inicial y a la implementación de las actuaciones. En todos los casos se salvaron los problemas que fueron surgiendo y los programas llegaron a acabarse en líneas generales siguiendo las estrategias que habían establecido. En este sentido cabe señalar que hubo programas que presentaron una estrategia basada en un conjunto de actuaciones que se mantuvo casi inalterado durante su desarrollo (San Sebastián-Pasaia, Gijón, Jaén), mientras que en otros casos se dio un grado relevante de anulación de actuaciones previstas y de introducción de nuevas actuaciones (Ourense y Granada). El resto de los programas presentaron un nivel de corrección de la estrategia original medio (ver figura 5).

En base a lo anterior, se pone de manifiesto que existió una correspondencia entre los programas que presentaron un mayor carácter colaborativo y un grado bajo o medio-bajo de corrección de la estrategia original (en el caso de Pamplona y Gijón, e incluso de Jaén). Esto sugiere que la contribución que el proceso colaborativo hace al perfeccionamiento del diagnóstico y de la estrategia de actuación, al integrar en los programas la visión de todos los actores relevantes, da lugar a estrategias más consistentes. 


\begin{tabular}{|c|c|c|}
\hline PAMPLONA & OURENSE & TERUEL \\
\hline - Eje 1: $62,65 \%$ & - Eje 1: $60,54 \%$ & - $\quad$ Eje $1: 41,43 \%$ \\
\hline - Eje $2: 17,86 \%$ & - $\quad$ Eje $2: 22,96 \%$ & - $\quad$ Eje 2: $5,47 \%$ \\
\hline - $\quad$ Eje $3: 3,31 \%$ & - $\quad$ Eje $3: 5,27 \%$ & - $\quad$ Eje 3: $5,93 \%$ \\
\hline - $\quad$ Eje $4: 2,33 \%$ & - $\quad$ Eje 4: -- & - $\quad$ Eje $4: 37,07 \%$ \\
\hline - $\quad$ Eje $5: 2,22 \%$ & - $\quad$ Eje $5: 1,91 \%$ & - $\quad$ Eje $5: 2,61 \%$ \\
\hline - Eje 6: $7,60 \%$ & - Eje 6: $5,55 \%$ & - Eje $6: 2,80 \%$ \\
\hline - Eje $7: 4,00 \%$ & - $\quad$ Eje $7: 3,74 \%$ & - Eje $7: 4,66 \%$ \\
\hline CÁCERES & GRANADA & JAEN \\
\hline - $\quad$ Eje $1: 48,79 \%$ & - $\quad$ Eje $1: 47,87 \%$ & - $\quad$ Eje $1: 60,26 \%$ \\
\hline - $\quad$ Eje $2: 15,80 \%$ & - Eje 2: $14,61 \%$ & - Eje $2: 20,85 \%$ \\
\hline - Eje $3: 6,66 \%$ & - $\quad$ Eje $3: 9,44 \%$ & - Eje 3: $7,45 \%$ \\
\hline - $\quad$ Eje $4: 3,88 \%$ & - $\quad$ Eje $4: 12,17 \%$ & - $\quad$ Eje 4: -- \\
\hline - Eje $5: 11,16 \%$ & - Eje 5: $6,56 \%$ & - $\quad$ Eje $5: 4,43 \%$ \\
\hline - Eje 6: $8,07 \%$ & - Eje $6: 3,41 \%$ & - Eje $6: 3,19 \%$ \\
\hline - $\quad$ Eje $7: 5,61 \%$ & - Eje $7: 5,91 \%$ & - $\quad$ Eje $7: 3,79 \%$ \\
\hline SAN SEBASTIAN & SANT ADRIA & GIJON \\
\hline - $\quad$ Eje $1: 71,26 \%$ & - $\quad$ Eje 1: $78,19 \%$ & - $\quad$ Eje $1: 46,39 \%$ \\
\hline - $\quad$ Eje $2: 12,24 \%$ & - $\quad$ Eje $2: 3,79 \%$ & - $\quad$ Eje $2: 18,641 \%$ \\
\hline - $\quad$ Eje $3: 4,80 \%$ & - $\quad$ Eje $3: 12,54 \%$ & - $\quad$ Eje $3: 9,68 \%$ \\
\hline - $\quad$ Eje 4: --\% & - $\quad$ Eje 4: --\% & - $\quad$ Eje 4: -- \\
\hline - $\quad$ Eje 5: --\% & - Eje $5: 2,37 \%$ & - Eje $5: 10,70 \%$ \\
\hline - $\quad$ Eje 6: $5,91 \%$ & - Eje $6: 1,01 \%$ & - $\quad$ Eje $6: 9,14 \%$ \\
\hline - $\quad$ Eje $7: 5,76 \%$ & - $\quad$ Eje $7: 2,07 \%$ & - $\quad$ Eje $7: 5,41 \%$ \\
\hline SAN CRISTOBAL & MEDIA & \\
\hline - $\quad$ Eje $1: 36,86 \%$ & - $\quad$ Eje 1: $55,42 \%$ & \\
\hline - Eje $2: 24,91 \%$ & - Eje 2: $14,71 \%$ & \\
\hline - Eje 3: $10,05 \%$ & - $\quad$ Eje 3: 6,43 \% & \\
\hline - Eje $4: 0,62 \%$ & - $\quad$ Eje 4: 5,60\% & \\
\hline - $\quad$ Eje $5: 20,38 \%$ & - $\quad$ Eje 5: 6,23\% & \\
\hline - $\quad$ Eje $6: 2,15 \%$ & - $\quad$ Eje 6: $4,88 \%$ & \\
\hline - $\quad$ Eje $7: 4,99 \%$ & Eje 7: 4,59 \% & \\
\hline
\end{tabular}

Figura 4. Porcentaje del gasto elegible que cada programa dedicó a cada uno de los ejes de actuación. Fuente: Elaboración propia a partir de los últimos Complementos de Programa disponibles (Ministerio de Hacienda, 2008) 


\begin{tabular}{|l|c|c|c|c|c|}
\hline Ciudad & Act. Previstas & Act. introducidas & Act. Canceladas & Act. Implem. & Grado de Corrección \\
\hline Pamplona & 40 & 0 & 10 & 30 & Media-Baja \\
\hline Ourense & 20 & 15 & 6 & 29 & Alta \\
\hline Teruel & 53 & 12 & 24 & 41 & Media-Alta \\
\hline Cáceres & 42 & 6 & 18 & 30 & Media-Alta \\
\hline Granada & 46 & 7 & 16 & 37 & Alta \\
\hline Jaén & 50 & 7 & 7 & 50 & Baja \\
\hline S. S.-Pasaia & 22 & 5 & 3 & 24 & Baja \\
\hline S. Adrià B. & 25 & 8 & 4 & 29 & Media \\
\hline Gijón & 29 & 5 & 5 & 29 & Baja \\
\hline S. Cristóbal & 49 & 12 & 16 & 45 & Media \\
\hline
\end{tabular}

Figura 5. Grado de corrección de la estrategia original en función del mantenimiento de las actuaciones inicialmente previstas en 2001-02 (leyenda: Act. Previstas: no actuaciones previstas en 2001-02, Act introducidas: $n^{\circ}$ actuaciones no previstas en 2001-02 introducidas posteriormente, Act. Canceladas: $n^{\circ}$ actuaciones previstas en 2001-02 canceladas durante la vida del programa, Act. Implementadas: $n^{\circ}$ de actuaciones finalmente implementadas, Corrección: grado de corrección de la estrategia original en base a las actuaciones.

Fuente: Elaboración propia

\section{Dimensión de participación}

En la mayor parte de los casos, los programas URBAN II se implementaron en ciudades que no habían emprendido procesos relevantes de participación con anterioridad en el marco de las políticas urbanas (por ejemplo, no habían desarrollado su Agenda $21 \mathrm{~L}$ o su Plan Estratégico). Muchas de ellas emprendieron algunos de esos procesos coincidiendo con el periodo durante el que se implementó el programa URBAN II. En esos casos los entes ejecutores no contaban con experiencia práctica previa sobre la aplicación de enfoques colaborativos. No se había llevado a cabo con anterioridad una reflexión sobre este tema por parte de los decisores políticos y los técnicos de esas administraciones locales. En la mayor parte de los casos tampoco se había desarrollado una demanda por parte del tejido asociativo de explorar esta práctica para abrirse un espacio en la gestión local.

La falta de experiencia previa explica en gran medida por qué en la mayor parte de los casos el enfoque colaborativo de los programa se identificó desde un primer momento con la puesta en marcha de un proceso de participación que se equiparó a la provisión de información y rendición de cuentas a los ciudadanos o a la consulta sobre una estrategia ya definida y casi cerrada por parte del ente ejecutor del programa, que no daba lugar a una implicación real de la comunidad local.

En los dos municipios (Pamplona y Gijón) en los que se habían dado procesos de participación previa en el marco de distintos instrumentos y existía un tejido asociativo relevante, los programas fueron capaces de poner en marcha procesos en los que se dio una interacción entre la administración local, la ciudadanía y otros actores, que derivó posteriormente en construcción de capacidad local. En estos programas el enfoque colaborativo de la Iniciativa se entendió de manera más 
cercana a la plasmada por la Comisión en sus documentos, por lo que fueron capaces de poner en marcha procesos participativos sostenidos que se mantuvieron durante la vida del programa.

Se detecta, por lo tanto, una relación entre la experiencia previa en la implementación de enfoques participativos y la existencia de un tejido social activo, como factores que ejercieron un efecto positivo en la plasmación del enfoque colaborativo en los programas URBAN II.

No obstante, a estos factores se suma otro relevante en ambos casos: en el caso de Pamplona la existencia de la Unidad de Coordinación de Proyectos Europeos, que tenía como cometido identificar las ayudas europeas a las que la ciudad podía potencialmente acceder. Este hecho probablemente llevó a los técnicos de la misma a realizar un análisis de la metodología URBAN (y por tanto también de su componente colaborativa), profundizando en ella con anterioridad a la asignación del programa. En el caso del programa de Gijón, hay que recordar que su gerente había estado al frente de la Oficina de gestión del URBAN de Valladolid durante los últimos años del programa $y$, por lo tanto, contó desde el inicio con un importante conocimiento de la metodología participativa recomendada por la Comisión Europea. Ambas circunstancias demuestran que en estas ciudades se tenía un conocimiento previo del "método URBAN", que las permitió abordar la estrategia a plasmar en sus respectivos programas con mayor coherencia metodológica. Esta coherencia se pone de relieve principalmente si se comparan los procesos de participación de esos programas con los que se pusieron en marcha en otros contextos municipales, donde no se contaba con experiencia previa.

De la revisión de los análisis DAFO que las ciudades incluyeron en los documentos de programa de 2001 (Ministerio de Hacienda, 2001a-j) se pone en evidencia que, aunque en ese momento el grado de participación de la ciudadanía y de los actores sociales y económicos en la gestión municipal era muy bajo, o inexistente en algunos casos, los Ayuntamientos no consideraron esta circunstancia como un extremo a mejorar a pesar de que en la Comunicación de la Comisión relativa a URBAN II se establecía que el programa debería contar con la colaboración activa de la comunidad local. En muy pocos casos aparece esta circunstancia caracterizada como una amenaza al programa o una debilidad de la ciudad a subsanar a través de las acciones planificadas (es así en el caso del programa de Teruel). Este extremo pone en evidencia que los entes ejecutores no consideraron esta circunstancia una debilidad relevante porque no contaban con conocimiento completo sobre la participación y su complejidad.

El análisis también pone de relieve que en todos los casos el proceso de diálogo entre los entes ejecutores y la comunidad local, que se llevó a cabo durante el proceso de redacción del programa inicial (al ser obligatorio, en base a la normativa que regía la Iniciativa URBAN II), derivó en el consenso en relación a los programas entre las distintas administraciones, los partidos políticos presentes en los plenos de los Ayuntamientos, la comunidad y los actores locales. En ocho de los diez casos se hace referencia explícita a este extremo en los documentos de programa, mientras que en 
los otros dos esta circunstancia está implícita en la descripción del proceso de gestión (Teruel y Jaén).

En este sentido, cabe destacar que la obligatoriedad introducida por la normativa que regulaba esta segunda fase de la Iniciativa, consistente en iniciar un diálogo por parte del ente ejecutor del programa con los distintos actores, fue positiva y llevó a los entes ejecutores a no iniciar el proceso de diseño del programa de manera unilateral como había sucedido en la mayor parte de los programas URBAN de la primera fase. Por otro lado, esta circunstancia permitió que la información relativa al programa URBAN II para cada ciudad llegara a los distintos actores locales desde un primer momento por lo que, una vez que el programa fue aprobado por la Comisión Europea, estos contaban ya con un conocimiento inicial de lo que conllevaba el desarrollo de la Iniciativa en su ciudad. Esto derivó en que en algunas ciudades se crearan expectativas de participación que no siempre fueron alcanzadas (se ha constatado este extremo en los casos de Pamplona y Granada). Paradójicamente en esos casos, el inicio de un proceso de participación de la comunidad en los programas, derivó en la desconfianza y alejamiento de esta respecto al Ayuntamiento al paralizarse unilateralmente el proceso participativo.

También hay que señalar en relación al diálogo que los entes ejecutores mantuvieron con los distintos actores en el momento inicial, que en algunas ciudades los primeros llevaron a cabo una selección de los actores que dejó fuera de ese diálogo a otros entes y colectivos presentes en la realidad local, lo que introdujo desde el principio un sesgo en el proceso de participación.

En algunos casos, cuando no se implementó posteriormente un proceso real de participación, ese primer contacto constituyó el momento de máxima colaboración entre la Administración, la ciudadanía y los actores locales.

Como sucedió en la primera fase de la Iniciativa, los programas de la segunda fase tampoco consideraron la participación colaborativa entre actores como un elemento esencial de la metodología a aplicar. También en relación a este tema faltó una reflexión sobre los resultados que habían conseguido los programas de la primera fase. Así, no se introdujo una modificación que derivase en una corrección metodológica en relación al enfoque colaborativo. La acción de la Autoridad de Gestión se mantuvo en la línea de la que había desarrollado en la primera fase, por lo que siguió faltando una figura que "tutelase" que la metodología de los programas superase las dificultades de partida y se acercase en mayor medida a lo recomendado por la Comisión en relación a la implicación en los programas de actores no institucionales.

La falta de intención de reforzar esta componente de URBAN derivó también en una falta de directrices claras en relación a este tema. Esto dio lugar a un alto grado de heterogeneidad en el modo en el que cada programa abordó este aspecto. Así, algunos plantearon procesos de participación abiertos a la comunidad y los actores locales, estructurados y dirigidos conscientemente a construir capacidad local (e incluso a "institucionalizar" en el futuro la participación), mientras que otros programas fueron muy vagos e incluso contradictorios en relación a este aspecto, ya desde el momento de su presentación a través del documento de programa inicial de 2001. Se observa como algunos programas hablaban en dichos documentos (Ministerio de Hacienda, 2001a-j) de implicar a la comunidad local (particularmente 
a la ciudadanía) en el proceso de diseño de la estrategia, pero también en el seguimiento e implementación de las actuaciones. Sin embargo, no identificaron los recursos técnicos y económicos para hacerlo. También se observa que en los documentos iniciales, en algunos casos, se menciona la creación de entes de participación. En algunos casos esos entes no llegaron a constituirse o propiciaron sólo un foro donde las instituciones informaban a la comunidad de las decisiones ya tomadas.

En cuanto al enfoque colaborativo adoptado por los programas en relación a la participación de la comunidad y los actores locales y su posterior materialización, se distinguen los siguientes posicionamientos de los entes ejecutores:

- El entendimiento de URBAN II como una oportunidad para poner en marcha un proceso de participación entre la administración, la ciudadanía y los actores locales en torno a la regeneración de un ámbito de la ciudad, para lo que se dotó al programa de recursos económicos y técnicos. Tanto en la descripción del programa, como en la asignación de medios, se vislumbra la intención de dar lugar a un proceso colaborativo, estructurado y seguido por expertos en participación, que derive a su vez en la creación de capacidad local. Este fue el caso del programa de Pamplona. Los programas que se situaron dentro de este grupo desarrollaron procesos de difusión y consulta durante el periodo de redacción del documento de proyecto inicial que quedaron descritos en ese documento. Ese proceso sirvió para detectar los actores relevantes, que una vez iniciado el programa fueron convocados a un proceso de participación colaborativa. Sólo quedaron fuera de ese proceso los actores que se autoexcluyeron. Estos programas se dotaron de órganos en los que los actores presentes en el proceso de participación tenían capacidad de hacer propuestas para integrarlas en la estrategia de regeneración.

- La adopción de un enfoque colaborativo en el documento de programa inicial en el que se señalaba explícitamente la intención de implicar a la comunidad y los actores locales a través de un proceso de participación, que sin embargo no encontró reflejo en la identificación de acciones y financiación. En estos casos se detecta una falta de coherencia interna en los mismos. En casi todos los casos se previó la creación de algún ente de participación (Consejo Asesor en Ourense, Comisión Consultiva en Teruel, MA-TIC en Cáceres y el Grupo de Acción Local en el caso de San Cristóbal de La Laguna), sin embargo, tanto la estructura de dichos entes, como los periodos establecidos entre reuniones, ponen de manifiesto que se trató de foros concebidos para informar del contenido y desarrollo del programa y no para hacer posible un proceso de participación colaborativa. Los programas que se situaron dentro de este grupo desarrollaron procesos de difusión y consulta durante el periodo de redacción del proyecto inicial. En ese marco, y también durante el inicio de su desarrollo, se dieron procesos de diálogo entre la administración local y los actores contactados. Posteriormente esa implicación empezó a perder fuerza. Esta circunstancia derivó en la frustración de los mencionados actores. Aunque con notables diferencias en la implementación, pero con un enfoque general parecido, este fue el caso de Teruel, Cáceres, Granada, San Sebastián-Pasaia y San Cristóbal de La Laguna. 
- La adopción de un enfoque colaborativo que queda plasmado en el documento de Programa inicial, así como en las acciones previstas. Se trata de programas que no pusieron en marcha procesos de participación estructurados y guiados por facilitadores, pero que consiguieron a través de la creación de pequeños foros de participación (en ocasiones informales) acercar la administración a la ciudadanía y los actores locales. La participación a través de estos foros informales jugó un papel importante en la creación de redes locales a través de las que empezar a construir la capacidad local en entornos donde no existía un tejido asociativo con el que trabajar. En esos foros no se dio la discusión conjunta de todos los actores relevantes, sino que los distintos actores trabajaron de manera bilateral con la administración (por ejemplo: empresarios con administración, entes sociales con administración, etc.).

Esta circunstancia permitió que se diera un acercamiento a la administración municipal, que derivara en la superación de la desconfianza inicial hacia la misma. Sin embargo, impidió que en un momento dado los distintos actores con intereses en el área URBAN (sociales, económicos, ambientales, etc.) interaccionasen, dando lugar a un conocimiento mutuo que es central en los procesos colaborativos.

El tiempo de desarrollo de los programas no fue suficiente para dar ese paso, con el fin de, una vez vencidas las limitaciones a la colaboración entre todos los actores, emprender un proceso de participación que les permitiera su conocimiento mutuo y la creación de redes que derivaran en capacidad institucional. Con matices diferenciadores, este fue el caso del programa de Jaén, Gijón y San Adrià de Besòs.

Como deriva de lo anterior, la mayor parte de los programas adoptó un enfoque participativo, e incluso colaborativo, en el documento de programa inicial aprobado por la Comisión, pero sin incluir dentro del mismo las acciones y medios necesarios para plasmarlo. Así, la mayor parte de los programas pusieron en marcha procesos de participación cercanos a lo que Arnstein denominó "manipulación o terapia" en su escala de la participación (Arnstein, 1968).

En los programas URBAN II se dieron también algunos procesos colaborativos que derivaron en la construcción de la capacidad local. Desde este punto de vista, el caso más representativo fue el de Gijón, en el que, en base al trabajo realizado por algunas asociaciones en el marco del programa, estas pudieron asumir la gestión de dos mediatecas. Una vez finalizado el programa estas asociaciones siguieron gestionándolas. El programa de Pamplona, que implementó un proceso de participación estructurado, seguido y organizado por expertos, con la presencia de todos los actores relevantes, no consiguió dar frutos concretos en este sentido.

En la actualidad muchos de los entes que participaron en el proceso son críticos con la administración local porque una vez acabado URBAN II no ha puesto en marcha procesos colaborativos que los impliquen en la gestión local. Explícitamente piden a la administración local que desarrolle procesos de participación como el que tuvo lugar en el marco del programa URBAN II.

En todos los casos en los que se ha obtenido la respuesta del cuestionario enviado a los responsables o técnicos de los programas y a los actores locales (ver Anexo de la tesis doctoral) se ha detectado que, independientemente del grado de introducción 
del carácter colaborativo en el programa, se valora positivamente el proceso de participación abierto, incluso en los casos en los que este estuvo limitado a facilitar información sobre el programa y recibir sugerencias sobre el mismo, o se bloqueó desde el Ayuntamiento en algún momento. Esta dimensión de la Iniciativa es la señalada como la que es capaz de dar lugar a mayor valor añadido por los técnicos de los programas. Sin embargo, los técnicos también señalan las dificultades que presentan este tipo de procesos, haciendo notar que la complejidad organizativa que conllevan hace difícil que las administraciones locales acaben optando por estas soluciones si no es en casos excepcionales.

Como deriva del estudio, no se estableció en el marco de alguno de los programas una asociación estable en la que estuvieran representados todos los actores relevantes junto con la administración. El programa que estuvo más cerca de establecer un modelo parecido fue el de Pamplona a través de la constitución de la Comisión Gestora y la Mesa URBAN.

En base al análisis descrito, se puede afirmar que en el caso español la Iniciativa URBAN logró en su segunda fase construir capacidad institucional en el marco de una minoría de programas, aunque de modo incipiente y con las debilidades que se han descrito.

Los procesos de participación colaborativa que se dieron en el marco de esos programas URBAN II muestran avances en la construcción de infraestructuras blandas (las denominadas soft infrastructures por Healey: redes relacionales y prácticas participativas informales), sin embargo estas se encuentran todavía en el proceso de propiciar una transformación de los instrumentos y prácticas en base a los cuales se gestionan los procesos de regeneración urbana u otras políticas (hard infrastructures). No han sido capaces, por tanto, de transformar la gobernanza local durante la vida del programa institucionalizando procesos colaborativos.

Por otra parte, el pequeño avance que se ha verificado hasta ahora, no excluye que las infraestructuras blandas que han surgido no sean capaces de propiciar una transformación más profunda a medio plazo.

Esta podría tener lugar en base a la transformación "informal" de la gobernanza que se ha dado en el marco de algunos programas, que ha consistido en la concienciación de la comunidad local respecto a su derecho a participar en la gestión local, y particularmente en los procesos de transformación de su hábitat, y en la construcción de redes relacionales entre los distintos actores. En esos casos se ha construido capacidad local que ya es patrimonio de las ciudades beneficiarias y que podría actuar como factor de cambio de la gestión local a medio plazo. 


\section{CONCLUSIONES}

El análisis llevado a cabo pone en evidencia que en el caso español los programas URBAN y URBAN II han encontrado problemas para aplicar la metodología de regeneración propuesta por la Comisión Europea, y en particular los elementos metodológicos relacionados con la Planificación Colaborativa en los programas. No obstante, se observa una evolución positiva en relación a este tema entre los programas que formaron parte de la primera fase de esta Iniciativa Comunitaria (1994-1999) y los de la segunda URBAN II (2000-2006).

Esta evolución, se manifiesta también en relación a otros aspectos como la interpretación del enfoque integrado, la coherencia de las estrategias desarrolladas y la mayor integración de los programas en estrategias urbanas o territoriales. Los resultados generales obtenidos por los programas URBAN II también evolucionaron positivamente, situándose más cercanos a las expectativas expresadas en la documentación emanada de la Comisión Europea. Por lo tanto, los programas desarrollados en la segunda fase de la Iniciativa contribuyeron en mayor medida que sus antecesores a mejorar el medio urbano y la cohesión económica y social de las ciudades en las que actuaron.

Como en el resto de los catorce Estados miembros donde se implementó URBAN, la Iniciativa fue transformada al entrar en el escenario español en base a un conjunto de factores inherentes al contexto nacional, principalmente relacionados con el enraizamiento de una determinada forma de entender la actuación en el medio urbano degradado, la inercia frente al cambio y el interés por parte de algunos actores implicados en mantener los aspectos relativos a la gestión de las políticas urbanas inalterados. En base a esto, los programas que se implementaron en la primera fase de la Iniciativa establecieron estrategias muy cercanas a las que se venían desarrollando en la práctica habitual de las instituciones locales y nacionales al afrontar los problemas de degradación del medio urbano.

Una minoría de los programas intentó acercarse a través de sus estrategias a las orientaciones de la Comisión, integrando elementos metodológicos como el enfoque integrado y colaborativo, pero una vez que empezaron a implementarse esa intención quedó limitada por la realidad en la que se trabajaba. Como resultado los programas mejoraron los medios urbanos donde operaron, pero no alcanzaron en general resultados diferentes de los que habría conseguido la acción sectorial que venían implementando los ayuntamientos.

El mayor grado de adicionalidad de la primera fase de URBAN se materializó en aspectos intangibles, relacionados con la experiencia y el conocimiento que adquirieron las instituciones implicadas en la implementación de la Iniciativa y otros entes activos en el marco teórico y práctico de la regeneración urbana en el país. En efecto, este se situó en el aprendizaje de los técnicos que estuvieron directamente relacionados con los programas (desde los entes ejecutores, la autoridad de gestión o consultoras participantes). También fue importante el aprendizaje de los técnicos que desde instituciones públicas (sobre todo ayuntamientos) que no habían conseguido acceder a la Iniciativa empezaron a estudiar el "método URBAN" con el fin de poder acceder a la siguiente fase (URBAN II). Aunque en menor medida que en otros Estados miembros, también se dio un interés por parte del mundo académico 
por analizar este instrumento. Todo ello redundó en una penetración de los presupuestos de URBAN en el contexto español, a través de la difusión de la metodología que se proponía desde la Comisión para afrontar los problemas de los barrios degradados. Se trató de una contribución que consistió en la introducción de elementos intangibles de transformación, que se situó en el ámbito de la reflexión y la penetración de conocimiento sobre un nuevo modo de actuar.

Durante este periodo no se desarrolló en el país algún instrumento de regeneración urbana que recibiera de manera explícita la influencia de la Iniciativa Comunitaria URBAN. Hubo que esperar un poco más para que esto sucediera. Tampoco se observa que en las ciudades donde se implementaron los programas se diera un cambio en la gestión local o en la aplicación del resto de los elementos metodológicos propios de URBAN en su práctica habitual.

La segunda fase de la Iniciativa mostró cambios respecto al periodo anterior, en gran medida derivados de dos factores: los cambios que se habían introducido en el ámbito comunitario en la normativa de los Fondos Estructurales que afectaban a la Iniciativa, y la experiencia ganada en el contexto español a través de los programas desarrollados entre 1994 y 1999 y otras líneas de trabajo (planes estratégicos, Agenda $21 \mathrm{~L}$, iniciativas y planes de regeneración, etc.).

El primer factor mencionado derivó en la mejora técnica de los documentos de los programas que se tradujo también en una mayor calidad y coherencia de las estrategias, de la manera de implementarlas, del seguimiento y de los resultados obtenidos. Los programas también mejoraron en relación a la transparencia de la toma de decisiones y la rendición de cuentas. El conocimiento previo de URBAN por parte de la Autoridad de Gestión y los entes ejecutores fue clave para que fuera posible ese avance. Como se ha dicho, es ahí donde se situó la principal aportación de la primera fase de la Iniciativa: en la introducción de un conocimiento que hizo posible que la segunda fase se desarrollase en España alcanzando en mayor medida los objetivos comunitarios.

Coincidiendo con el periodo de desarrollo de esta segunda fase cristalizaron en el contexto español algunos instrumentos dirigidos a la regeneración urbana lanzados por el Gobierno Central y las Comunidades Autónomas que asumían de manera directa la metodología de URBAN. En 2001 se puso en funcionamiento el programa vasco Izartu, en 2004 se aprobó la Ley de Barrios de Cataluña, en 2005 se definió el Área de Rehabilitación Urbana (ARU) en el marco del Plan de Vivienda 2005-2008, en 2007 el desaparecido Ministerio de Vivienda lanzó la Iniciativa Urbana 2007-2013, los programas dirigidos a ciudades medianas y pequeñas y la Red de Iniciativas Urbanas, al final de 2008 se aprobó el Plan Estatal de Vivienda y Rehabilitación 2009-2012. Todos ellos asumieron un enfoque hacia la regeneración con importantes similitudes con URBAN, también en 2009 el Gobierno Balear aprobó la Ley de rehabilitación y mejora de barrios de los municipios de las Illes Balears. Estos instrumentos constituyen la aportación más visible de URBAN a la práctica de la regeneración urbana en España, ya que en ellos de manera explícita se "institucionalizó" una metodología de acción contra la degradación urbana que en esencia es coincidente con el "método URBAN".

La formalización de estos instrumentos a través del respaldo legislativo o institucional, aseguraba la continuidad en la implementación del "método URBAN" en 
el marco español, aunque hay que señalar que en la actualidad algunos de ellos han dejado de desarrollarse de manera definitiva o temporal. Por otra parte, la existencia de estos instrumentos pone de manifiesto que se dio una transferencia de políticas de regeneración urbana desde el ámbito británico al español a través de la política urbana de la Unión Europea.

Como se ha visto, en el caso español existían multitud de elementos "innovadores" en URBAN respecto a la práctica dominante de la regeneración urbana en el país, pero aquel que era más lejano no sólo al modo de proceder, sino también a la forma de entender las políticas y la gestión urbana era la dimensión colaborativa. Esta circunstancia hizo que durante la primera fase de la Iniciativa el "filtro" que la realidad propia del país ejerció sobre la metodología de URBAN, tuviese como efecto la pérdida de presencia del carácter participado de los programas. Los programas que se diseñaron no introdujeron este aspecto en la estrategia de actuación y cuando lo hicieron entendieron, por lo general, que la participación conllevaba sólo la puesta en marcha de procesos de información, permitiendo en algunos casos la presentación de sugerencias por parte de los diferentes actores locales asistentes a las reuniones. El bajo nivel de relevancia que se dio a esta componente metodológica quedó patente en la ausencia casi total de menciones a este tema en los documentos oficiales de la Iniciativa editados por el Ministerio de Hacienda (programas iniciales, informes finales, etc.).

Como resultado de todo lo anterior, en general en el marco de los programas URBAN no se dio interacción y conocimiento mutuo entre los diferentes actores relevantes, las estrategias de actuación no fueran consensuadas, no se utilizó el conocimiento "no experto" para mejorar el diagnóstico de las áreas de actuación y no se construyó capacidad local. Si que se dio, sin embargo, una implicación relevante de actores sociales en la gestión de acciones de carácter social en el marco de los programas. Esta circunstancia derivaba de la tradición de colaboración entre los Ayuntamientos y el tercer sector para afrontar problemáticas sociales en barrios degradados. En este caso la práctica habitual jugó a favor de la integración de los actores sociales en el proceso de implementación de algunas actuaciones, que supusieron movilizar y poner al servicio de los programas recursos presentes en la comunidad local.

Los programas no desarrollaron asociaciones estables y fueron gestionados por los entes ejecutores sin crear arenas/foros de gestión que dieran alguna capacidad de intervenir en las decisiones a la comunidad local. En general no se dio una implicación de actores económicos. No se consiguió movilizar financiación privada, por lo que los programas fueron cofinanciados por el FEDER, el FSE y los entes ejecutores.

Como consecuencia, se puede afirmar que durante la primera fase de la Iniciativa los programas URBAN no introdujeron presupuestos colaborativos en su metodología de actuación. Sí que se mejoró la transparencia y la rendición de cuentas de la gestión local, a través de los procesos de información que se pusieron en marcha en el marco de los programas.

Durante la segunda fase de la Iniciativa la introducción del enfoque colaborativo en los programas mejoró debido a diferentes factores. Aunque una parte de los programas URBAN II desarrollaron esta dimensión de manera parecida a la 
predominante durante la primera fase, una minoría implementó procesos colaborativos. Esos programas han llegado a dar lugar a construcción de capacidad local al propiciar el aprendizaje y el conocimiento mutuo entre los diferentes actores con intereses en el proceso de mejora urbana, que ha derivado en la construcción del consenso y de redes relacionales entre ellos. También ha derivado en la puesta en marcha de procesos de colaboración en el marco del programa, que han abierto el camino hacia la construcción de la capacidad institucional en las ciudades donde han operado. Se ha comprobado que estos procesos de colaboración no se han exportado a otros procesos de regeneración o políticas locales de las ciudades donde se han implementado los programas, pero la capacidad adquirida por los diferentes actores es un factor que sigue vivo y puede generar cambios en el futuro.

A pesar de los avances que presenta la segunda fase de la Iniciativa respecto a la primera en relación a la participación colaborativa, se sigue observando que la realidad del país pesa fuertemente sobre las instituciones cuando tienen que decidir si poner en marcha procesos de ese tipo. Por lo general se decantan por no hacerlo como demuestran los programas URBAN y URBAN II desarrollados en el país.

En la revisión de la evolución de la práctica de la regeneración urbana en España se ha puesto el foco en entender qué elementos de la realidad nacional están en la base de ese modus operandi. El análisis ha puesto en evidencia que, aunque los factores son muchos y complejos y se sitúan en múltiples dimensiones, tienen que ver en gran medida con la tradición política e institucional del país, con la que ha chocado el enfoque colaborativo (de tradición anglosajona) presente en URBAN. La observación del escenario nacional ha puesto en evidencia que lo mismo ha sucedido en el caso de otros instrumentos e iniciativas (Agenda 21L, planes estratégicos, etc.) que desde el ámbito internacional han intentado introducir procesos de participación colaborativa a lo largo de las últimas dos décadas en España.

En una realidad como esta, cuesta pensar que URBAN pudiese haber alcanzado resultados distintos a los descritos. Por el contrario, el conocimiento de este escenario pone en valor los procesos y resultados relativos a la implementación de enfoques colaborativos alcanzados por algunos de los programas de la segunda fase, que en muchos aspectos son comparables a los puestos en marcha y alcanzados por países con experiencia anterior en relación a este tema.

Cabe aquí señalar de nuevo, por la relación que tiene con el punto anterior, la importancia que hubiera tenido implicar a las Comunidades Autónomas en la gestión de las Iniciativas Comunitarias URBAN y URBAN II desarrolladas en España, para acercarlas al tema de la regeneración urbana, un ámbito de actuación que está dentro de sus competencias y que hasta ahora sólo algunas de ellas han atendido específicamente.

Todas las conclusiones expuestas, ponen de manifiesto que a pesar de que el resultado particular de los programas URBAN y URBAN II en España ha sido limitado en lo que concierne a la dimensión colaborativa, la implementación de la Iniciativa en el país ha actuado como un factor de cambio. Los instrumentos de regeneración como el Programa Izartu o la Ley de Barrios, nacidos tras la estela de URBAN e integrando un enfoque colaborativo en su metodología, son los más visibles, pero están complementados con otros intangibles que desde distintas dimensiones están contribuyendo a transformar el escenario de la regeneración urbana en el país. Desde 
este reconocimiento, es posible afirmar que la realidad de la regeneración urbana en España no sería la misma si esta Iniciativa Comunitaria, y particularmente su dimensión colaborativa, no se hubieran implementado entre 1994 y 2006.

Al trabajo realizado en el marco de esta investigación se le está dando continuidad a través del estudio del eje de programación del FEDER relativo a desarrollo local y urbano que España ha plasmado en su Marco Estratégico Nacional de Referencia 2007-2013. El mismo conlleva analizar la mencionada Iniciativa Urbana y la Red de Iniciativas Urbanas que están siendo coordinadas por el Ministerio de Fomento en 2015. Dicho estudio quedaría completado con el análisis del otro instrumento que la UE puso al alcance de las ciudades para afrontar la degradación urbana durante el presente periodo presupuestario: JESSICA. Todo ello permitiría entender cómo se ha dado continuidad a la metodología de URBAN en España durante el periodo 20072013 en el marco de la política urbana comunitaria, y hacer una reflexión sobre el efecto que está teniendo el mainstreaming de dicha política y la desaparición de URBAN en el caso español, así como otras contribuciones relevantes a la agenda urbana de la UE. 


\section{BIBLIOGRAFÍA}

ALBRECH, L. ALDEN, J. Y DA ROSA PIRES, A. (2001). The Changing Institutional Landscape of Planning. Hants (Canada): Ashgate.

ALDANONDO OCHOA, P. (1996). "Actuaciones urbanas de la Unión Europea", en Revista de la Federación Española de Municipios y Provincias, número 70, p. 4-8.

ALTROCK, U. GÜNTNER, S. HUNING, S Y PETERS, D. (2006). "Spatial Planning and urban development in the new EU Member States: From adjustment to reinvention. Aldershot (United Kingdom): Ashgate.

ARIAS GOYTRE, F. (2000). "La desigualdad urbana en España", en "Ciudades para un Futuro más Sostenible", fecha de referencia: 20-10-2001, recurso on-line disponible en http://habitat.aq.upm.es/due/ac.html

ARSTEIN, S. R. (1969). "A Ladder of Citizen Participation", en Journal of American Institute of Planners, volumen 35, número 4, pp. 216-224.

ATKINSON, R. (2001)."The Emerging Urban Agenda and the European Spatial Development Perspective: Towards an EU Urban Policy?", en European Planning Studies, volumen 9, p. 385406.

ATKINSON, R. (2000)."Combating social exclusion in Europe: The new urban policy challenge", en Urban Studies, volumen 37, número 5-6, p. 1037-1055.

ATKINSON, R. (1999). "An Urban Policy for Europe", en North, volumen 10(4) y disponible en http://www.nordregio.se/filer/north9904art.htm

ATKINSON, R. \& MOON, G. (1994b)."The City Challenge Initiative: An Overview and Preliminary Assesment", en Regional Studies, volumen 28 (1), p. 94-97.

BAILEY, N. \& BARKER, A. (1992). City Challenge and Local Regeneration Partnerships: Conference Proceedings. Londres: University of Westminster.

BLANCO, I. \& GOMÁ, R. (2006). "Del gobierno a la gobernanza: oportunidades y retos de un nuevo paradigma", en Ekonomiak, número 2, p.11-27.

BORJA, J. (1975).Movimientos sociales urbanos. Buenos Aires: Ediciones Siap-Planteos,

BORJA, J. (2001). "Participación, un desafío, una oportunidad, una cuestión política", en Proyecto Educativo de Ciudad. Gijón: Ayuntamiento de Gijón.

BRAND, R. (sin año). Annotated Bibliography on Collaborative Planning: Innes, Judith and Booher, David: Consensus Building and Complex Adaptive Systems - A Framework for Evaluating Collaborative Planning. Belfast: Queen's University.

BRENNER, N. (2004).New State Spaces: Urban governance and the rescaling of statehood. Oxford: Oxford University Press.

CHISHOLM, R. E. (1998).Developing Network Organizations: Learning from Practice and Theory. Nueva York: Adisson-Wesley. 
CHORIANOPOULOS, I. (2002). "Urban Restructuring and Governance: North-South Differences in Europe and the EU URBAN Initiative", en Urban Studies, volumen 39(4), p. 705726.

COMISIÓN EUROPEA (1990). Libro verde sobre el medio ambiente urbano, COM (90) 218 final. Publicaciones de la Comunidad Europea.

COMISIÓN EUROPEA (1994a). Iniciativa comunitaria de zonas urbanas (URBAN), COM (94) 61 final, de 02-03-1994. Publicaciones de la Unión Europea.

COMISIÓN EUROPEA (1994b). Comunicación a los Estados miembros por la que se fijan las orientaciones para los programas operativos que se les invita a elaborar dentro de una iniciativa comunitaria de zonas urbanas (URBAN), Diario Oficial de las Comunidades Europeas no L 180, de 01-07-1994, p. 06-09.

COMISIÓN EUROPEA (1996). Comunicación a los Estados miembros por la que se fijan las orientaciones para los programas operativos que se les invita a elaborar dentro de una iniciativa comunitaria de zonas urbanas (URBAN), Diario Oficial de las Comunidades Europeas no C 200, de 10-07-1996, pp. 04-06.

COMISIÓN EUROPEA (1997a). Communication from the Commission - Towards an urban agenda in the European Union, COM (97) 197 final. Publicaciones de la Unión Europea.

COMISIÓN EUROPEA (1997b). La Europa de las ciudades: actuaciones comunitarias en el marco urbano. Publicaciones de la Unión Europea.

COMISIÓN EUROPEA (1998). Marco de actuación para el desarrollo urbano sostenible en la Unión Europea, COM (98) 605 final. Publicaciones de la Unión Europea.

COMISIÓN EUROPEA (2000). Comunicación de la Comisión a los Estados miembros de 28 de abril de 2000 por la que se fijan las orientaciones de una iniciativa comunitaria relativa a la regeneración económica y social de las ciudades y de los barrios en crisis con el fin de fomentar un desarrollo urbano sostenible ó URBAN II. Diario Oficial de las Comunidades Europeas 2000/C 141. Bruselas.

COMISIÓN EUROPEA (2001). La Gobernanza Europea. Un Libro Blanco, COM(2001) 428 final. Publicaciones de la Unión Europea.

COMISIÓN EUROPEA (2002). Comunicación de la Comisión al Consejo, al Parlamento Europeo, al Comité Económico y Social y al Comité de las Regiones. Programación de los Fondos Estructurales 2000-2006: Evaluación inicial de la Iniciativa URBAN, COM (2002) 308 final, de 14-06-2002. Publicaciones de la Unión Europea.

COMISIÓN EUROPEA (2003). Cooperación con las Ciudades. La Iniciativa Comunitaria URBAN. Publicaciones de la Unión Europea.

COMISIÓN EUROPEA (2006). Ciudades para el Crecimiento, el Empleo y la Cohesión. La Acción Urbana de los Fondos Estructurales. Publicaciones de la Unión Europea.

COMISIÓN EUROPEA (2007). The Territorial and Urban dimension in the national strategic reference framworks and operacional programmes (2007-2013). A first assessment. Working paper of the services of the Directorate General for Regional Policy. Publicaciones de la Unión Europea. 
COMISIÓN EUROPEA (2010). The urban dimensión in European Union policies 2010. Publicaciones de la Unión Europea.

DAVIDOFF, P. (1965). "Advocacy and Pluralism in Planning", en Journal of the American Institute of Planning, número 31, p. 331-338.

DE GREGORIO HURTADO, S. \& KOCEWICZ, R. (2007). Iniciativa Comunitaria URBAN 19941999. Análisis comparativo de tres casos españoles de programas europeos de rehabilitación urbana. Cuadernos de Investigación Urbanística, número 55, Madrid.

DE GREGORIO HURTADO, S. (2009). "The Contribution of the URBAN Community Initiative to the Urban regeneration practice in Spain", en Conferencia City Futures'09 (EURA), Madrid, junio de 2009.

DE GREGORIO HURTADO, S. (2010). "El desarrollo de las Iniciativas Comunitarias URBAN y URBAN II en las periferias degradadas de las ciudades españolas: una contribución a la práctica de la regeneración urbana en España", en Ciudades, número 13, p 39-59.

DE GREGORIO HURTADO, S. et Al. (2011). "Urban Regeneration as Transition Pathway towards Resilient Cities: Comparing Spanish, Norwegian and Portuguese National Programmes", en Conferencia The city without limits (EURA), Copenhagen, junio de 2011.

DE GREGORIO HURTADO, S. (2012). "La Regeneración Urbana en la Acción Estatal en España durante el periodo 2004-2011. Una historia a continuar", en Perspectivas, número 1, p. 2751.

DE GREGORIO HURTADO, S. (2014). "La Iniciativa Comunitaria URBAN como factor de transformación de la práctica de la regeneración urbana: aproximación al caso español", en Ciudad y Territorio, número 180, p 253-275.

DREWE, P. (2000). "European Experiences", en Roberts, P. y Sykes, H. (editors).Urban Regeneration.A handbook, Sage Publications, Ltd, Londres, p. 281-294.

EIUA (European Institute of Urban Affairs) (1992). Urbanisation and the Function of Cities in the European Community. Liverpool: EIUA. Liverpool: John Moores University.

FABER, C. (1994). Consider the view that the City Challenge initiative represents a fundamental realignment in Urban Policy. Curso Urban Regeneration in Britain de Lawless, P., disponible en http://www. clausfaber.net/uploads/media/citychallenge.pdf

FARINÓS DASÍ, J. (2008). "Gobernanza Territorial para el desarrollo sostenible: estado de la cuestión y agenda", en Boletín de la $A G E$, número 46, abril de 2008, p. 59-74.

FORESTER, J. (1980). "Critical Theory and Planning Practice", en Journal of the American Planning Association, número 46(3), p. 275-286.

FORESTER, J. (1989). Planning in the Face of Power, University of California Press, LosÁngeles.

FRANK, S. et Al. (2006). The European URBAN Experience seen from the Academic Perspective. Study Report. Berlin: URBACT.

FRIEDMANN, J. (1993). "Towards a Non Euclidian Mode of Planning", en Journal of the American Planning Association, volumen 59, número 4, p. 482-485. 
FriedmanN, J. (2001). Planificación en el Ámbito Público. Madrid: Ministerio de Administraciones Públicas (ed. orig., Princeton 1987).

FRIEDMANN, J. (2011). Insurgencies: Essais in Planning Theory. Londres y Nueva York: Routledge.

GHK (2003). Ex Post Evaluation of URBAN Community Initiative 1994-1999. GHK, Bruselas y Londres.

GLASS, J. J. (1979). "Citizen participation in planning: the relationship between objectives and techniques", en Journal of the American Planning Association, volúmen45(2), p. 180-189.

HAMBLETON, R. (1993). "Issues for urban policy in the 1990s", en The Town Planning Review, volumen 64, número 3, p.313- 328.

HAMBLETON, R. \& GROSS, J. S. (2007). Governing cities in a global era.Urban innovation, competition and Democratic Reform. Nueva York: Palgrave Macmillan.

HEALEY, P. (1992). Rebuilding the city. Property led and urban regeneration. Londres: E \& FN Spon.

HEALEY, P. (1996). "The Communicative Turn in Planning Theory", en Campbell, S. y Fainstein, S. S. (editors).Readings in Planning Theory, Blackwell Publishing, Oxford, p. 237256.

HEALEY, P. (1998a). "Building Institutional Capacity Through Collaborative Approaches to Planning", en Environment and Planning, volumen A 30, número 9, p. 1531-1546.

HEALEY, P. (1998b). "Collaborative Planning in a stakeholders society", en Town Planning Review, volumen 69, número 1, p. 1-22.

HEALEY, P. (2003). "Collaborative Planning in Perspective", en Planning Theory, volumen 2(2), p.101-123.

HEALEY, P. (2004). "Towards a "Social Democratic" Policy Agenda for the Cities", en Johnstone, C. y Whitehead Mark (editores).New Horizons in British Urban Policy, Aldershot, Ashgate, p. 159-171.

HEALEY, P. (2006). Collaborative Planning: Shaping Places in Fragmented Societies. Londres: Macmillan (ed. orig., Londres 1997).

INNES, J. (1995). "Planning Therory's Emerging Paradigm", en Journal of Planning Education and Research, volumen 14, número 3, p. 128-135.

INNES, J. \& BOOHER, D. (2000a). Public Participation in Planning: New Strategies for the 21st Century. Berkeley: Institute of Urban and Regional Development, University of California.

INNES, J. \& BOOHER, D. (2000b). Collaborative Dialogue as a Policy-Making Strategy. Berkeley: Institute of Urban and Regional Development, University of California.

INNES, J. \& DE BOOHER, D. (2004a). "Reframing Public Participation: Strategies for the 21th Century", en Planning Theory and Practice, volumen 5, número 4, p. 419-436. 
INNES, J. \& DE BOOHER, D. (2004b). "Consensus Building: Clarifications for the critics", en Planning Theory, volumen 3, número 1, p. 5-20.

LINDBLOM, C. E. (1992). Inquiry and Change.The troubled Attempt to Understand and Shape Society. Yale: Yale University Press.

LINDBLOM, C. E. (1959). "The Science of "Muddling Through""' en Public Administration Review, número 19, p. 79-88.

MASSON-VINCENT, M. (2008). "Governance and geography explaining the importance of regional planning to citizens, stakeholders in their living space", en Boletín de la $A G E$, número 46 , p. $59-74$.

MINISTERIO DE HACIENDA (1994). Programa Operativo URBAN 1994-1999. Madrid: Ministerio de Hacienda.

MINISTERIO DE HACIENDA (2001). Programa Iniciativa Comunitaria URBAN 2001-2006. Madrid: Ministerio de Hacienda.

MINISTERIO DE HACIENDA (2005). Informe al 40 Comité de Seguimiento URBAN II 20012006. Madrid: Ministerio de Hacienda.

MINISTERIO DE HACIENDA (2008). Informe al $8^{\circ}$ Comité de Seguimiento URBAN II 20012006. Madrid: Ministerio de Hacienda.

MOPU (1990). La política de rehabilitación urbana en España. Evolución, experiencias y efectos. Madrid: MOPU.

MOPTMA (Ministerio de Obras Públicas Transporte y Medioambiente) (1996). Primer Catálogo Español de Buenas Prácticas. I Conferencia ONU Asentamientos Humanos. Madrid: MOPTMA.

NEL.LO, O. (2011). "The five challenges of urban rehabilitation. The Catalan Experience", en Urban Research and Practice, número 4:3, p. 308-325.

NORTH, P. (2003). "Communities at the heart?Community action and urban policy in the UK", en Imrie, R. Y Raco, M. (editores).Urban renassance? New Labour, Community and Urban Policy, Bristol, The Policy Press, p. 121-138.

ORTEGA, M. (2003). "La ciudad y los sistemas urbanos desde una visión territorial", Urban, número8, p. 55-62.

PARKINSON, M. (2005). "Urban policy in Europe: where have we been and where are we going", en Antalowsky, E., Dangschat, J. S. y Parkinson (ed.). European Metropolitan Governance: Cities in Europe- Europe in Cities, proyecto NODE (Ministerio Austriaco de Educacion, Ciencia y Cultura), p. 7-32.

REITER, R. (2008). "The "European City" in the European Union. Comparing the implementation conditions for the EUs urban development agenda in Germany and France", en Atkinson, R. y Rossignolo, C. (editores).The Re-creation of the European City. Governance, Territory \& Policentricity. Amsterdam, TechnePress, p. 17-38.

REUNIÓN INFORMAL DE MINISTROS SOBRE DESARROLLO URBANO Y COHESIÓN TERRITORIAL (2007a). Carta de Leipzig sobre Ciudades Europeas Sostenibles. Leipzig. 
REUNIÓN INFORMAL DE MINISTROS DE DESARROLLO URBANO DE LA UE (2010). Declaración de Toledo, 22 de junio de 2010. Toledo.

RODRÍGUEZ, A. MOULAERT, F. Y SUYNGEDOUW, E. (2001). "Nuevas políticas urbanas para la revitalización de las ciudades en Europa", en Ciudad y Territorio, Estudios Territoriales, número XXXIII (129), p. 409-424.

SÁNCHEZ DE MADARIAGA, I. (2000). "Nuevos enfoques de planeamiento", en Urban, número 5, p. 31-38.

SUBIRATS, J. (2010). "Si la respuesta es gobernanza, ¿cuál es la pregunta? Factores de cambio en la política y en las políticas", en Ekonomiaz, número 74, p.16-35.

TEWDWR-JONES, M. \& ALLMENDINGER, P. (2002a). "The Communicative Turn in Urban Planning: Unravelling Paradigmatic, Imperialistic and Moralistic Dimensions", en Space and Polity, número 6, p 5-24.

TEWDWR-JONES, M. Y ALLMENDinger, P. (2002b). Planning Futures: New Directions in Planning Theory. Londres: Taylor and Francis.

THORNLEY, A. (2003). "El caso británico: del thatcherismo a la Tercera Vía", en Urban, número 8, p. 94-99.

TOFARIDES, M. (2003). Urban Policy in the European Union- A multilevel Gatekeeper System. Aldershot (United Kingdom): Ashgate.

URRUTIA, V. (1992). "Transformación y persistencia de los movimientos sociales urbanos, en Política y Sociedad, número 4, p. 49-56. 


\section{BIBLIOGRAFÍA}

\section{Entrevistas telefónicas:}

- María Teresa Errea

Fecha de la entrevista: 18-03-2009

Responsable de la Oficina URBAN de Pamplona (URBAN II)

\section{- Santiago García-Patrón}

Fecha de la entrevista: 22-04-2009

Dirección General de Política Regional

Comisión Europea

\section{- Monserrat Pareja}

Fecha de la entrevista: 21-07-2010

Investigadora en GRC Creativitat, innovació i transformació urbana

Facultatd'Economia i Empresa

Departamento de Teoría Económica

Universidad de Barcelona

- María Isabel del Moral

Fecha de la entrevista: 24-03-2011

Gestora del programa de Palencia de la Iniciativa Urbana

Ayuntamiento de Palencia

\section{Entrevistas presenciales:}

- Luis Felipe Alonso

Fecha de la entrevista: 02-07-2010

Urbanista y Profesor Titular del Departamento de Urbanística y Ordenación del Territorio de la Escuela Técnica Superior de Arquitectura de la Universidad Politécnica de Madrid

\section{- Eduardo de Santiago}

Fecha de la entrevista: 20-09-2010

Consejero Técnico de Suelo y Políticas Urbanas

Secretaría General de Vivienda - Ministerio de Vivienda

- Michael Parkinson

Fecha de la entrevista: 19-01-2011

Director del EuropeanInstituteforUrbanAffairs

Liverpool John MooresUniversity

\section{- Teresa Bonilla}

Fecha de la entrevista: 08-03-2011

Urbanista y Profesora Asociada del Departamento de Urbanística y Ordenación del Territorio de la Escuela Técnica Superior de Arquitectura de la Universidad Politécnica de Madrid.

\section{- Margarita Ortega}

Fecha de la entrevista: 16-03-2011

Hasta octubre de 2010 ha sido Vocal Asesor de la Dirección General de Desarrollo Sostenible del Medio Rural del Ministerio de Medio Ambiente y Medio Rural y Marino. 
- Marian Leboreiro

Fecha de la entrevista: 03-05-2011

Urbanista y Profesora Asociada del Departamento de Urbanística y Ordenación del Territorio de la Escuela Técnica Superior de Arquitectura de la Universidad Politécnica de Madrid.

\section{- Agustín Hernández}

Fecha de la entrevista: 05-05-2011

Director del Departamento de Urbanismo y Ordenación del Territorio de la Escuela Técnica Superior de Arquitectura de la Universidad Politécnica de Madrid.

\section{- Oriol Nel.lo}

Fecha de la entrevista: 30-05-2011

Profesor en el Departamento de Geografía de la Universidad Autónoma de Barcelona.

\section{- Félix Árias}

Fecha de la entrevista: 07-06-2011

Director General de Suelo y Políticas Urbanas del Ministerio de Fomento.

\section{Cuestionarios recibidos de los entes ejecutores de las oficinas URBAN II:}

- Montserrat Blanco

Fecha de recepción del cuestionario: 20-03-2009

Responsable de la Oficina URBAN de Jaén entre 2001 y 2007 (URBAN II)

\section{- Rosa Nieves García}

Fecha de recepción del cuestionario: 17-05-2009

Técnico del URBAN de la ciudad de San Cristóbal de La Laguna (URBAN II)

\section{Cuestionarios recibidos de los actores locales en los programas URBAN II:}

- Asociación Gaztelan de Pamplona (Abel Sanz).

Fecha de recepción del cuestionario: 16-11-10

- Asociación Alter Nativas, Iniciativas Interculturales de Pamplona. Fecha de recepción del cuestionario: 15-11-10

- Insona. Jesús Hernández. Profesor Titular del Área de Trabajo Social y Servicios Sociales de la Universidad Pública de Navarra y coordinador del equipo de investigación INSONA.

Fecha de recepción del cuestionario: 28-11-10

- Asociación de Vecinos Bajo Albayzin de Granada (Manuel Navarro, Presidente de la Asociación):

Fecha de recepción del cuestionario: 16-11-10

\section{Intercambio de correo electrónico:}

\section{- Santiago Calvo}

Fecha: marzo de 2009 
- Francisco Fernández Lafuente

Fecha: marzo de 2009

Director General de Actuaciones Concertadas en las Ciudades del Ministerio de Fomento entre 1991 y 1996.

\section{Suministro de información:}

- Jan Mikolaj Dzieciolowski (DG de Política Regional de la Comisión Europea)

- Francisco Luis (Geointegra)

- Jesús Egea (Sociedad Urban Teruel)

- ECOTEC 
LOS CUADERNOS DE INVESTIGACIÓN URBANÍSTICA publicados por el Departamento de Urbanística y Ordenación del Territorio desde el año 1993, difunden bimensualmente aquellos trabajos de investigación realizados en el área del Urbanismo, la Ordenación Territorial, el Medio Ambiente, la Planificación Sostenible y el Paisaje, que por sus características, muchas veces de investigación básica, tienen difícil salida en las revistas profesionales. Su objetivo es la difusión de estos trabajos, en el convencimiento de que es necesario potenciar el uso de este idioma entre el mundo científico para conseguir alcanzar ámbitos de difusión a los que, de otra forma, no se podría acceder.

Su formato no es el convencional de una revista de este tipo, con artículos de diferentes autores que, en realidad, abordan aspectos parciales de cada trabajo, muy adecuados para la difusión y el conocimiento rápido de los mismos, pero que no pueden profundizar demasiado debido a su limitada extensión, sino que se trata de amplios informes de la investigación realizada que ocupan la totalidad de cada número. Esto permite, sobre todo a aquellos investigadores que se inician, el tener accesibles los aspectos más relevantes del trabajo y conocer con bastante precisión el proceso de elaboración de los mismos.

La realización material de los Cuadernos de Investigación Urbanística está a cargo del Departamento de Urbanística y Ordenación del Territorio de la Escuela Técnica Superior de Arquitectura de Madrid, garantizándose el respeto de la propiedad intelectual, pues el registro es siempre en su totalidad propiedad del autor. Está permitida su reproducción parcial en las condiciones establecidas por la legislación sobre propiedad intelectual citando autor, previa petición de permiso al mismo.

\section{NORMAS DE PUBLICACIÓN}

Las condiciones para el envío de originales se pueden consultar en la página web:

http://www.aq.upm.es/Departamentos/Urbanismo/publicaciones/ciurpublicar.html

\section{FORMATO DE LAS REFERENCIAS}

Monografías: APELLIDOS (S), Nombre (Año de edición). Título del libro (No de edición). Ciudad de edición: Editorial [Traducción castellano, (Año de edición), Título de la traducción, No de la edición. Ciudad de edición: editorial].

Partes de monografías: APELLIDOS (S), Nombre (Año de edición). "Título de capítulo". En: Responsabilidad de la obra completa, Título de la obra (No de edición). Ciudad de edición: Editorial.

Artículos de publicaciones en serie: APELLIDOS(S), Nombre (Año de publicación). "Título del artículo", Título de la publicación, Localización en el documento fuente: volumen, número, páginas.

Asimismo, se recuerda que el autor tendrá derecho a tres ejemplares gratuitos.

\section{CONSULTA DE NÚMEROS ANTERIORES/ACCESS TO PREVIOUS WORKS}

La colección completa se puede consultar en color y en formato pdf en siguiente página web:

The entire publication is available in pdf format and full colour in the following web page:

http://www.aq.upm.es/Departamentos/Urbanismo/publicaciones/ciurnumeros.html

\section{ÚLTIMOS NÚMEROS PUBLICADOS:}

97 Juan Ramón Selva Royo: "Antecedentes y formación del Plan General de Valencia de 1966 ", 68 páginas, Noviembre 2014.

96 Irina Tumini: "The urban microclimate in open space. Case studies in Madrid", 78 páginas, Septiembre 2014.

95 Luz Elena Cornejo Ganga: "Categorías de análisis de un modelo de planificación turística sustentable", 96 páginas, Julio 2014.

94 Mattia Bertin: "Cittá al limite. Per una trattazione urbanística del disastro", 78 páginas, Mayo 2014.

93 Luis Alberto Salinas Arreortúa: "Transformaciones urbanas en el contexto neoliberal", 74 páginas, Marzo 2014. 


\author{
PREINSCRIPCIÓN DEL 15 DE MARZO AL 27 DE JUNIO DE 2014 \\ COORDINADORA DEL MÁSTER: Ester Higueras García \\ PERIODO DE DOCENCIA: Septiembre 2014 -Junio 2015 \\ MODALIDAD: Presencial y tiempo completo \\ NUMERO DE PLAZAS: 40 plazas \\ CREDITOS: 60 ECTS
}

\begin{abstract}
El Máster se centra en la comprensión, análisis, diagnóstico y solución de los problemas y la identificación de las dinámicas urbanas y territoriales en curso, atendiendo a las dos dimensiones fundamentales del fenómeno urbano actual: por un lado, el proceso de globalización y, por otro lado, las exigencias que impone la sostenibilidad territorial, económica y social. Estos objetivos obligan a insistir en aspectos relacionados con las nuevas actividades económicas, el medio físico y natural, el compromiso con la producción de un espacio social caracterizado por la vida cívica y la relación entre ecología y ciudad, sin olvidar los problemas recurrentes del suelo, la vivienda, el transporte y la calidad de vida. Estos fines se resumen en la construcción de un espacio social y económico eficiente, equilibrado y sostenible. En ese sentido la viabilidad económica de los grandes despliegues urbanos y su metabolismo se confrontan con modelos más maduros, de forma que al estudio de las técnicas habituales de planificación y gestión se añaden otras nuevas orientaciones que tratan de responder a las demandas de complejidad y sostenibilidad en el ámbito urbano.
\end{abstract}

El programa propuesto consta de un Máster con dos especialidades:

- Especialidad de Planeamiento Urbanístico (Profesional)

Especialidad de Estudios Urbanos (Investigación Académica)

Se trata de 31 asignaturas agrupadas en tres módulos:

MÓDULO A. Formación en Urbanismo.

MÓDULO B. Formación en Estudios Urbanos e Investigación.

MÓDULO C. Formación en Planeamiento.

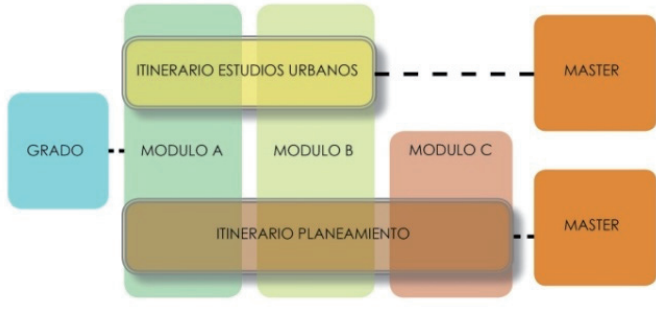

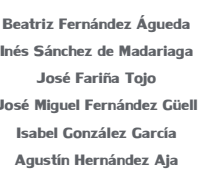

Agustín Hernández
PROFESORADO:

Ester Higueras García
Francisco José Lamiquiz
Julio Pozueta
Fernando Roch Peña
Felipe Colavidas
Luis Moya
José María Ezquiaga

Llanos Masiá

avier Ruiz Sánche Carlos Verdaguer Enrique Villa Polo

Carmen Andrés Mateo Álvaro Sevilla

ENTIDADES COLABORADORAS: Q Cilur] =urban

CONTACTO: masterplaneamiento.arquitectura@upm.es www.aq.upm.es/Departamentos/Urbanismo/masters/index.html 


\section{ALGUNAS DE LAS ACTIVIDADES REALIZADAS DURANTE EL CURSO 2014/15...}
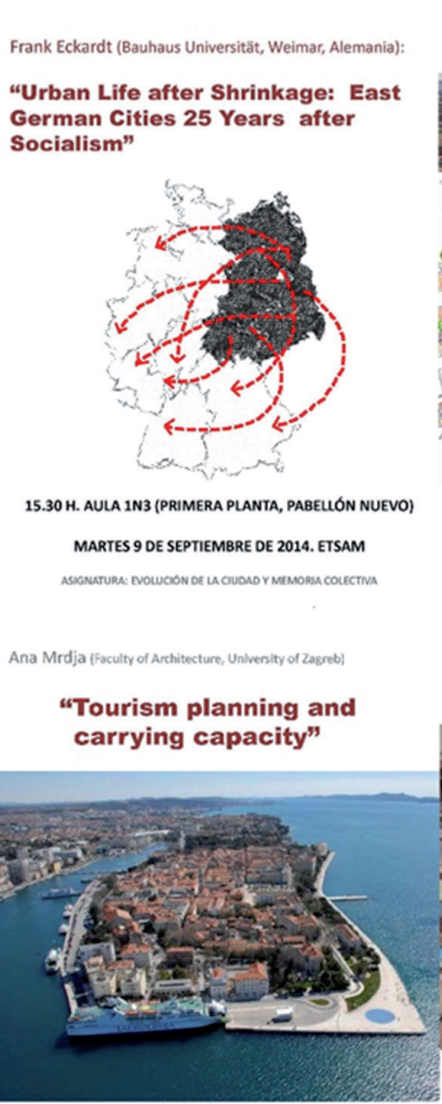

11.30 H. SALA DE GRADOS B (PABELLÓN ANTIGUO) JUEVES 18 DE SEPTIEMBRE DE 2014. ETSAM ASORATURA: SEM MARO EN UINEAS DE INESSIGAOON

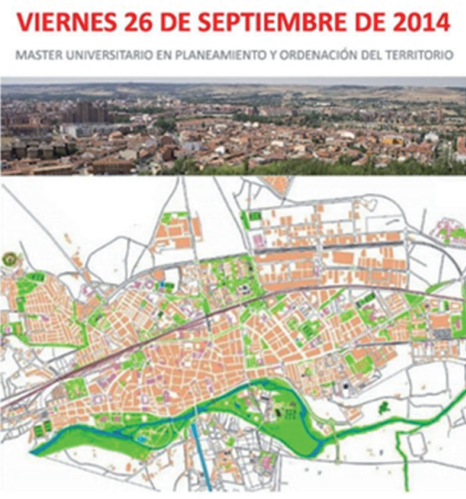

"Visita a la ciudad de Palencia"

RECEPCION EN LL AYUNTAMIENTO Y PASEO POR LA CIUDAO Y SUS BARRIOS

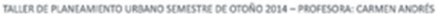

MIÉRCOLES 11 DE FEBRERO DE 2015. ETSAM MASTER UNIVERSTARIO EN PLANEAM ENIO Y ORDERACÓN OEL TERRIORIO

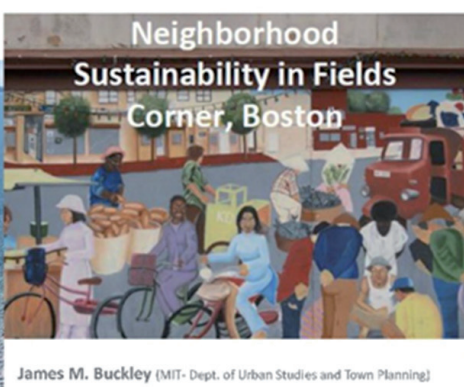

"Urban regeneration in USA"

11.30 H. AULA 1N3 (AULA MÁSTER)

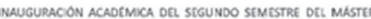

José Fariha Tojo (Cotedratico UPM, Duvor)

Luis Felipe Alonso Teixidor (Catedratico "Ad Honorem" UPM, Duro Ramón López de Ludio (Catodrático "Ad Honorem" UPM, DU,OT)

"El sprawl y su paisaje"

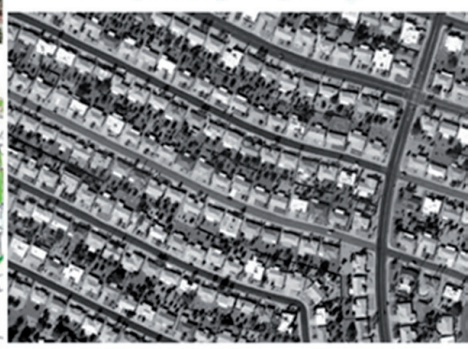

11.30 H. SALA DE GRADOS B (PABELLÓN ANTIGUO)

JUEVES 9 DE OCTUBRE DE 2014. ETSAM

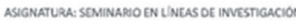

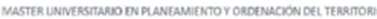

MIÉRCOLES 5 DE NOVIEMBRE DE 2014. ETSAM MUSTER UNVERSTINRO EN PLANEAMIENTO Y ORDERMCON DEL TERR TORIO

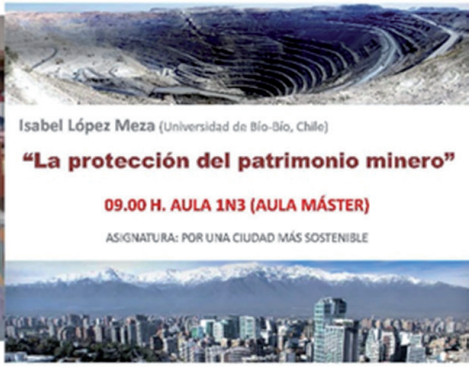

Mario Torres Jofré \{Univensidad de Chile)

"La ciudad contemporánea. Una perspectiva crítica"

$16.00 \mathrm{H}$. AULA 1N3 (AULA MASTER)

VIERNES 27 DE FEBRERO DE 2015 JUEVES 19 DE MARZO DE 2015 MIÉRCOLES 25 DE MARZO DE 2015

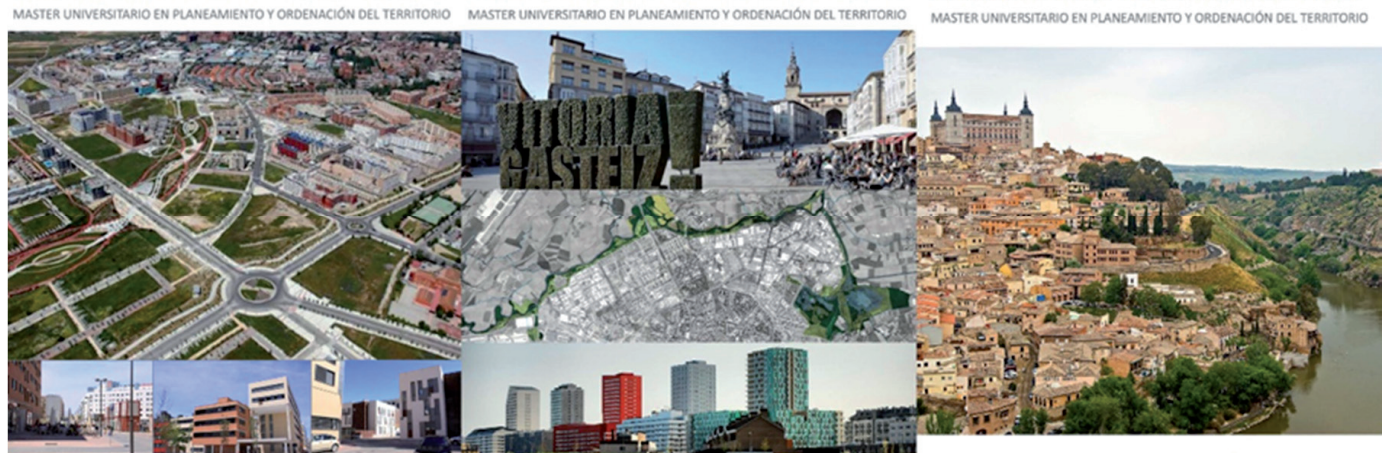

"Visita a Móstoles Sur (Madrid)"

15.30 H. METRO MANUELA MALASAÑA (METROSUR)
"Visita a Vitoria-Gasteiz"

12.00 H. PLAZA DE LA VIRGEN BLANCA (CENTRO)
"Visita a Toledo"

16.00 H. PLAZA DE ZOCODOVER (CENTRO)

JOINT WORKSHOP - SPRING 2015 - EVOLVING CTIIES

(1) (1) DUyOT 
Otros medios divulgativos del Departamento de Urbanística y Ordenación del Territorio:

\section{urban}

\section{ReVista del Departamento de URbanística y Ordenación del TerRitorio ESCUELA TÉCNICA SUPERIOR DE ARQUITECTURA}

\section{PRESENTACión SEGUNDA ÉPOCA}

DESDE el año 1997, URBAN ha sido vehículo de expresión de la reflexión urbanística más innovadora en España y lugar de encuentro entre profesionales y académicos de todo el mundo. Durante su primera época la revista ha combinado el interés por los resultados de la investigación con la atención a la práctica profesional, especialmente en el ámbito español y la región madrileña. Sin abandonar dicha vocación de saber aplicado y localizado, la segunda época se centra en el progreso de las políticas urbanas y territoriales y la investigación científica a nivel internacional. Ayer y hoy, nuestro objetivo es contribuir al desarrollo de las técnicas y modelos de ciudad y territorio, desde una perspectiva crítica y conjugando las ventajas de nuestra posición en la encrucijada entre el Norte y el Sur globales, entre Europa, el Mediterráneo y Latinoamérica.

Apoyándose en cuatro vectores de interés -carácter generalista y transversal, espíritu crítico, visión regional de los procesos globales y recuperación de la memoria de la disciplina- la nueva URBAN se propone servir de espacio para un debate en el que la planificación se juegue sus condiciones de posibilidad. Frente a la deriva disciplinar de las últimas décadas, frente al desplazamiento paulatino del lugar social de la planificación urbana y territorial en los modos de gobierno, nos parece urgente replantear el papel que ésta merece en las economías políticas de la producción de espacio.

\section{CONVOCATORIA PARA LA RECEPCIÓN DE ARTÍCULOS: nº6- Teoría urbana. Estados del arte}

Sin una teoría urbana consistente nunca habrá buen urbanismo. Este problemático aforismo podría servir para abrir el debate que la revista Urban se propone albergar en un próximo número especial. La teoría urbana (teoría de la ciudad, teoría del proceso urbanizador) ha presentado una relación histórica compleja con la práctica de la planificación y las políticas de la ciudad y el territorio: anticipación de mundos más o menos felices, re-conocimiento pericial de fenómenos urbanos ya materializados, interpretación crítica que re-imagina el pasado y el presente de la ciudad y el territorio, abriéndolos a un nuevo horizonte... El trabajo teórico es, qué duda cabe, un indicador efectivo de la salud y orientación de la disciplina urbanística pero ¿es también un arma cargada de futuro? ¿Cabe aún idear teorías capaces de cambiar los hechos de un mundo urbano que se presenta cada vez más complejo, abigarrado y ajeno a cualquier indicio de racionalidad? ¿Debe la teoría conformarse, por el contrario, con adoptar una actitud de 'testigo modesto', buscar producciones de sentido en los intersticios de los discursos urbanos dominantes? ¿Qué perspectivas teóricas debemos perseguir, con qué herramientas conceptuales y en qué marcos intelectuales? ¿Cómo debe la teoría pensar su articulación con la práctica? ¿Qué tipo de teoría demanda nuestro mundo urbano en un contexto de crisis global? ¿En qué medida los ensayos por comprender la crisis pueden contribuir a ensanchar el campo teórico del fenómeno urbano?

Este número especial de la revista Urban pretende albergar aportaciones internacionales que exploren sistemática y críticamente los estados del arte en los distintos campos de la teoría urbana y los conecten a las tendencias más amplias de la teoría social contemporánea - de la planificación a la geografía, de la sociología a la historia y más allá, en el horizonte general del conocimiento técnico, las ciencias sociales y las humanidades. Serán especialmente bienvenidas las contribuciones que analicen corrientes actuales de reflexión sobre las intersecciones de ciudad, economía, sociedad, política, cultura, tecnología, naturaleza, medio ambiente, diseño, instituciones... Asimismo se espera que los autores consideren y problematicen la articulación entre teoría y práctica urbanística, recordando que 'la experiencia sin teoría es ciega, pero también que la teoría sin experiencia es un mero juego intelectual'. En definitiva ¿cómo puede contribuir la teoría urbana a cambiar no sólo el conocimiento y discurso sobre la ciudad, sino también los propios procesos que la sostienen y transforman? ¿Enfrenta el urbanismo un horizonte de 'miseria de la teoría' o, por el contrario, cabe imaginar un futuro floreciente y un lugar propio para la teoría urbana en el campo más amplio de la teoría social? 
Urban mantiene abierta una convocatoria permanente para la remisión de artículos de temática relacionada con los objetivos de la revista: Para más información:

http://www2.aq.upm.es/Departamentos/Urbanismo/institucional/publicaciones/urban/ns/instrucciones-para-autores/

Por último, se recuerda que, aunque La revista URBAN organiza sus números de manera monográfica mediante convocatorias temáticas, simultáneamente, mantiene siempre abierta de forma contínua una convocatoria para artículos de temática libre.

\section{DATOS DE CONTACTO}

Envío de manuscritos y originales a la atención de Álvaro Sevilla Buitrago: urban.arquitectura@upm.es Página web: http://www.aq.upm.es/Departamentos/Urbanismo/public/urban/info.html

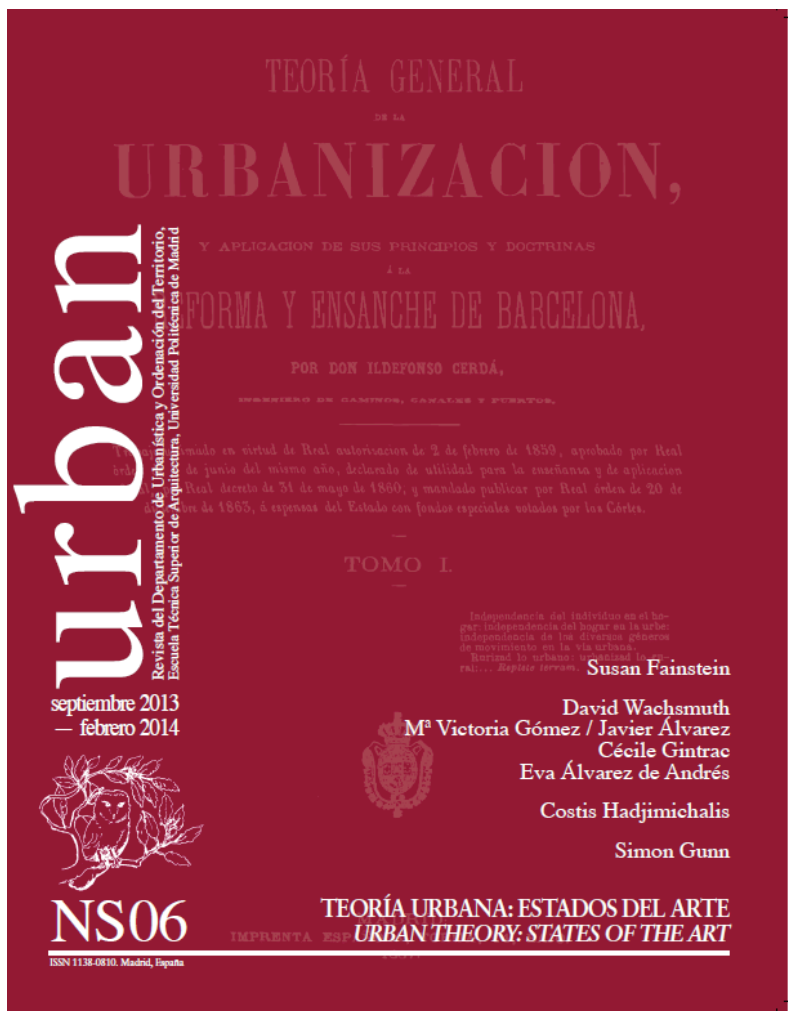

Consulta y pedido de ejemplares: ciur.urbanismo.arquitectura@upm.es

Web del Departamento de Urbanística y ordenación del Territorio:

http://www.aq.upm.es/Departamentos/Urbanismo

Donde figuran todas las actividades docentes, divulgativas y de investigación que se realizan en el Departamento con una actualización permanente de sus contenidos. 